Portland State University

PDXScholar

Summer 8-10-2015

\title{
Mistrust: An Exploration of African Americans' Attitudes and Perspectives Toward Healthcare
}

Adolfo Gabriel Cuevas

Portland State University

Follow this and additional works at: https://pdxscholar.library.pdx.edu/open_access_etds

Part of the Medicine and Health Sciences Commons, and the Psychology Commons Let us know how access to this document benefits you.

\section{Recommended Citation}

Cuevas, Adolfo Gabriel, "Mistrust: An Exploration of African Americans' Attitudes and Perspectives Toward Healthcare" (2015). Dissertations and Theses. Paper 2459.

https://doi.org/10.15760/etd.2457

This Dissertation is brought to you for free and open access. It has been accepted for inclusion in Dissertations and Theses by an authorized administrator of PDXScholar. Please contact us if we can make this document more accessible: pdxscholar@pdx.edu. 
Mistrust: An Exploration of African Americans' Attitudes and Perspectives Toward Healthcare

\author{
by \\ Adolfo Gabriel Cuevas
}

A dissertation submitted in partial fulfillment of the requirements for the degree of

\author{
Doctor of Philosophy \\ in \\ Applied Psychology
}

Dissertation Committee:

Kerth O'Brien, Chair

Eric S. Mankowski

Somnath Saha

David L. Morgan

Portland State University

2015 
(C) 2015 Adolfo Gabriel Cuevas 


\begin{abstract}
This dissertation explored mistrust through focus group discussions (study 1), responses to standardized laboratory vignettes (study 2), and survey questionnaires (study 3). In the first study, I found that African American community members ( $\mathrm{N}=60)$ experienced perceived discrimination, medical mistrust, and poor communication in numerous and interrelated ways. For example, medical mistrust occurred when clinicians did not convey respect to patients, leaving patients to wonder whether their clinician's treatment was discriminatory or not. Based on these findings, I wanted to see whether these experiences of perceived discrimination and mistrust were related to other dimensions of Black experience, such as racial identity. I conducted a secondary analysis of data from a laboratory study (Somnath Saha, PI) in which 104 primary care patients viewed video-recorded, standardized vignettes depicting a cardiologist recommending heart bypass surgery to a patient diagnosed with angina and 3-vessel coronary artery disease. In this study, those who viewed a video of European American cardiologistactors had lower physician mistrust and lower hypothetical likelihood of having bypass surgery compared to those who viewed the video of African American cardiologistactors. However, racial centrality did not moderate the relationship between ethnicity of the cardiologist-actor and patients' decision making. The third study explored other dimensions of racial identity (e.g., unfavorable public regard for African Americans) and mistrust (e.g., medical mistrust), while also exploring their association with perceived healthcare discrimination among African American community members $(\mathrm{N}=210)$. In this study, perceived discrimination was positively associated with racial centrality, but
\end{abstract}


not associated with unfavorable public regard. Perceived discrimination was also positively associated with medical mistrust and physician mistrust. Although racial centrality and unfavorable public regard were not significant moderators between perceived discrimination and the two dimensions of mistrust, they were positively associated with medical mistrust. Together, these studies provide a better understanding of African Americans' healthcare attitudes and experiences, particularly mistrust toward medical institutions and clinicians. For example, the association between racial centrality and perceived discrimination may suggest that past experience of discrimination in healthcare may influence a person to seek others who experience similar stressors, giving way to identifying more with her or his racial group. Racial centrality may influence a person's trust towards healthcare, prior to entering the doctor's office. However, once the person enters the doctor's office, racial centrality may play a less significant role the patient's trust towards her or his provider. These findings generated new questions to explore for future studies. For example, future studies should explore the relationship between racial centrality and African Americans' healthcare behavioral responses. In addition, the current studies only focused only on attitudes and perspectives; future studies should investigate how the construct medical mistrust may influence healthrelated outcomes such as adherence in race-discordant patient-provider relationships. 
Para mi mamá, Bibiana Cuevas. Siempre serás mi inspiración. 


\section{Acknowledgements}

First and foremost, I would like to express my deepest appreciation to my mentor, Dr. Kerth O'Brien. Her enduring support during my academic career got me through the tough times and helped me fully enjoy the good times. This has been an amazing journey. Without her guidance and unwavering care, I would not be where I am today.

I would like to thank my committee members, Dr. Eric S. Mankowski, Dr. Somanth Saha, and Dr. David Morgan. It was an honor to learn from these scholars, especially during the development of my dissertation. I hope my future work makes them proud. I would also like to thank my mentors, Dr. Yves Labissière and Dr. Dalton MillerJones. They are an inspiration to all current and future scholars of color.

I am grateful to my colleagues and friends. To Cameron T. McCabe, Jean M. McMahon, Lindsey Grimes Alley, and Hyuny Clark-Shim for their knowledge, encouragement, and humor throughout my academic career. To Mitch Ross and Eddie Leuken, for their wisdom and care. There are many colleagues and friends I have not mentioned, but that does not diminish their impact in my development as a scholar and as a person.

Without the support of my family, I would not be here. The women in my family are strong, brilliant, and caring. Throughout my academic career, my sisters and nieces would always remind me of where I came from, and I will always be grateful for that. To my wife, Linda, thank you for all your love and support. You made this journey be full of laughter, inspiration, and joy. Para mi papá, gracias por su apoyo. 
Lastly, I would like to thank the Black community of Portland, Oregon. Their contribution to this study has been invaluable. I hope my work does justice to their influence. 


\section{Table of Contents}

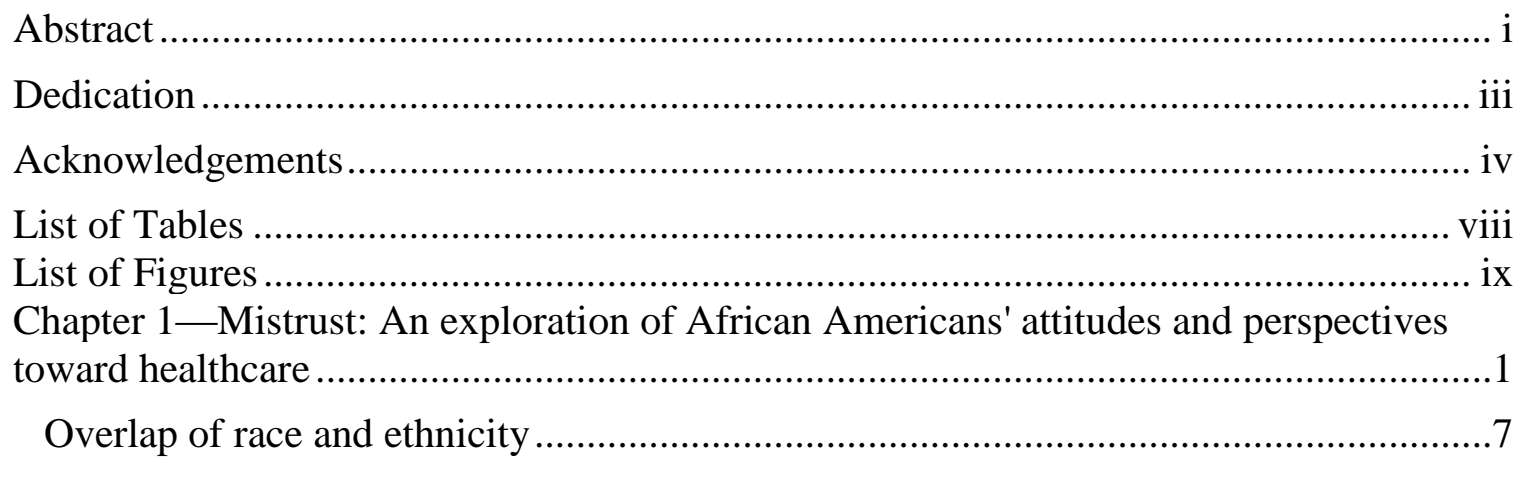

African Americans' experience in healthcare .......................................................9

Mistrust toward physicians and patients' decision-making: Does racial centrality play a

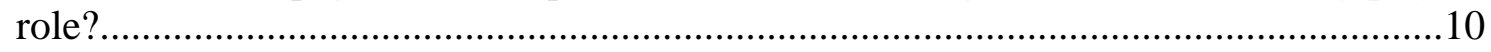

Perceived discrimination and mistrust: The moderating role of racial identity ..............14

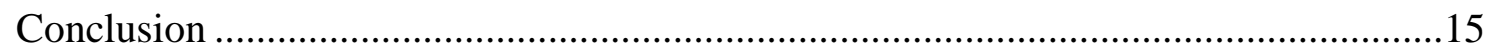

Chapter 2- “I always feel like I'm getting skipped over:" African Americans'

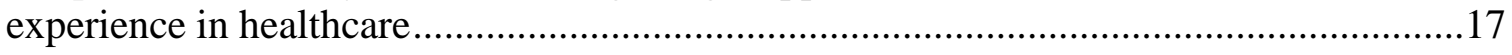

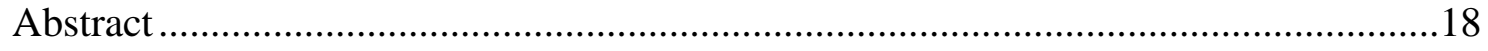

“I always feel like I'm getting skipped over:” African Americans' experience in

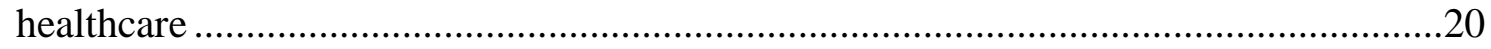

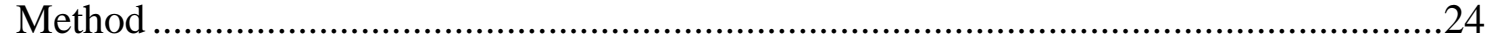

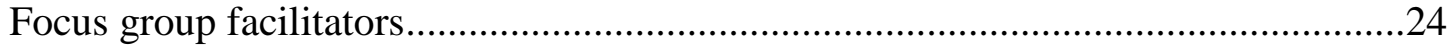

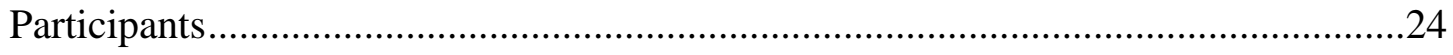

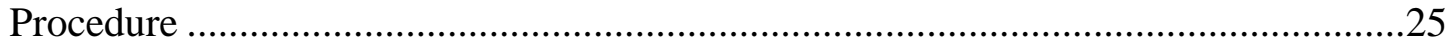

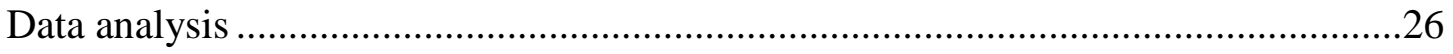

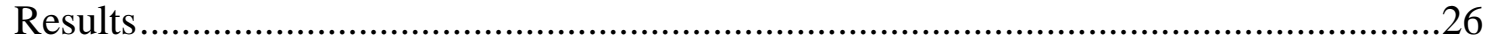

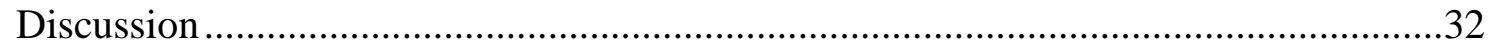

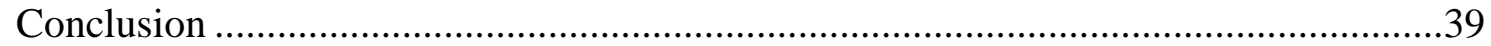

Chapter 3-Mistrust toward physicians and patients' decision-making: Does racial

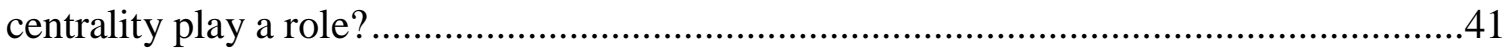

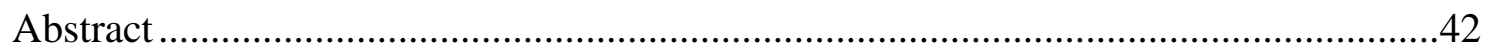

Mistrust toward physicians and patients' decision-making: Does racial centrality play a role?

Methods.

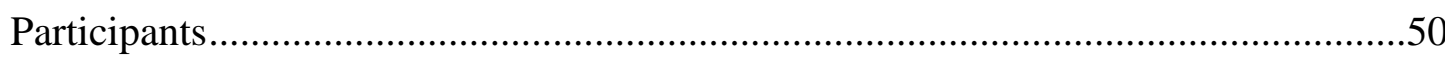




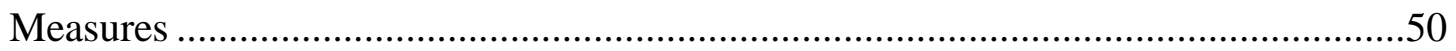

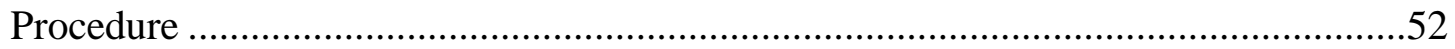

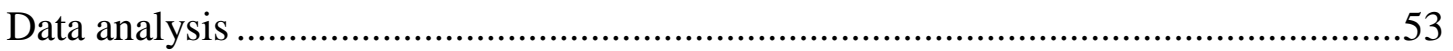

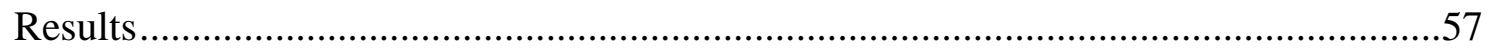

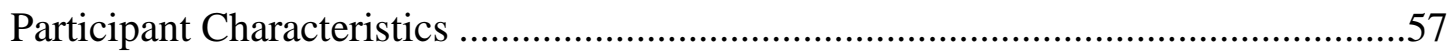

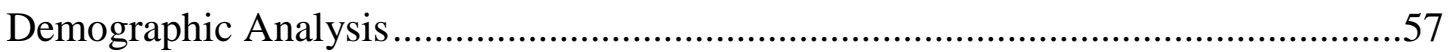

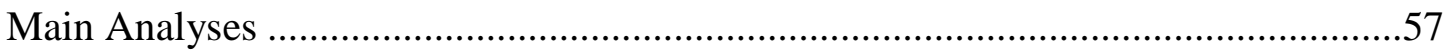

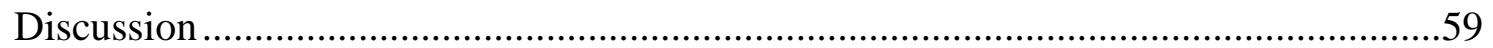

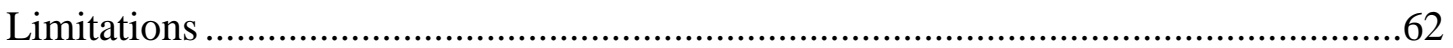

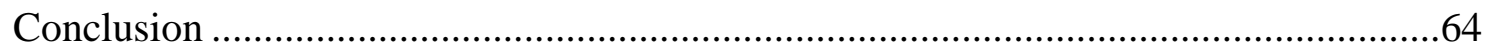

Chapter 4-Perceived discrimination and mistrust: The moderating role of racial

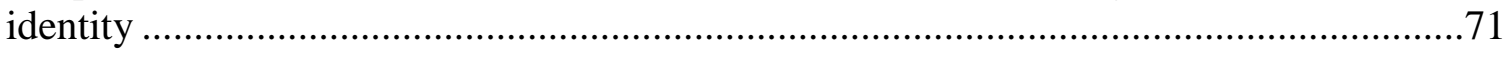

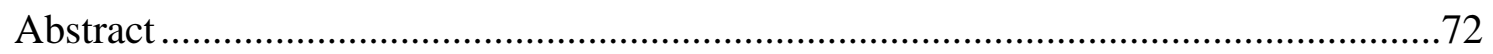

Perceived discrimination and mistrust: The moderating role of racial identity .............74

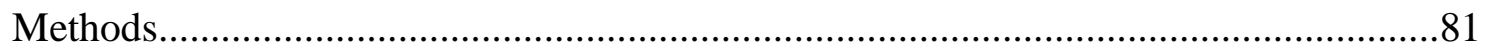

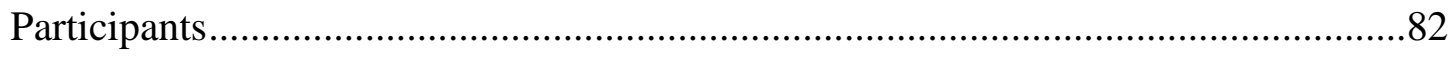

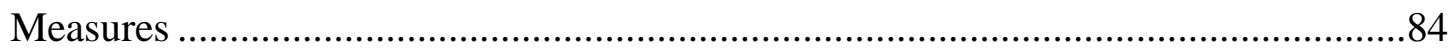

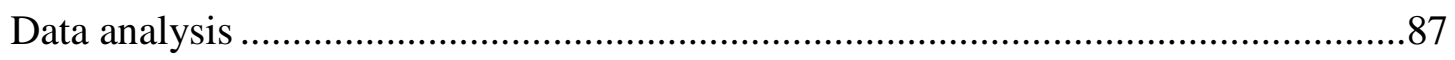

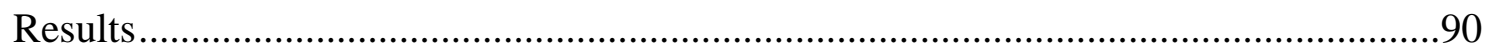

Participant Characteristics ...................................................................... 90

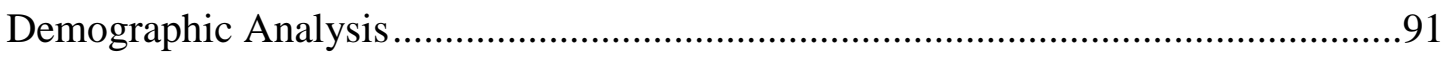

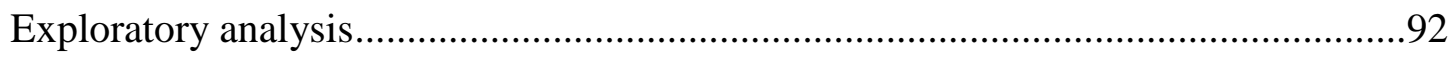

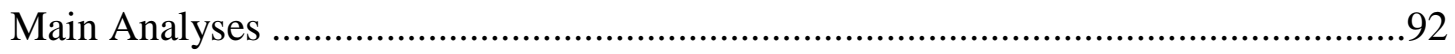

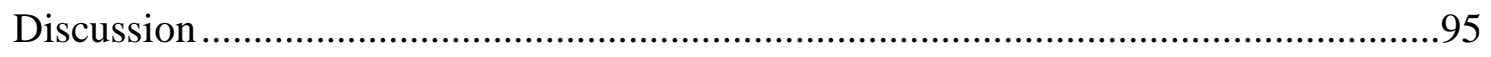

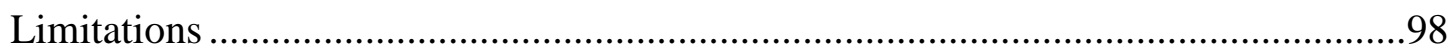

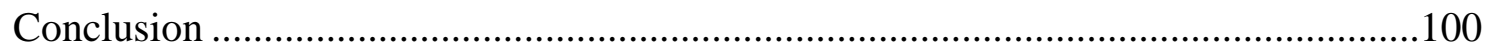

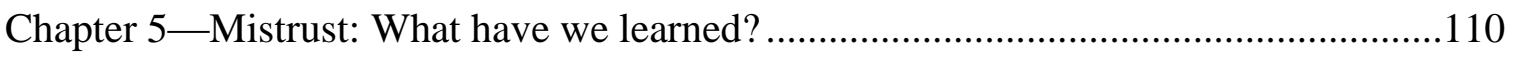

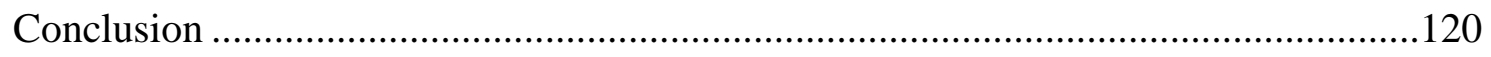

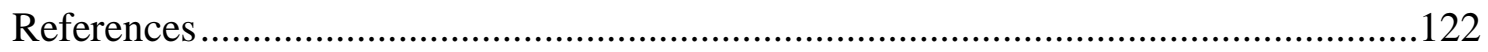


List of Tables

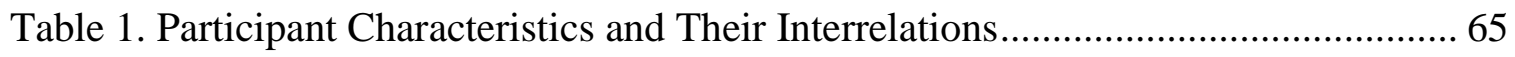

Table 2. Relationship of Demographic Predictors to Racial Centrality.......................... 66

Table 3. Relationship of Demographic Predictors to Physician Mistrust........................ 67

Table 4. Relationship of Demographic Predictors to Likelihood of Bypass Surgery....... 68

Table 5. Relationship of Demographic Predictors to Likelihood of Getting Second

Opinion 69

Table 6. Results of Regression of Surgery Decision and Getting Second Opinion.......... 70

Table 7. Participant Characteristics and Their Intercorrelations ............................... 102

Table 8. Relationship of Demographic Predictors to Racial Centrality........................ 103

Table 9. Relationship of Demographic Predictors to Unfavorable Public Regard ......... 104

Table 10. Relationship of Demographic Predictors to Perceived Discrimination .......... 105

Table 11. Relationship of Demographic Predictors to Medical Mistrust ..................... 106

Table 12. Relationship of Demographic Predictors to Physician Mistrust.................... 107

Table 13. Regression of Mistrust with a DiscriminationXCentrality Interaction ........... 108

Table 14. Regression of Mistrust with a DiscriminationXRegard Interaction .............. 109 


\section{List of Figures}

Figure 1. Adapted version of the Centers for Disease Control and Prevention (2013) social ecological model of health. .......................................................... 3

Figure 2. The Impact of Race-Related Attitudes on Racially Discordant Medical Interactions

Figure 3. This figure depicts the pathways in how perceived discrimination and racial identity lead to mistrust and health-related outcomes................................ 11

Figure 4. Diagram of Hypothesis 1, separated by outcome........................................ 48

Figure 5. Diagram of Hypothesis 2, separated by outcome......................................... 49

Figure 6. This figure represents the overall findings of the analyses. Each arrow indicates

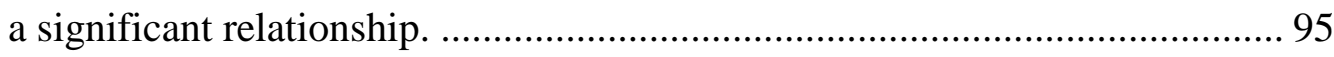

Figure 7. A conceptual model reflecting the findings of all three studies. ................... 113 


\section{Chapter 1}

Mistrust: An exploration of African Americans' attitudes and perspectives toward healthcare 
EXAMINING AFRICAN AMERICAN ATTITUDES

Mistrust: An exploration of African Americans' attitudes and perspectives toward healthcare

Disparities of healthcare services are sustained and presumably preventable differences among population groups in the availability, accessibility, and quality of health care services designed to prevent, treat, and manage diseases and their complications (Smedley, Stith, \& Nelson, 2009). Despite efforts through community interventions and healthcare training programs (Chin, Walters, Cook, Huang, 2007; Smedley, Stith, \& Nelson, 2009), healthcare disparities persist for African Americans. For example, after using a given healthcare service such as a doctor appointment or checkup, African Americans are less likely than European Americans to adhere to medication or utilize the same healthcare service again (Diala et al., 2000; Traylor et al., 2010). Even when taking into account insurance status and socioeconomic status, much of the differences between racial and ethnic groups remain unexplained (Smedley, Stith, $\&$ Nelson, 2009). More research is highlighting the importance of identifying and understanding the role of attitudes and perceptions toward the healthcare system to help explain these differences. LaVeist and colleagues (2000), for example, found that when controlling for perceived racism and medical mistrust, race is no longer a significant predictor of patient satisfaction. A greater understanding of the factors that influence perception of healthcare providers and quality of care may help contribute to our understanding of healthcare disparities.

A synergy of social and community psychology can contribute to this pursuit. A combination of these two substantive perspectives is illustrated in the socioecological 
model (Figure 1; Centers for Disease Control and Prevention, 2013), depicting the individual within the broader society. At the core, the individual is surrounded by four layers of influence representing interpersonal, organizational, community, and policy levels. Each layer influences the layer below it, ultimately affecting the individual. To elucidate this model, individual characteristics of the person (e.g., racial identity, mistrust), the influence of their family structure in the interpersonal level (e.g., nuclear family or single parent family), work space and organizational environments in the organizational level (e.g., workplace safety), community organizations in the community level (e.g., health coalitions) and broader community policies (e.g., unemployment insurance benefits) all affect the individual. Social and community psychological theories can yield valuable insight into psychological processes in healthcare settings of members of socially disadvantaged groups- in this case of African Americans- which in turn can inform medical training and interventions to reduce healthcare disparities.

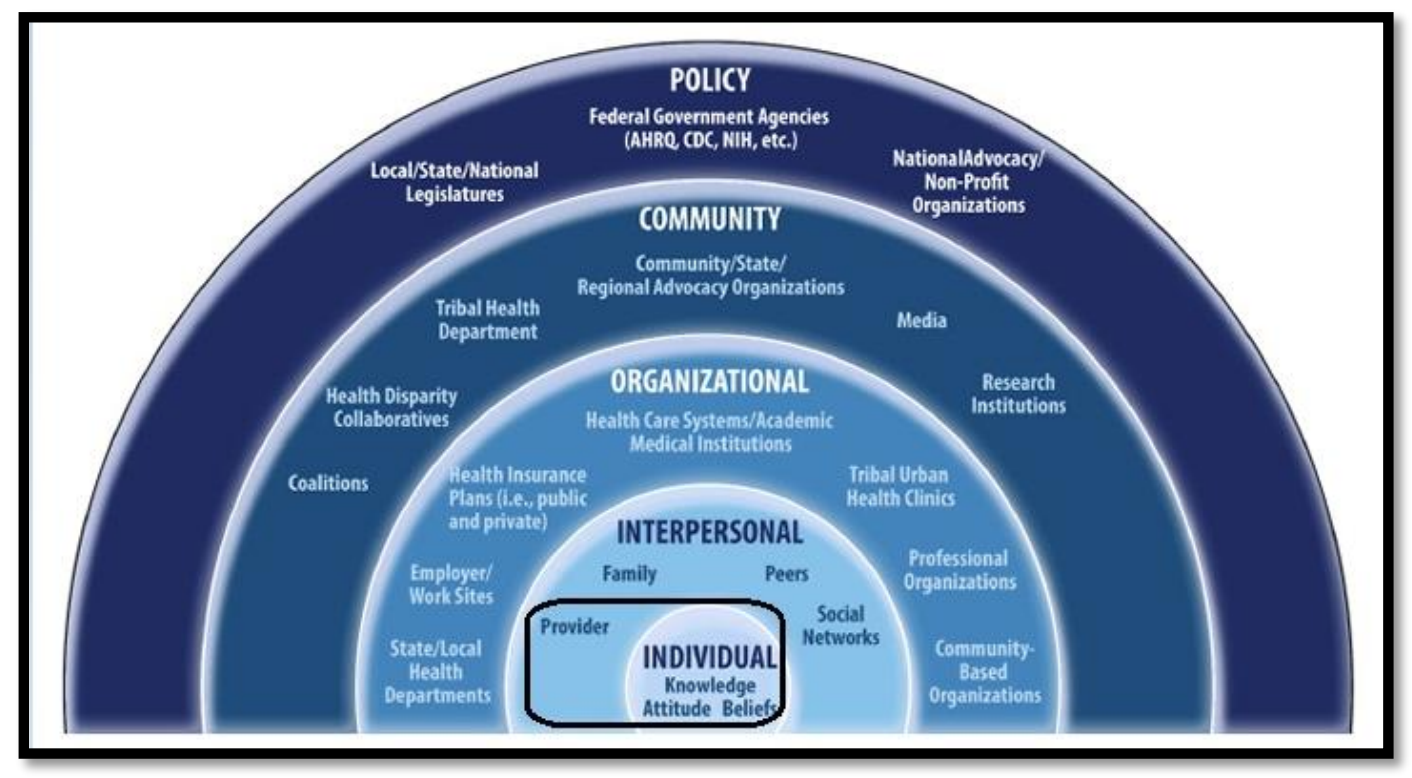

Figure 1. Adapted version of the Centers for Disease Control and Prevention (2013) social ecological model of health. 
Patient-provider relationships are an area of healthcare disparities in which social and community psychological theories can be applied. Many upstream influences of the ecological model that affect patients and providers come together in the provider's office. For example, studies have found that neighborhood characteristics, such as segregation, are associated with individual-level characteristics, such as mistrust. Shelton and colleagues (2010) argue that African Americans who live in highly segregated areas experience poorer medical treatment, which contributes to a deep-rooted lack of confidence in the ability of health care systems to provide appropriate care for African Americans. These aspects (circled in Figure 1) of the ecological model can influence a patient's perceptions and interactions in the healthcare setting, which in turn can influence patient outcomes, such as adherence to the doctor's recommendation.

In a race-discordant patient-provider relationship, these upstream influences are amplified when the patient and provider come with their own level of mistrust and biases toward the other's racial/ethnic background. Penner (2014) presents a model showing the impact of race-related attitudes on race-discordant interactions (Figure 2). It provides a good example of how race-related influences play a role in race-discordant relationships and how they may contribute to negative health-related behaviors. 


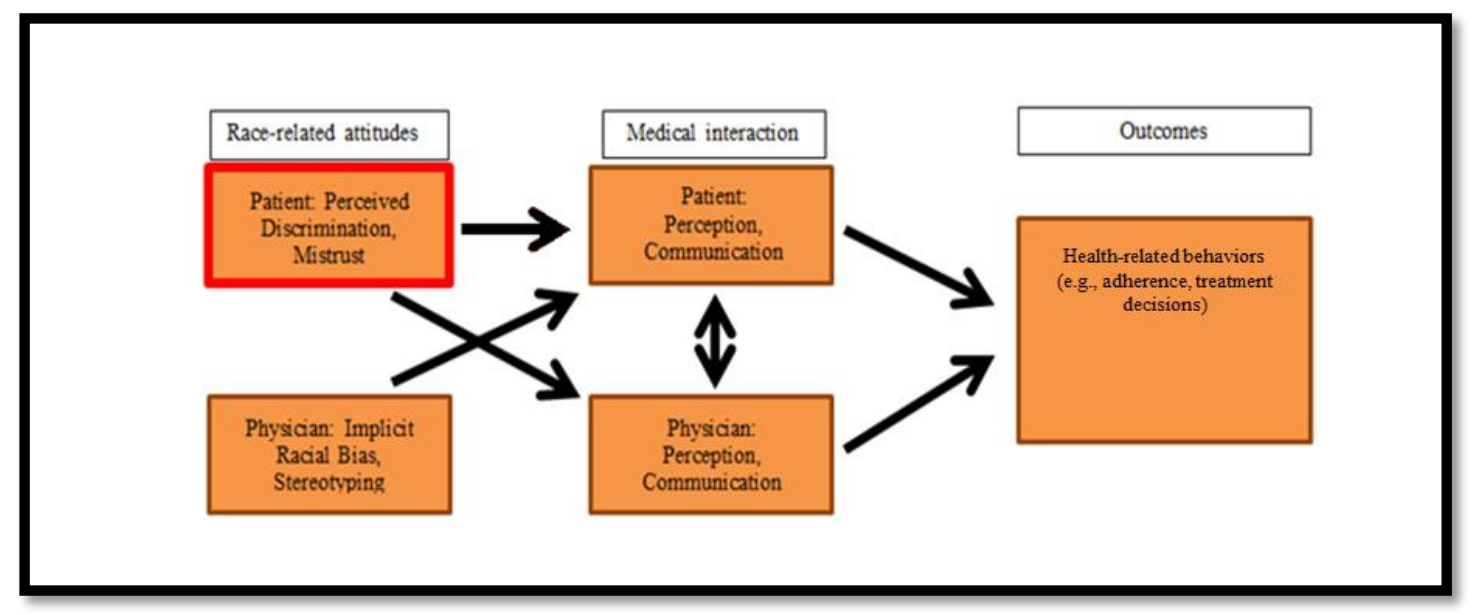

Figure 2. The Impact of Race-Related Attitudes on Racially Discordant Medical Interactions. This figure depicts the unique influences that patients and providers contribute to the interactions, affecting perceptions and communications, which in turn affect patients' behaviors. The highlighted box (i.e., patients' race-related attitudes) is the focus of the three studies in this dissertation (from Penner, 2014).

There is growing evidence showcasing patient and provider contributions to patient health-related outcomes. For example, van Ryn and Burke (2000) found that European American physicians rated African American patients as less intelligent, less compliant, and more likely to engage in risky health behaviors than other patients. Further, there is evidence that physicians have implicit stereotypes of African Americans as being less cooperative with medical procedures and less cooperative generally than European Americans. In a study utilizing physician self-report, this bias increased the likelihood of physicians recommending medical procedures for European American patients and decreased that likelihood for African American patients (Green et al., 2007). African American patients, on the other hand, are less active participants than European American patients and engage in fewer communication behaviors (e.g., asking questions, expressing concerns, making assertions) that usually bring forth more information from doctors. According to qualitative analysis, this behavior may partially be explained by 
perceived discrimination or reluctance to trust healthcare providers (Cuevas, O’Brien, \& Saha, 2015). More research is needed, however, to identify what gives rise to patients perceiving discrimination, to medical mistrust, and to other barriers in patient-provider relationships.

This dissertation is composed of three manuscripts that focus on patients' racerelated attitudes and experiences. This is just one component of the patient-provider relationship, but identifying the situations that gives rise to African Americans experiencing certain barriers, and exploring the importance of racial identity can further improve our understanding of the mechanisms that affect patient outcomes in racediscordant relationships. This dissertation explores discrimination, mistrust, and racial identity through focus group discussions (study 1), responses to standardized laboratory vignettes (study 2), and survey questionnaires (study 3 ). The triangulation of different data sources brings forth credibility and more valid and reliable findings. In the first study, I used a qualitative approach to understand the perspectives and experiences of African American patients to understand what gives rise to perceived discrimination, medical mistrust and poor communication. Building upon the findings of the first study, I have concluded an analysis of existing laboratory data and have completed an original data collection involving survey questionnaires in order to pursue topics of racial identity in healthcare contexts. The laboratory study helped to reduce a number of confounding variables that may exist in the doctor's office through a lab setting. I was able to investigate how a provider's race may affect patients' trust, as well as patients' decisionmaking. Further, I was able to look at how racial centrality would moderate the 
relationship between provider's race and patients' decision-making. Lastly, the third study was able to provide additional information by exploring other dimensions of mistrust and racial identity. The triangulation of these studies provided a more comprehensive understanding of African Americans' experiences in health care and drew new research questions for future studies.

\section{Overlap of race and ethnicity}

Before I continue, it is important for me to discuss how I am using race and ethnicity in these studies. Race is a social construction that categorizes humans into groups based on phenotypic characteristics (e.g., skin color, facial features, hair color). The concept of race, however, is imprecise, subjective, and has many exceptions. For instance, an African American can be quite light skinned, and a European American can be quite dark skinned. Race, therefore, offers no clear categorical distinction between all members of one group versus all members of another group. Hazel Markus (2008) argues that categorizing a group as a racial group draws attention to the difference in the power relationships between this and other groups. The "one drop rule," for example, in which a person in the U.S. with any known trace of African ancestry was considered Black, distinguished the empowered group from the oppressed group. Race, therefore, as a construct, implicates power and indicates the history or ongoing imposition of one group's authority over another. Ethnicity offers a conceptual alternative to race. Ethnicity recognizes other qualities of human beings, such as culture, meanings, values, and way of living that is not based on physical characteristics. 
At a conceptual level, the often muddled uses of race and ethnicity in the social sciences echo the uses of the terms sex and gender. Although at first these may seem to be different matters, they bear conceptual parallels. For example, feminist scholarship on sex and gender argues that gender serves as both a subject variable - an enduring characteristic of persons - and a stimulus variable - a perceived characteristic which is mainly of interest because of the responses of others who perceive and respond to that characteristic (Unger, 1979). The difficulty of the concept race is its misuse as a supposed subject variable. The difficulty of the concept ethnicity is its nature as a subject variable, when the phenomena of interest require a construct which is in part subject variable and in part stimulus variable.

In the proposed studies, I examined the experiences and perspectives of individuals who hold in common a self-identified ethnicity as African Americans (the subject variable). However, as the reader will see in Study 2 and Study 3, the construct racial identity is used to discuss African Americans' experiences and perspectives. Experts in the area of racial identity use race as a subject and stimulus variable. Although one can argue that ethnic identity is the more accurate terminology, racial identity is more appropriate when wanting to include a group's power and privilege, or lack thereof, in society. This perspective also allows researchers to understand how racial identity is associated with other constructs, such as perceived discrimination and medical mistrust. As I focused on African Americans' race-related attitudes and perspectives in these studies, I used the term Black when discussing African American's awareness of race and their socialization to an Afrocentric identity. 
African Americans' experience in healthcare

In the first manuscript, I examine African Americans' narratives about their experience in healthcare. African Americans perceive discrimination in healthcare settings, experience higher levels of medical mistrust, and experience poorer communication with healthcare providers compared to European Americans (Blendon et al., 2007; Gordon et al., 2006; LaVeist et al., 2000). However, very little is known about what factors give rise to African Americans experiencing these barriers (Smedley, Stith, \& Nelson, 2009). The study involved a secondary analysis of data from Project EQUALED (Exploring the Quality of African American and Latino/Latina Experiences with Doctors; Saha, PI). This project examined the views of Latina/Latino, African American, and European American adult community members living with diabetes or hypertension or both, concerning their views of what make a good relationship with a doctor. The study examined experiences of African American community members regarding these barriers, while also exploring participants' perspectives on physicians' race in the patient-provider relationship. African American adults participated in one of 9 focus groups segmented by gender. Discussion topics included what makes a good or bad relationship with a provider, what leads one to trust a provider, and whether a provider's race concordance matters to participants. In our analyses of the study data, we, Dr. Somnath Saha (PI; Portland Veterans Affairs Medical Center and Oregon Health \& Science University), Dr. Kerth O’Brien (Portland State University) and myself, used NVivo 10 to deductively investigate these three barriers of perceived discrimination, medical mistrust, and poor communication. We found that African Americans experience 
perceived discrimination, medical mistrust, and poor communication in numerous and sometimes interrelated ways. For example, perceived discrimination arose when African American patients, particularly women, felt their symptoms or problems were being ignored. This experience negatively influenced later communications with clinicians. Mistrust occurred when clinicians did not treat the patient with respect, leaving the patient to wonder whether the clinician's treatment was discriminatory or not. Poor communication arose when clinicians did not acknowledge the patient's perspective during interactions. These interactions were often seen as discriminatory behaviors exhibited by the clinician.

This study helped us to further understand how race-related attitudes and perceptions can detrimentally affect relationships with providers. Even so, more research is needed to address the role that intrapersonal factors play in interpersonal interactions. For example, discriminatory behaviors described by patients in the first study may be based on certain dimensions of the Black experience such as racial identity. Racial identity may help broaden our understanding of African Americans' healthcare experiences. The subsequent research addresses these questions by exploring its moderating role among certain factors such as physician's race, mistrust, and discrimination.

Mistrust toward physicians and patients' decision-making: Does racial centrality play a role?

The second study seeks to address the problem that, in general, African Americans are less trusting of physicians than are European Americans. Mistrust leads to 
negative perception of physicians, which in turn affects outcomes such as adherence to treatment regimens and use of healthcare services. At the same time, African Americans differ in certain dimensions of the Black experience, based on the ecological model's assumption that age, gender, race, ethnicity, and socioeconomic status shape the context in which individuals function in the broader society. It is important to understand dimensions on which African Americans may vary from each other vis-a-vis healthcare relationships. These dimensions, such as racial identity, help give us a better understanding of a how African Americans' healthcare experiences vary widely based on intrapersonal factors.

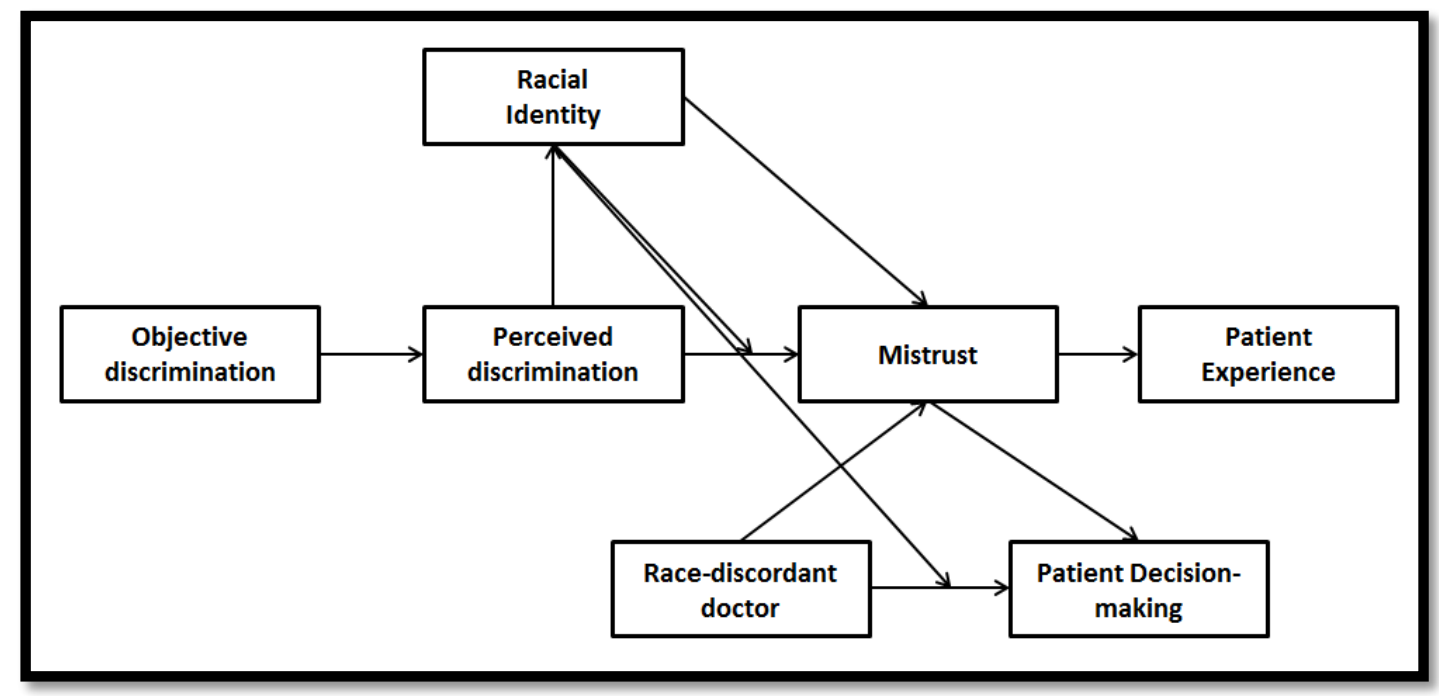

Figure 3 . This figure depicts the pathways in how perceived discrimination and racial identity lead to mistrust and health-related outcomes.

The model above (Figure 3 ) depicts how racial identity plays a role in patient experiences. Because the great majority of African Americans interact with non-African American physicians, this model and this dissertation also address patient-provider race discordance. Figure 3 provides a basis for Study 2 and Study 3 to understand how racial identity, perceived discrimination, and mistrust are interrelated. The model describes the 
process beginning at the far-left, with objective discrimination, which can take the form of verbal or non-verbal behaviors. For example, a physician can speak in a harsh tone or provide little eye-contact during an interaction. This experience can take two pathways: 1) The individual can perceive that experience as discriminatory. This experience influences the person to seek validation or social support from other Black individuals. She or he builds strong ties with these individuals because of their similar perspectives and experiences, in turn, strengthening their racial identity. 2) Racial identity can serve as an antenna as the individual interacts with her or his environment. Individuals who strongly identify with being Black are highly aware of their oppressed conditions, which leads them to be more perceptive of racial discrimination than those who identify less with their race. Racial identity may also moderate the effects of discrimination on mistrust. In other words, the relationship between perceived discrimination and mistrust may be stronger for African Americans who identify closely with their racial group than to those who do not identify as closely with their racial group.

The patient may become more mistrustful towards physicians and the general healthcare system. Conceptually, physician mistrust and medical mistrust are different concepts in the literature. However, both dimensions fall under the main construct of mistrust. In the model, mistrust (i.e., physician mistrust and medical mistrust) can lead to the patient having a negative experience (e.g., perceiving the quality of care as poor) or affecting the patient's decisions (e.g., not adhering to treatment regimen). Within this context, the race of the doctor also plays an important role in patients' healthcare experiences. For example, African American patients would be more trusting of African 
American doctors than of European American doctors. Although there is evidence to support certain pathways of this model, many of the pathways remain unexplored (Casagrande, Gary, LaVeist, Gaskin, \& Cooper, 2007; LaVeist, Nickerson, \& Bowie, 2000).

Before I continue, it is important to mention that I am not construing racial identity as a negative aspect of an individual's sense of self. In fact, I see racial identity as being beneficial to an individual's well-being. Sellers and colleagues (2003) found that those with high racial centrality (a dimension of racial identity) have better mental health than those with low racial centrality. Further, racial centrality also serves as a buffer between the harmful effects of discrimination and mental health (Sellers et al., 1997). Within the context of healthcare, African American patients with high racial centrality may perceive more healthcare discrimination than African American patients with lower racial centrality. However, they may have better health-related outcomes that do other African Americans because the patients' sense of closeness to other Black individuals may serve as a buffer between the harmful effects of healthcare discrimination and health-related outcomes.

Using secondary data from a laboratory study in which patients viewed videorecorded, standardized vignettes depicting a cardiologist recommending heart bypass surgery to a patient with angina and 3-vessel coronary artery disease, I examined specific pathways of this model. I investigated the interrelatedness of race of doctor and patients' racial centrality (a dimension of racial identity), and how they may lead to mistrust toward physicians (an aspect of mistrust) and patients' decision-making (likelihood of 
having bypass surgery and likelihood of getting a second opinion). I expected that African American patients who viewed the video of the European American cardiologist instead of the African American cardiologist would have a higher likelihood of seeking another opinion and a lower estimated likelihood of having the recommended heart surgery. I expected that racial centrality would moderate the relationship between race of cardiologist and patient decision-making (i.e., likelihood of seeking another opinion and likelihood of having the recommended heart surgery). Lastly, for African American patients who viewed the video of the European American cardiologist, physician mistrust would enhance the relationship between racial centrality and patient-decision making. In other words, racial identity may serve as a moderator of the relationship between perceived discrimination and mistrust. This research laid the groundwork for a third study that sought to examine this relationship by using the additional dimensions of racial identity (i.e., unfavorable public regard) and of mistrust (i.e., medical mistrust). Perceived discrimination and mistrust: The moderating role of racial identity

The third study examined the concepts of racial identity, perceived discrimination, and medical mistrust. The study involved a cross-sectional survey to investigate whether racial identity moderated the relationship between perceived discrimination and an individual's trust toward physicians and the healthcare system. I examined whether the perceived discrimination would be more strongly related to mistrust toward healthcare and providers for African Americans who identified strongly with their own racial group (racial centrality) and felt that others viewed their group negatively (low public regard). I did this by conducting a primary data collection with a local sample of African American 
EXAMINING AFRICAN AMERICAN ATTITUDES

community members $(\mathrm{N}=210)$. This study provides further evidence about whether racial identity should be considered as an intrapersonal influence on race-discordant patientprovider relationships. By incorporating this construct in future studies and interventions we can get a more robust understanding of how these race-related factors eventually contribute to patients' health-related outcomes.

\section{Conclusion}

Taken together, these studies provide a comprehensive understanding of the racerelated attitudes that African American patients bring to the provider's office and how they may affect patients' experiences (e.g., communication with providers) and decisionmaking (e.g., adhering to providers' treatment plan), while also highlighting the importance of certain dimensions of the Black experience such as racial centrality. Using multiple methods, I address new questions about race-discordant patient-provider relationships. A ramification of this dissertation is that incorporating the theories of social and community psychology can help us develop interventions that improve the trust between African American patients and non-African American providers. The socioecological model that I presented earlier (Figure 1; Centers for Disease Control and Prevention, 2013) can help us draw new questions while also focusing on other units of measurement. For example, considering that patients' perceptions and behaviors are partially influenced by the provider, we can use these findings as a template in the future to explore the factors that influence physicians' attitudes and perceptions as well. Physicians bring their own attitudes, beliefs, and values that are influenced by the broader society, which may differ from the patients' own attitudes, beliefs, and values. In the 
doctor's office, these differences may lead to poorer health-related outcomes for the patients. While, I did not examine the providers' race-related attitudes in the dissertation, the studies presented give us a basis to understand how upstream influences in the ecological model manifest in the doctor's office and how they interact with intrapersonal characteristics and attitudes of patients. With this new knowledge, we can develop interventions to improve the trust of African American patients and non-African American providers. 
Chapter 2

“I always feel like I'm getting skipped over:” African Americans' experience in healthcare 


\begin{abstract}
Objective: Although African Americans perceive discrimination in healthcare settings, experience higher levels of medical mistrust compared to European Americans, and experience poor communication with healthcare providers, very little is known as to what situations give rise to African Americans experiencing these barriers. This study examined experiences of African American community members regarding these barriers and additionally explored participants' perspectives on race discordance in the patientprovider relationship. Methods: Focus groups were conducted as part of a study applying community based participatory research (CBPR) principles to understand patients' experiences with providers. Participants were recruited through community settings and activities. Sixty African American adults participated in one of 9 focus groups segmented by gender. Discussion topics included what makes a good or bad relationship with a provider, what leads one to trust a provider, and whether a provider's race concordance matters to participants. Data were analyzed deductively using NVivo 9. Results: Perceived discrimination arose when African American patients, particularly women, felt their symptoms or problems were discredited. Medical mistrust occurred when clinicians did not convey respect to patients, leaving patients to wonder whether their clinician's treatment was discriminatory or not. Poor communication arose when clinicians did not acknowledge patients' perspectives during interactions. Patients often viewed these actions as discriminatory behaviors. Conclusions: African Americans experience poor communication with their healthcare providers, medical mistrust and perceived discrimination when accessing healthcare in numerous and sometimes interrelated ways.
\end{abstract}


The investigators recommend focusing on these situations to reduce the experience of these barriers to improve patient-provider relationships for African Americans in healthcare.

Keywords: Perceived discrimination, medical mistrust, communication, race concordance, patient-provider relationships 
"I always feel like I'm getting skipped over:" African Americans' experience in healthcare

Underuse of health services is an important factor contributing to existing health disparities for African Americans (Haas et al., 2004; Weinick \& Krauss, 2000). However, Ashton et al. (2003) argue that even when African Americans have access to services they experience further disparities during their visits to the clinician's office. African Americans have been shown to receive lower quality of care than their European American counterparts (Bach et al., 2004; Mayr et al., 2010). Further, African Americans are less likely to receive many types of medical services and procedures (Egede \& Bosworth, 2008). Although many factors, such as location of health care facilities, may contribute to disparities on a broader level, localized contributions to disparities include the barriers patients experience when they encounter their clinicians during healthcare visits (Ashton et al., 2003; Green et al., 2007; Scheppers et al., 2006). African Americans report less satisfaction with the quality of care and they are more likely to report communication problems with clinicians than European Americans (Collins et al., 2002). Research to date has identified that barriers to quality patient-provider relationships for African Americans include perceived discrimination (Casagrande et al., 2007), medical mistrust (Benkert et al., 2006), and poor communication (Rim et al., 2011). However, very little is known about what experiences shape these three barriers and how they manifest in patient-provider interactions. Investigation to identify and describe these experiences can improve our understanding of the African American 
perceptions of healthcare and contribute to long term reductions in healthcare disparities for African Americans.

\section{Perceived discrimination}

A report of 4,157 U.S. adults that compared perceptions of health care among a variety of ethnic groups found that non-European Americans often view their health care experiences more negatively than do European Americans. Particularly, African Americans perceive discrimination in receiving health care, and many feel they would receive lower quality care than White patients if they were sick (Blendon et al., 2007). Similarly, Van Houtven et al. (2005) found that individuals reporting perceived discrimination are more likely than others to delay medical tests and treatment. Reports from African American patients of perceived discrimination are associated with lower likelihood of high-quality treatment and patient adherence (Casagrande et al., 2007; Facione \& Facione, 2007; Fowler-Brown et al., 2006; Hoyo et al., 2005; NapolesSpringer et al., 2005; Penner et al., 2009). Although there is mounting evidence to show that experience of discrimination affects the quality of care for African American patients, little is known as to which aspects of their healthcare experience patients themselves find discriminatory. Identifying factors that African American patients find to represent unfair treatment on the basis of their ethnic background can help patients and clinicians be more successful in the care relationship.

\section{Medical mistrust}

An enduring distrust towards institutions and health professionals is linked to dissatisfaction, nonadherence, and underuse of healthcare services (Hammond, 2010; 
LaVeist et al., 2000; LaVeist et al., 2009). African American men sometimes choose not go to clinicians because of their lack of trust toward healthcare providers (Hammond, 2010). African Americans who hold mistrust tend to have more negative views and expectations of their clinicians than do other African Americans who do not hold mistrust (Thompson, Bazile, \& Akbar, 2004). Some scholars have argued that mistrust need not be based on personal past experience, but can be learned through members of one's group (Katz et al., 2009). Consequently, learned mistrust may become part of the schematic framework with which one sees, and responds to, medical interactions. Lack of trust is associated with lower medication adherence and patient satisfaction (Roberts, 2002; Schoenthaler et al., 2013). Identifying the ways trust can be improved through the perspective of patients themselves can augment the quality of the patient-clinician relationship and quality of care for African American patients.

\section{Poor communication}

Patient ethnic background is an often overlooked but important variable within clinician-patient communication studies (Schouten \& Meeuwesen, 2006). Gordon et al. (2006), for example, found that African American patients diagnosed with pulmonary nodules or lung cancer receive less information from their clinicians and are less active participants in care than European American patients. They also found that African American patients engage in fewer behaviors of the sort that bring forth information from clinicians, such as asking questions and expressing concerns. These findings imply that African American patients are less active in the exchange of information and involvement in decision making, thus decreasing the chance of obtaining high-quality care. Van Ryn 
and Burke (2000) found that European American clinicians rated African American patients as less intelligent, less compliant, and more likely to engage in risky health behaviors than other patients. Van Ryn and Burke suggested that such attitudes may be perceived by patients via nonverbal cues or verbal tone, consequently influencing patients to disengage from the interaction. Identifying the antecedents and consequences of poor communication, from the perspectives of patients themselves, can inform interventions to improve patient-clinician communication.

\section{The role of race discordance}

Race discordance plays an important role in African American patients' interactions with clinicians. For example, Saha, Komaromy, Koepsell, and Bindman (1999) found that African Americans patients were more likely to rate a race-concordant clinician favorably and were more likely to report receiving preventive care and medical care than patients with race-discordant clinicians. Similarly, Cooper-Patrick et al. (1999) found that African Americans patients who had race-concordant clinicians rated their visits as significantly more participatory than patients who had race-discordant clinicians. Because race discordance may contribute to the experience of discrimination, poor communication, and lack of trust among African American patients, the authors in this study explored African American patients' experience with race-discordant clinicians in relation to the three identified barriers in patient-provider relationships.

The relationship between patient and clinician is a key place to look to improve our understanding of patients' experiences. This study asked, "What situations give rise to perceived discrimination, medical mistrust, and poor communication when African 
American patients speak about their experiences with, and their perspectives on, healthcare providers?" The study also asked, "How does ethnic/race discordance influence barriers experienced by African Americans, in their interactions with their clinicians?"

\section{Method}

This study took place as part of a larger project which aimed to identify the perspectives of people living with diabetes or hypertension or both on what constitutes a good or bad relationship with clinicians, The larger project incorporated communitybased participatory research (CBPR) principles in many aspects of the research process, including but not limited to development of the focus group discussion guide, engagement of community members as moderators, and recruitment of participants. Although the larger project included participants of three ethnic groups, in the current study the investigators conducted a deductive analysis based only on the discussions among African American participants.

\section{Focus group facilitators}

Community Advisory Board members and key informants identified several African American community members who were interested candidates for moderator training. Trainees indicated a preference to work in moderator pairs; thus, two African American men co-moderated the men's focus groups and two African American women co-moderated the women's focus groups.

\section{Participants}


The research team recruited Portland, Oregon residents through attendance at community events, through flyers posted in a variety of venues (e.g., restaurants and barber or beauty shops), and through participant word of mouth. The research team avoided clinics and hospitals as recruitment sites in order to keep the study procedures truly community-based, not clinic-based, and in order not to oversample from any particular health care facility. Participants were recruited who had diabetes and/or hypertension in part so that the investigators would learn from participants who interact with clinicians fairly regularly.

\section{Procedure}

With help from the project's Community Advisory Board, research team members created the focus group guide to learn about people's actual experiences in the healthcare system, particularly their interactions with clinicians and their values and preferences regarding clinician-patient interactions. The focus group guide included questions about experiences with most recent visits to the clinician; questions about good experiences with clinicians (i.e., actual experiences and what makes a good experience); questions about bad experiences with clinicians (actual experiences and what would have made for a better experience); questions of experiences and preferences regarding clinician's race/ethnicity, and hypothetical advice to clinicians as to how to improve the experience of health care for patients. Focus groups took place at a community coffee house in inner northeast Portland, Oregon, a location familiar to and convenient for many African American community members. During focus group discussions, typically one moderator asked questions and led discussion while the other moderator took notes and 
monitored discussion to ensure balanced participation. After each focus group discussion, the investigators distributed a brief questionnaire asking participants to provide demographic information.

\section{Data analysis}

The authors used the qualitative software NVivo 10 Student and employed a deductive approach (Boyatzis, 1998; Hayes, 1997) in this secondary analysis of transcripts from the original study. Beginning with the three barriers in patient-provider relationships derived from extant literature with African American patient samples, the first author coded all transcripts for perceived discrimination, medical mistrust, and poor communication, applying a common set of codes and sub-categories across all transcripts. The first and second authors met frequently to discuss codes and reach agreement on the codes and sub-categories. Next, the first author used these codes to investigate the comparisons or connections across groups and to examine how well the data accommodated the framework of these three key concepts. The research team met to review analytic memos, to discuss discrepancies of thinking, and to reach agreement on analytic findings.

\section{Results}

A total of 60 African Americans participated in a total of 9 focus groups, including four groups of women and five of men. Thirty-five men participated with ages ranging from 27 to 81 and mean age being 56 . Twenty-five women participated in the study with ages ranging from 24 to 89 and mean age being 58. About three quarters of the 
participants had high blood pressure, about one-half had diabetes, and about one-third had both conditions.

Discussions of the three barriers examined in this study arose in both the men's and women's focus groups. Issues of perceived discrimination spontaneously arose from discussions on what makes a good clinician, while discussions of poor communication manifested mainly when moderators asked participants what constitutes a good and bad relationship with doctors. Discussions on trust and race discordance also arose spontaneously, but the moderators also directly explored these topics as part of the focus groups. The research team found relationships among these concepts; for example, statements about poor communication also referenced experiences of discrimination. Race concordance also played a prominent role in the relationship among the three barriers.

\section{Perceived discrimination}

African Americans perceived discrimination in the doctor's exam room. African American women, in particular, reported they had to assert their interests constantly in order to receive fair treatment from the medical staff and doctor. An African American woman described her negative experience receiving care from her clinician where she felt she was being perceived as a drug user:

When I flare all up, I like to have something just because my pain go from my toes all the way up to my neck and shoulders sometime, and I can't hardly function. I need something, and that's why I be saying, give me something, or tell me something I can do. I need help and that's my biggest gripe. I think it's 
because I'm a Black woman I don't get no medication or no kind of other kind of treatment. So, I'm saying, I think it's that kind of an issue, because you got White druggies, they are all kinds of people are druggies, but they suspect the African American. [Emphasis added]

Another African woman described a situation in which her symptoms were dismissed, and in which she believed she received substandard care:

They act like they're afraid to touch you or they can't tell you. You say, "I got a bump right here where I can't see." They can't see anything on you and I have heard a lot of Black people have issues about that, where they act like they can't see anything on you. You just kind of a nobody. You don't have nothing on you. "What's that?" You tell them, "I've got a bump right here." They say, "Hmm... bump? I can't see nothing," And a lot of time... they won't touch you. [Emphasis added]

Some participants reported that experiences of discrimination began at the front desk or waiting room of their doctors' offices, well before they entered the doctors' examining rooms. Participants often felt mistreated by staff, and the uncertainty as to whether this mistreatment was related to their racial or ethnic background caused concern and distress. One participant discussed his experience in a waiting room:

They saw me for the first time about a month ago. I always feel like I'm getting skipped over. I don't know if it's a Black thing or not, but I always feel like, I was here before somebody else, and they went in before I did, but I sort of try to keep that to myself. [Emphasis added] 
One woman perceived a difference in how the medical staff interacted with African American patients compared to European American patients:

Well, um, my primary care doctor...is very helpful towards me, and she goes out of her way to help me, but I notice when I'm with the, um, when I'm in the receptionist's area, the receptionists seem more willing to chit-chat with the white clients that come through than they are with me. They'll have them standing there talking to them and laughing and joking, and when I step up and make a comment, you know, it's all business. I feel (laughs), I feel like they're prejudiced.

\section{Mistrust}

Lack of trust seemed to pervade reports from the women's group discussions. Men also provided accounts of mistrust, but in those accounts, mistrust was closely linked to other barriers. One African American woman mentioned she did not trust physicians because they would not advocate for her:

[I do not trust clinicians] because I feel like they're a part of a big system. If there was some treatment that I needed that went outside of what my insurance covered, y'know, would they tell me? Would they, y'know, advocate to the insurance for me to get that? I just feel it's big business and that I'm just a consumer. I just really feel like that medical care is a lot different now than it was.

Another woman recommended bringing someone else along to the doctor visit to advocate for the patient and bring some form of support because she does not trust 
doctors to treat patients well. She said, "I want to add that many people go to the doctor and, if at all possible, they should never go to the doctor alone."

The feeling of being disrespected led to mistrust and was sometimes attributed to discrimination based on race and/or gender:

I didn't trust [her]. She was very unprofessional. She was rude, very inconsiderate, and I didn't feel comfortable saying one thing to her, not even telling her my last name. I wouldn't spell it for her, because she came into the room like she didn't like me, and [it was] the first time we met. She just came in like she had a problem with me being a man or me being a Black man, one or the two. I wanted her to know, “I don’t like you! You're rude. You're completely rude." I didn't understand why.

\section{Poor Communication}

Listening and showing concern were highlighted in descriptions of good and bad patient-clinician communication. An African American woman described her experience where the physician did not take the time to listen to her concerns and make sure she understood her treatment regimen:

[I want doctors] to show concern and listen to you, not just shoving you off.

Saying what they have to say and blowing that one off the door. Actually stopping and you know, some eye contact. And they just showing that they care. I had one doctor one time I almost didn't even recognize him he was in and out the door. Who was just seeing me? I need to see him again! [laughter] I think that, eye contact and showing concern... [I need] them to tell me things and I'm just 
like "I don't know what I'm supposed to do. I need you to write things down for me because a lot of times my head bothers me and things don't sink in.

Perceptions of poor communication contributed to perceived discrimination. Often participants attributed poor communication to how the doctors responded to the patient's racial/ethnic background. They believed that doctors (typically race-discordant doctors) devalued their symptoms or ignored their comments because they were African American. One man described being upset when clinicians ignored his symptoms or issues:

I don't know, I guess I was a little upset because I go in, I went in with a problem, and it seems like my problem was downplayed and I was told something else was wrong, when I knew better. It was more or less just being ushered out as quickly as possible. It's as though when they see an African American come in there, it's like we're trying to get over and that's the impression I get every time I go. It's a little upsetting.

\section{The role of race discordance}

Focus group participants varied in their preference or lack of preference for raceconcordant doctors. Many said they did not care whether their doctor was African American as long as the doctor was competent. One participant described what she wanted from a doctor, which went beyond race, ethnicity, and culture:

I see a Black doctor now, but I don't think either way that it would make any difference, the culture or the race of the doctor. I just want to have a doctor that's a good doctor, that's willing to listen, and has a good understanding. 
The men's groups echoed this preference: "If it happened to be a Black doctor, I wouldn't have any problem with it, but I just want to have a good doctor.” Those who did prefer race-concordant doctors believed African American doctors were better communicators and more caring; as one woman expressed, "They are more compassionate. They always want to give you as much information and they seem to have empathy with you and everything."

While many African Americans preferred to see an African American doctor, some preferred a European American doctor. One man said his expectations for African American doctors would be too high, underpinning his preference for a race-discordant health care provider with his past extensive experiences of discrimination:

I think my expectations would be too high if I saw a Black doctor... So, me, personally, I just want to go to the best doctor, but, no, I'd rather not see a Black doctor because if he does one single thing that I don't appreciate, I'm going to have a fit... I'm used to being offended by White doctors. It's nothing new to me. I've been offended by White people all my life. I don't appreciate being offended by somebody of my own race. [Emphasis added]

In sum, the three key concepts identified in prior literature evinced themselves in participants' comments, with participants also providing examples of how race concordance and discordance may play an important part in their interactions with healthcare providers.

\section{Discussion}


What do these findings tell us about patient-clinician relationships for African Americans? These findings helped us to understand what at least some African American patients considered discriminatory, what influenced their lack of trust towards clinicians, what factors negatively affected communication with clinicians, and why they might have preferred race-concordant clinicians. Further, this study showed ways in which these concepts are interrelated in participants' own experiences. This interrelationship suggests that future studies would do well to study these concepts together, in order to develop a better understanding of African Americans' experiences in health care.

African American patients perceive more discrimination than do European American patients (LaVeist, Nickerson, \& Bowie, 2000; Sorkin, Ngo-Metzger, \& De Alaba, 2010), and for African American patients, perceived discrimination is associated both with delays in seeking medical care and with poor adherence to medical care recommendations (Casagrande et al., 2007; Cuffee et al., 2013; Thrasher et al., 2008). But what exactly do African American patients find discriminatory? Our results indicate that the experience of discrimination actually begins before the patient enters the clinician's exam room. For our study participants, having to wait a long time in the waiting room made them question whether they were being discriminated against or not. African American women, in particular, noticed how the medical staff interacted differently with European American patients, finding those interactions to be friendly and warm, as opposed to their own interactions being cold and businesslike. In the clinician's office, African American patients, particularly the women, felt their symptoms or problems were dismissed, often feeling that they were viewed by the medical staff and 
clinicians as drug users. Some experiences felt clearly discriminatory and caused distress or anger, while other experiences left patients wondering whether the event had been discriminatory or not, with the ambiguity of the situation potentially negatively influencing future interactions with medical staff and clinicians.

Mistrust towards institutions and health professionals is also linked to dissatisfaction, non-adherence, and underuse of healthcare services (Hall et al., 2001; Hammond, 2010; LaVeist et al., 2000; LaVeist et al., 2009). What factors in healthcare influence a patient to mistrust clinicians? For some African Americans, the way the healthcare system is structured leads them to feel depersonalized and objectified, rather than being seen as people. They feel rushed during healthcare visits and they believe clinicians would not advocate on their behalf. Their reluctance to trust clinicians may stem from feeling disrespected, coupled with uncertainty as to whether the disrespect was related to physicians' issues with their race. This negative experience and uncertainty led to patients' keeping their distance from and distrusting clinicians. There also appeared to be a cycle of mutual mistrust, in which patients' mistrust of clinicians was a reaction to perceived mistrust by clinicians toward patients, such as when patients felt they were being viewed as drug abusers. The lack of trust they felt from the clinicians influenced their own feelings of trust as well.

Pertaining to poor communication, prior studies have shown that African American patients report unfavorable interactions with their clinicians (Gordon et al., 2006; van Ryn and Burke, 2000). What are some of the factors that may negatively affect communication between patient and clinician? When group members spoke about 
negative experiences communicating with clinicians, they often spoke about how clinicians did not acknowledge their perspective during interactions. These interactions were often seen as discriminatory behaviors from the clinician. This might explain previous studies that found African American patients reporting that clinicians do not spend enough time with them, do not respect their intelligence, and do not provide sufficient explanations (Gordon et al., 2006; van Ryn and Burke, 2000). Because they do not have a chance to be heard, they are less likely to be engaged in the treatment. This in turn may lead them to receive less information from their clinicians and be less active participants (Gordon et al., 2006). In the focus group discussions, African Americans spoke about how physicians did not listen or express concern. The clinicians' lack of concern or care led African American patients to not fully understand their treatment regimens. This provide insight into previous findings showing physicians being more verbally dominant and engaging in less patient-centered communication with African American patients than with European American patients (Johnson, Roter, Powe, \& Cooper, 2004).

LaVeist and Nuru-Jeter (2002) argue that racial and ethnic disparities in the use of health services, quality of care, and health status would be reduced by increasing the number of minority health care providers in the U.S. Race-concordant relationship is associated with greater use of needed medical services (LaVeist et al. 2003), improved communication and participatory decision making (Cooper-Patrick et al. 1999, Cooper et al. 2003), and greater satisfaction with provider and healthcare (Cooper et al. 2003; LaVeist and Nuru-Jeter 2002; Saha et al., 1999). Therefore, the investigators sought to 
identify whether the race/ethnicity of the clinicians influence the barriers experienced by African Americans. The investigators asked participants to address race discordance directly; when they did address race discordance they frequently discussed having no preference about clinicians' ethnic background. Regardless of the clinician's race or ethnicity, participants preferred having a good clinician who communicated well with their patients. Those who did prefer a race-concordant clinician discussed how raceconcordant clinicians are better communicators and caring during interactions. This finding supports LaVeist and Nuru-Jeter's (2002) argument that African Americans who prefer race-concordant clinicians believe that communicating is comfortable and easier. Patients who prefer race-concordant clinicians may feel they are able to be a part of the decision-making process. Those who prefer a race-concordant clinician may also have the expectation that a race-concordant clinician will exercise greater agency in patient care. However, this expectation may sometimes be too high. As one participant discussed, the experience of being treated poorly by a race-concordant clinician may be too much to bear.

As shown by the findings, perceived discrimination, medical mistrust, and poor communication are not distinct barriers, but are interrelated problems experienced by African American patients. For example, negative communications between patient and clinician were often seen as discriminatory events. Moreover, past negative interactions contribute to mistrust, which in turn contributes to reluctance in disclosing information in future visits with clinicians. The interrelatedness of these barriers in conjunction with perception of race discordance indicates the complexity of patient experiences. It also 
provide insight into Greer, Brondolo and Porschia's (2014) study who found a positive relationship between perceived clinician racial biases and patient's mistrust of care. Perhaps negative interactions are perceived as clinician racial bias, which in turn may negatively affect a patient's trust toward her or his clinician.

African American patients view their experience through a racial lens which has been influenced by past and current experience of racial discrimination from the larger society. In the context of healthcare, such a lens may help patients to structure and make meaning of their interactions with medical staff and clinicians. This, in turn, may allow them to eventually cope with the potential stressors of the healthcare experience. In racediscordant patient-clinician relationships, healthcare related stressors are amplified. NonAfrican American clinicians and medical staff may bring their own biases to their interactions with patients. Clinicians may not be conscious of their preferential treatment toward one particular group over another (Dovidio et al., 2008; Green et al., 2007; Penner et al., 2010). The race-related attitudes and perspectives that clinicians bring to these interaction may lead to patient disengagement with care and thus to negative healthrelated outcomes. Understanding, as well, how bias manifests in the waiting room or at the front desk would help researchers develop interventions so that medical staff can work more helpfully with patients of a range of racial and ethnic backgrounds.

\section{Limitations}

This study has several limitations and considerations. The authors observed that when the topic of discrimination was introduced, people were reluctant to have a discussion about it. Once the conversation opened up participants sometimes appeared 
unsettled trying to figure out whether a negative event was discriminatory or not. The authors speculate the reluctance may be due to patients' fear that they will come across as "playing the race card," or avoidance of feeling powerless (Kaiser \& Miller, 2003).

Although the theme of discrimination still manifested in the discussions, this reluctance may have caused an under-reporting of more discrimination incidents.

Some aspects of the participants' experiences, such as the off-putting experience of being rushed through appointments or the sense that the clinician is disinterested in the patient's own report of a health problem, might be experienced by patients of other ethnic groups as well. This study did not compare experiences across ethnic groups. A better understanding as to how other ethnic group members experience discrimination will help investigators identify the overt and subtle forms of discriminatory behaviors from medical staff and clinicians that are uniquely experienced by other groups in the healthcare system.

Most of the participants lived in Portland, Oregon, a city with relatively low racial diversity (US Census Bureau, 2011). Because of the low proportion of African Americans in this geographic area, the reported experiences differ in unknowable ways from experiences of African Americans in other geographic regions. For example, our focus group participants were far more likely to have received care from European American than African American clinicians. This in turn lowered their ability to reflect on experiences with race-concordant clinicians. This lack of information has prevented us from fully understanding African American patients' experiences with race-concordant clinicians. 
Recruitment for the focus groups was based on community events and contacts, and was limited to persons with diabetes or hypertension or both. The inclusion criteria related to health conditions likely yielded an older sample than might have otherwise participated. In addition, as a method of data collection focus groups depend upon group interaction. Depending upon the population, the topic, and potentially also upon situational factors, normative influences can affect focus group participants' commentary. Real or imagined social pressures can influence individuals' decisions to report experiences that diverge from a perceived norm or indeed, diverge from what participants believe researchers wish to hear. This is a common criticism of focus groups (Ritchie \& Lewis, 2003). In part to minimize this problem, the focus group moderators welcomed all points of view on topics of discussion and solicited a wide range of experiences from study participants (Hughes \& DuMont, 1993). Even so, moderators were community members who were not professional focus group moderators, and their skill in soliciting dissenting opinions may have been limited.

\section{Conclusion}

Reducing situations that give rise to the barriers of perceived discrimination, medical mistrust, and poor communication may improve patient-provider interactions, and in turn reduce the pervasive problem of racial and ethnic disparities in healthcare. Because these barriers seem to be interrelated, reducing the effects of one barrier in the relationship may help reduce the effects of the other barriers as well. While the preference for racially concordant clinicians depends on the patient's belief that racially concordant clinicians can deliver better care, eliminating these barriers in healthcare can 
ameliorate the negative health-related outcomes currently associated with care relationships that are race-discordant. Further, attending to interactions with medical staff (e.g., waiting room) may improve patient-provider interactions and the overall patient experience for African Americans. 
Chapter 3

Mistrust toward physicians and patients' decision-making: Does racial centrality play a role? 


\begin{abstract}
Objective: African Americans are less trusting of physicians than are European Americans. The centrality of racial identity may affect African Americans' healthcare experience and level of trust. Although racial centrality influences individuals' everyday lives, little is known as to how racial centrality influences African Americans' healthcare experiences. Methods: I conducted a secondary analysis of data from a laboratory study (Somnath Saha, PI) in which 104 primary care patients viewed video-recorded, standardized vignettes depicting a cardiologist recommending heart bypass surgery to a patient diagnosed with angina and 3-vessel coronary artery disease. Research participants were asked to assume the role of the patient being addressed by the video-recorded physician. I examined the relationships among ethnicity of the cardiologist-actor, participants' racial centrality, their trust toward physicians, and their decision-making (i.e., participants' ratings of the likelihood of having bypass surgery and of getting a second opinion). Results: For these African American primary care patients, ethnicity of the cardiologist-actor was negatively associated with both physician mistrust and the hypothetical likelihood of having bypass surgery. Racial centrality did not moderate the relationship between ethnicity of the cardiologist-actor and patients' decision making. Racial centrality was not associated with physician mistrust for those who viewed the video with the European American cardiologist-actor. Conclusion: While racial centrality did not play a role, European American ethnicity of the cardiologist-actor was negatively associated both with patients' trust toward the cardiologist and with readiness to endorse surgery. Significance: This study provides further evidence of the importance of race
\end{abstract}


concordance in patient-provider relationships. Increasing the number of African American physicians would afford more opportunities for race concordance among African Americans.

Keywords: African Americans, racial identity, physician mistrust, decisionmaking 
Mistrust toward physicians and patients' decision-making: Does racial centrality play a role?

Trust is an important feature in patient-provider relationships. Patient trust is defined as a set of beliefs or expectations that a physician will behave in a certain way and confidence in the physician and her or his intent (Thom, 2002). These beliefs and expectations are associated with a variety of health-related outcomes, such as the utilization of health services (Chow, Jaffee, \& Snowden, 2002), adherence to doctor's orders, and the realization of the full benefit of medical treatment and procedures (Altice, Mostashari, \& Friedland, 2001; Thom, 2002). African Americans, however, are less trusting of physicians, hospitals, and the medical establishment than their European American counterparts (Boulware et al., 2003; Corbie-Smith, Thomas, St. George, 2002; Voils et al., 2004). For example, African Americans are more likely than European Americans to be concerned about the potential for harmful experimentation in hospitals (Boulware et al., 2003).

Why are African Americans less trustful of physicians and the healthcare system? African Americans may have an inclination to mistrust healthcare and European American healthcare providers based on historical and contemporary experience of discrimination (Benkert et al., 2006; Terrell \& Terrell, 1981). In the context of racediscordant patient-provider relationships, this inhibits African American patients from establishing a trusting relationship with European American physicians. This may help explain why African Americans who are in a race-discordant healthcare relationship are less likely than African Americans who are in a race-concordant relationship to rate their 
visit as significantly less participatory (Cooper-Patrick et al., 1999), to rate their physicians as excellent (Saha et al., 1999), and to report satisfaction with their provider (LaVeist \& Nuru-Jeter, 2002). This difference is amplified given that African Americans are more likely to see a European American healthcare provider than see an African American healthcare provider (Saha et al., 1999). These findings beg the question, how are healthcare satisfaction and mistrust related to race discordance and perceived discrimination? While prior studies offer insight into this question, very little is known as to how they may be related to other dimensions of the Black experience, such as racial centrality.

Racial centrality is an aspect of racial identity, defined as the extent to which a person normatively defines her or himself with regard to race (cf. Sellers et al., 1997). Individuals with high racial centrality are more accepting of the values and traditions of African American culture and are more likely to reject the values of the dominant European American culture (Mpofu \& Harley, 2006). Racial centrality has also been associated with negative attitudes toward European Americans (Cross, 1971; Lecci \& Johnson, 2008). These negative attitudes may influence mistrust towards European American health providers as well. Although research is needed to further examine the association between racial centrality and attitude toward healthcare and healthcare providers, studies have examined the relationship between racial identity and global cultural mistrust (i.e., disposition to mistrust European Americans), and have found cultural mistrust to be strongly and positively correlated with Black racial identity. Studies examining the link between racial centrality and medical mistrust found similar 
results in that African Americans who reported a stronger identification with their racial group expressed greater mistrust than those who reported identified less strongly with their racial group (Shelton et al., 2010). Although there is some evidence that racial identity may influence mistrust, more research is needed to see how racial identity specifically influences patient's trust toward physicians. It is important to mention that I am not construing racial centrality as problematic. In fact, I acknowledge that racial centrality is important to an individual's self-image and is associated with positive outcomes, such as better mental health and higher self-esteem (Sellers et al., 1998; Speight, Vera, \& Derrickson, 1996). Although racial centrality influences an individual's everyday life, little is known as to how racial centrality influences African Americans' healthcare experience, particularly in race-discordant patient-provider relationships.

This study seeks to address the relationship of racial centrality to mistrust of physicians by patients, and to patient decision-making. I use secondary data from a laboratory study (Somnath Saha, PI) in which primary care patients viewed videorecorded, standardized vignettes depicting a cardiologist recommending heart bypass surgery to a patient diagnosed with angina and 3-vessel coronary artery disease. Because African Americans patients are more likely to trust race-concordant healthcare providers (Sohler et al., 2007) and rate them more favorably than race-discordant providers (Saha, Komaromy, Koepsell, \& Bindman, 1999), I attend to the role that race concordance may play in the relationship between physician mistrust and patient's decision-making. First, I investigate whether race of cardiologist is related to patient decision-making (i.e., likelihood of seeking another opinion and likelihood of having the recommended heart 
surgery). I then look at how racial centrality moderates the relationship between race of cardiologist and patient decision-making. Lastly, I investigate the mechanism by which racial centrality is related to patient decision-making by investigating the mediating role of physician mistrust. A better understanding of this mechanism can help researchers incorporate a dimension along which African American patients vary to improve interventions that seeks to increase trust among African Americans who are in racediscordant healthcare relationships. My hypotheses were as follows:

Hypothesis 1. African American patients who viewed a video of a European American cardiologist will have a higher likelihood of seeking another opinion and a lower estimated likelihood of having the recommended heart surgery than African American patients who viewed a video of an African American cardiologist. Racial centrality will moderate the relationship between race of cardiologist and patient decision-making (i.e., likelihood of seeking another opinion and likelihood of having the recommended heart surgery). In other words, the relationship between race of cardiologist and patient decision-making will be stronger for African Americans with high racial centrality than for African Americans with low racial centrality. 


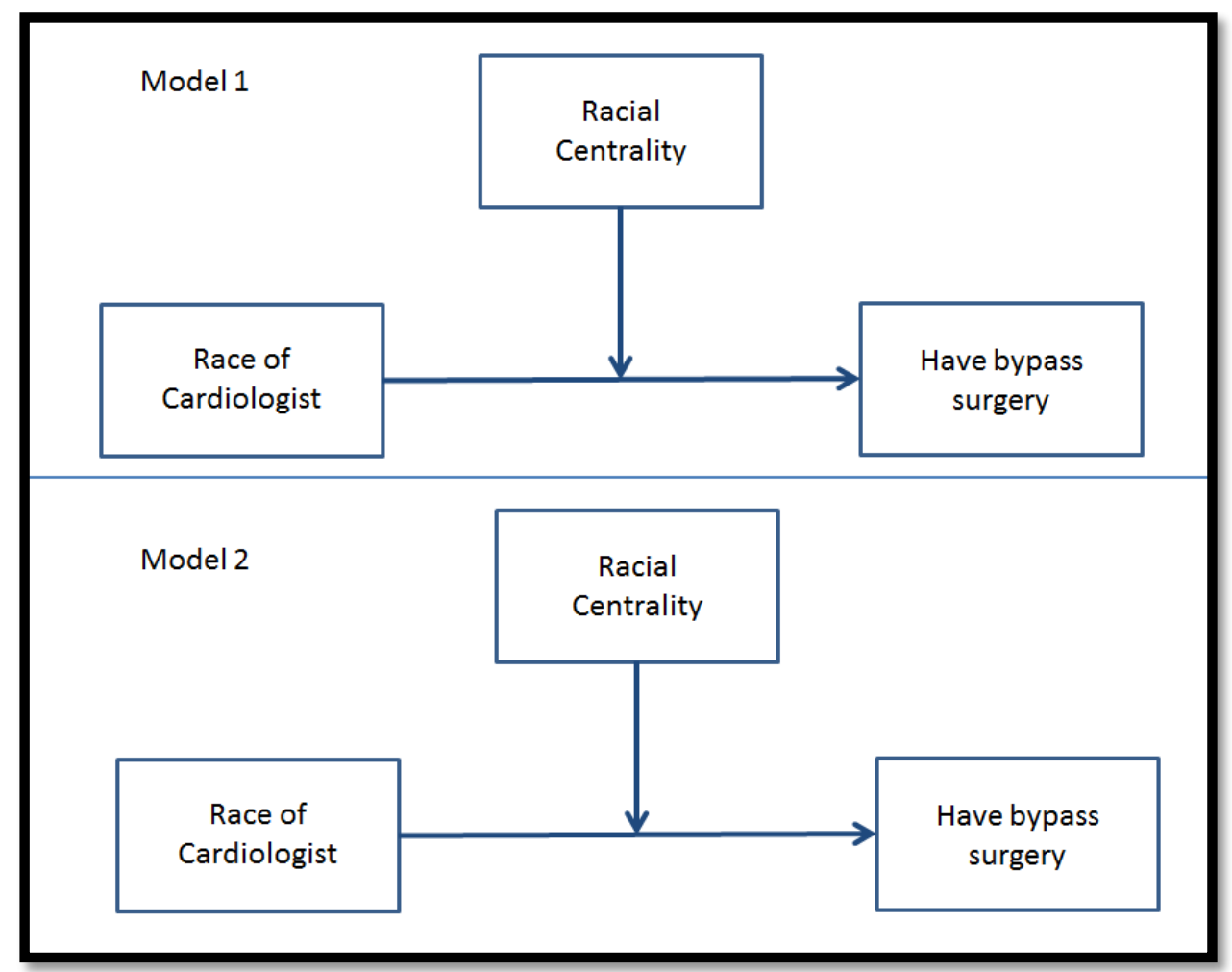

Figure 4. Diagram of Hypothesis 1, separated by outcome.

Hypothesis 2. For African American patients who viewed the video of the European American cardiologist, physician mistrust will mediate the relationship between racial centrality and patient decision-making. In other words, racial centrality will be associated with patient decision-making. Racial centrality will be associated with physician mistrust. Physician mistrust will be associated with patient decision-making, controlling for racial centrality. 


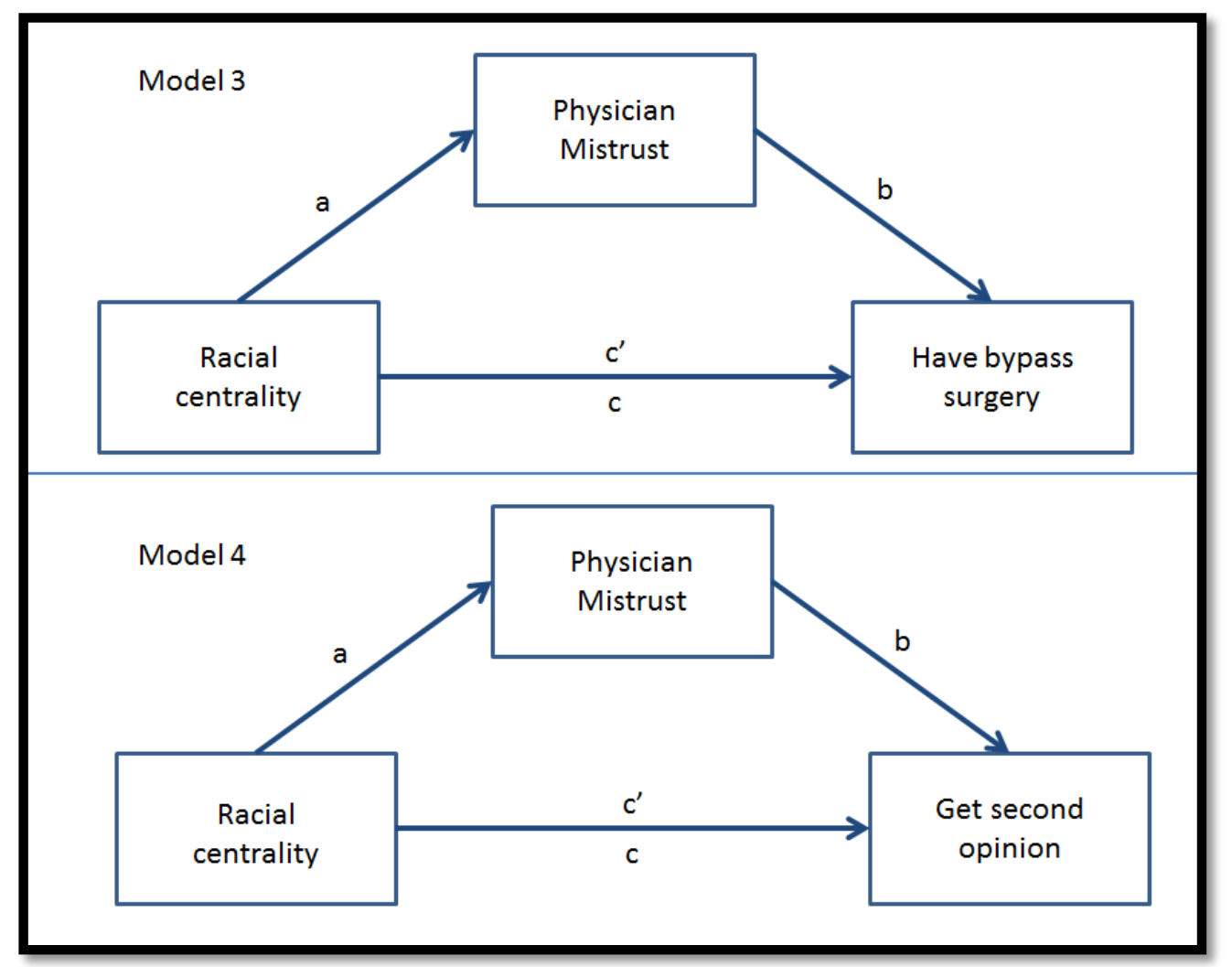

Figure 5. Diagram of Hypothesis 2, separated by outcome.

\section{Methods}

This secondary data analysis was based on an original study that assessed the impact of patient-centered communication behaviors on patients' evaluations of physicians and acceptance of clinical recommendations (Saha \& Beach, 2011). As described by Saha and Beach (2011), the research team recruited study participants at a hospital-based, adult primary care clinic in Portland, Oregon. the investigators randomized 248 patients (European Americans and African American patients) to view video-recorded, standardized vignettes, depicting a cardiologist (European American and African American actors) using a high vs. low degree of patient-centered communication 
while recommending heart bypass surgery to a patient with angina and 3-vessel coronary artery disease.

\section{Participants}

The investigators recruited African American participants at a hospital-based, adult primary care clinic in Portland, Oregon. They approached consecutive patients 40 or older whose medical records indicated a diagnosis of coronary artery disease or coronary artery disease risk factors (smoking, hypertension, diabetes, or hyperlipidemia). Patients were told that the study purpose was to examine their own decision making about heart disease. Acutely ill patients and those with cognitive or severe visual impairment were ineligible. Patients agreeing to participate gave informed consent and received $\$ 20$ for their time. After providing informed consent but before being randomly assigned, patients completed a brief questionnaire through face-to-face interviews conducted by research assistants, where they also reported their demographic characteristics, cardiac history, familiarity with different coronary artery disease treatment options, and preferred role in making medical decisions.

The original study was approved by the Legacy Health System Institutional Review Board. This secondary data analysis was approved under the exempt category by Portland State University's Institutional Review Board as the information was collected by the investigator in a manner that data are considered de-identified.

\section{Measures}

Racial Centrality. A total of 8 items was used to assess the extent to which a person normatively defines him or herself with regard to race (Racial Centrality is a dimension 
of the The Multidimensional Inventory of Black Identity [MIBI]; Sellers et al., 1997). The scale employs seven Likert-type response options ranging from "strongly disagree" to "strongly agree." The scale includes items such as "In general, being Black is an important part of my self-image" and "My destiny is tied to the destiny of other Black people." Responses were averaged, where higher scores indicate the more central race is to one's self. Reliability and construct validity for racial centrality was investigated in a study of 474 African American college students from predominantly African American universities and Cronbach's alpha for centrality was found to be .77 (Sellers et al., 1997). The scale has also been used with African American men from an urban city ( $\alpha=.76$; Shelton et al., 2010). Cronbach's alpha (an estimated of internal consistency) was .68 for the present study.

Physician mistrust. The Trust in Physician Scale (Anderson \& Dedrick, 1990) was adapted to assess the level of trust the participant had toward the video physician. The scale employs five Likert-type response options ranging from "strongly disagree" to "strongly agree." It includes items such as "I distrust that doctor's opinion and would like a second one" and "I trust that doctor so much I would always try to follow his/her advice." Before obtaining the mean of the scale, I flipped the positive worded items. For example, for item "I would trust that doctor's judgments about my medical care." a value of 1 represented Strongly Disagree. After flipping the values, a value of 5 represented Strongly Disagree. A summary measure of trust was obtained by taking the unweighted mean of the responses to the 10 questions. Higher scores reflect greater mistrust. The Trust in Physician Scale has demonstrated construct validity and has been used to assess 
patient trust toward physicians among diverse populations (Doescher, Saver, Franks, \& Fiscella, 2000; Nguyen et al., 2009; Thom, Ribisl, Stewart, \& Luke, 1999). Cronbach's alpha was .95 for the present study.

Patient's decision-making. Two items were used assess the patient's decision-making. The items asked participants to rate their likelihood of undergoing coronary artery bypass graft surgery and of obtaining a second opinion, if they were the patient in the video. The items employ four Likert-type response options ranging from "definitely" to "definitely not."

Sociodemographics. Sociodemographics included age, sex, partner status, and educational level. Sociodemographics were treated as covariates in the analyses due to known or expected associations with the concepts to be examined.

\section{Procedure}

The following procedures are reported in Saha and Beach (2011). Investigators of the larger laboratory study produced the video vignettes in collaboration with a California-based film production company (Crosskeys Media Works). Eight professional actors, 4 men and 4 women, played the role of the cardiologist. Two professional actors, one man and one woman, played the role of the patient. Each physician-actor wore scrubs, a white coat, and a stethoscope. Vignettes were filmed from a point-of-view angle: the patient was heard but not seen, and the physician faced the camera when speaking. The final set included 32 videos: 8 physician-actors performing 2 vignette versions (low and high patient-centered communication), each with 2 patient voices (male and female). The videos were placed on DVD-ROM media. 
An introductory screen appeared first, giving a brief patient history. The patient was introduced as a 55-year-old man (or woman) with hypertension and gradually worsening chest pain, who had a positive exercise treadmill test leading to an angiogram. The introduction explained what an angiogram was, that this was the patient's second visit to this heart specialist, and that the purpose of the visit was to discuss angiogram results. The vignettes involved a visit between a cardiologist and a patient with progressive angina who recently underwent coronary angiography revealing 3-vessel coronary artery disease. The physician reviewed the angiogram results and recommends coronary artery bypass graft surgery, citing evidence of improved quality of life and longterm survival. The physician provided reassurance by citing statistics about perioperative risks (i.e., risk relating to surgery) when the patient expresses fear about the surgery. A discussion then followed about treatment alternatives. The physician ended the interaction by reiterating his/her recommendation of coronary artery bypass graft surgery as the best option.

After participants viewed the video, they completed a self-administered questionnaire reporting on the extent to which they normatively define themselves with regard to race and on their impressions of the physician in the video. Participants completed a 7-point Likert-type scale on racial centrality, a 5-point Likert-type scale rating their trust in the physician, and a 4-point Likert-type scale rating their hypothetical likelihood of undergoing coronary artery bypass graft surgery and of obtaining a second opinion, if they were the patient in the video.

\section{Data analysis}


Descriptive data analysis was conducted to identify the levels of racial centrality, physician mistrust, rating of patients' likelihood to undergo coronary artery bypass graft surgery, and rating of patients' likelihood of obtaining a second opinion. Descriptives included measures of central tendency, variation, frequency distributions, and sample proportions. I used the Mahalanobis Distance to detect outliers (Rousseeuw, \& Van Zomeren, 1990). Mahalanobis Distance is a measure of distance of each data point from the mean that takes into account the variances of the variables. Anything close to 3 is considered problematic. In this data, three cases were considered outliers for the variables bypass surgery and second opinion. The cases were omitted from the data.

I then computed bivariate correlations between all pairs of study variables to determine which to include in later analyses as covariates. Further, the original study exposed patients to two types of the video-recorded, standardized vignettes. The videos depicted a cardiologist-actor (either a man or a woman) using either a high or low degree of patient-centered communication (e.g., using or not using empathic statements and eliciting patient concerns). Because the degree of patient-centered communication, as well as the gender of the cardiologist-actor, was not the focus of this study, I used these factors as covariates to help maintain adequate sample size for analyses and not affect the relationship between the predictors and dependent variables. Before summing the trust in physician scale, I flipped the items so that the construct can be named physician mistrust, which is in accordance with the hypotheses.

Model 1: Regression of surgery decision on race of cardiologist and centrality with a cardiologistXcentrality interaction 
To test Hypothesis 1 (with surgery decision as my dependent variable), I conducted a multiple linear regression. My predictors were race of cardiologist, racial centrality, and the interaction between race of cardiologist and racial centrality. Before I conducted this analysis, I dichotomized the variable racial centrality $(n=103$, mean and standard deviation $=4.86(1.22)$, skewness $=-.257$, kurtosis $=-.229)$, splitting it at the median to form a high and low group. I then centered all the continuous variables (i.e., age and physician mistrust). Centering the continuous variables helped reduce multicollinearity (Robinson \& Schumacker, 2009). Multicollinearity inflates the standard errors when the predictors are related to each other. This makes some variables statistically insignificant in the model while they should be otherwise significant. I standardized the continuous variables (e.g., age) by having a mean of zero and a variance of one (these are features of any standardized variable). The mean of zero is important for avoiding multicollinearity and having a variance of one makes it easier to interpret the possible interaction. I then created and included an interaction term in the model. The interaction term was the product of race of cardiologist and racial centrality. The model included the predictors, level of race of cardiologist (IV1), racial centrality (IV2), and cardiologistXcentrality (IV3), again with likelihood of having bypass surgery as the dependent variable.

Models 2: Regression of second opinion on mistrust and centrality with a mistrustXcentrality interaction

To test Hypothesis 1 (with second opinion as my dependent variable), I conducted a multiple linear regression. My predictors were race of cardiologist (IV1), racial 
centrality (IV2), and cardiologistXcentrality (IV3), with likelihood of getting a second opinion as the dependent variable.

Model 3: Mediated multiple regression of surgery decision on centrality with physician mistrust as mediator

To test Hypothesis 3 (with surgery decision as my dependent variable), I focused on African Americans who viewed the video of the European American cardiologist. Using Baron and Kenny's approach (1986) to mediation analysis, I conducted an analysis in three steps. In the first step, I analyzed the relationship between racial centrality and estimated likelihood of having bypass surgery. In the second step, I analyzed the relationship between racial centrality and physician mistrust. In the third, I analyzed the relationship between physician mistrust and estimated likelihood of having bypass surgery, controlling for racial centrality.

Model 4: Mediated multiple regression of second opinion on centrality with physician mistrust as mediator

To complete testing Hypothesis 3 (with second opinion as my dependent variable), I used Baron and Kenny's approach to test whether physician mistrust mediates the relationship between racial centrality and likelihood of getting a second opinion. In the first step, I analyzed the relationship between racial centrality and likelihood of getting a second opinion. In the second step, I analyzed the relationship between racial centrality and physician mistrust. In the third, I analyzed the relationship between physician mistrust and the likelihood of getting a second opinion, controlling for racial centrality. 


\section{Results}

\section{Participant Characteristics}

The study consisted of the 104 African American participants. Participants (58\% female) were 57.9 years old on average $(S D=10)$. Three quarters of participants were unemployed (e.g., disabled and not working, retired and not working, or not working but looking for work), 70\% had no partner (e.g., separated, divorced, or widowed), and 74\% reported at least a high school degree. See Table 1 for participant characteristics and their interrelations with other study variables.

\section{Demographic Analysis}

Before I conducted the main analyses, I tested whether sociodemographics predicted differences in the predictors and outcomes, respectively. These analyses were conducted to gain a better understanding of the sample at hand. As the reader will see in Tables 2-5, sociodemographics did not predict differences in the predictors nor outcomes, except for marital status and second opinion (Table 5). Controlling for the other sociodemographic variables, results indicated that participants with no partners were more likely to get a second opinion than participants with partners $(B=-.250, S E=.170, p$ $=.003,95 \% \mathrm{CI}=-.857,-.182)$.

Main Analyses

I hypothesized that African Americans who viewed a video of a European American cardiologist would have a higher likelihood of seeking another opinion and a lower estimated likelihood of having the recommended heart surgery than African American patients who viewed a video of an African American cardiologist. This 
relationship would be moderated by racial centrality (Hypothesis 1). I conducted a multiple linear regression with race of cardiologist, racial centrality, and the interaction between race of cardiologist and racial centrality as predictors. Two separate multiple regression analyses were conducted. The first multiple regression analyses (Model 1) had surgery decision as its dependent variable, while the second (Model 2) had second opinion as its dependent variable (please see Table 6 for the models' results).

For Model 1, the main effect of cardiologist's race on the hypothetical likelihood of getting the recommended bypass surgery was significant $(\mathrm{B}=.555, \mathrm{SE}=.25, \mathrm{p}=.029$, $95 \% \mathrm{CI}=-.059,1.05)$, such that African Americans who viewed a video of a European American cardiologist had a lower estimated likelihood of having the recommended heart surgery than African American patients who viewed a video of an African American cardiologist. The main effect of racial centrality on the likelihood of getting bypass surgery was not significant $(\mathrm{B}=.031, \mathrm{SE}=.229, \mathrm{p}=.893,95 \% \mathrm{CI}=-.424, .486)$. The degree to which a person normatively defines him or herself with regard to race did not moderate the relationship between cardiologist's race and the likelihood of getting bypass surgery $(\mathrm{B}=-.045, \mathrm{SE}=.317, \mathrm{p}=.886,95 \% \mathrm{CI}=-.676, .585)$.

For Model 2, the main effect of cardiologist's race on the hypothetical likelihood of getting a second opinion was not significant $(\mathrm{B}=-.443, \mathrm{SE}=.230, \mathrm{p}=.058,95 \% \mathrm{CI}=-$ $.417, .423)$. Similarly, the main effect of racial centrality on the likelihood of getting a second opinion was not significant $(\mathrm{B}=.003, \mathrm{SE}=.211, \mathrm{p}=.988,95 \% \mathrm{CI}=-.417, .423)$. The degree to which a person normatively defines him or herself with regard to race did 
not moderate the relationship between cardiologist's race and the likelihood of getting a second opinion $(\mathrm{B}=.311, \mathrm{SE}=.293, \mathrm{p}=.291,95 \% \mathrm{CI}=-.271, .893)$.

I hypothesized that for African American patients who viewed the video of the European American cardiologist, physician mistrust would mediate the relationship between racial centrality and patient-decision making. I used the Baron and Kenny (1986) approach to test this hypothesis. According to Baron and Kenny (1986), several requirements (i.e., steps) must be met in order to present a true mediation relationship. For example, if the independent variable is not significantly associated with the dependent variable (Step 1), one cannot proceed to test the relationship between the independent variable and the mediator (Step 2). Given this approach, I did not fully test Model 3 and Model 4 in this study. For Model 3, racial centrality was not significantly associated with likelihood of having the recommended bypass surgery $(\mathrm{B}=.007, \mathrm{SE}=$ $.125, \mathrm{p}=.956,95 \% \mathrm{CI}=-.245, .258)$. Similarly, for Model 4, racial centrality was not significantly associated with likelihood of seeking another opinion $(\mathrm{B}=.045, \mathrm{SE}=.095, \mathrm{p}$ $=.638,95 \% \mathrm{CI}=-.146, .236)$.

\section{Discussion}

African American patients who viewed the video of the African American cardiologist had a higher estimated likelihood of having the recommended heart surgery. This was a foreseeable result: prior literature finds that African Americans who are in a race-concordant healthcare relationship are more likely to rate their relationship favorably (LaVeist \& Nuru-Jeter, 2002; Saha et al., 1999) as well as be more participatory in the interaction (Cooper-Patrick et al., 1999) than those who are in a race-discordant 
healthcare relationship. Results of the current study suggest that race concordance indirectly affects the (hypothetical) decision to have the recommended heart surgery, through the effect of race concordance on trust toward the clinician. In other words, trust may be what binds race concordance with patient decision-making. Trust is the belief that health care providers will act competently and with the best interests of patients in mind (Mechanic, 1998). Trust is strengthened when patients see themselves as similar to their physicians in personal beliefs, values, and communication (Street, O'Malley, Cooper, \& Haidet, 2008). Race/ethnicity concordance may be a proxy for common identities between patients and their providers (Cooper, Beach, Johnson, \& Inui, 2006), which may influence the patient's acceptance of the physician's recommendations. This study further supports existing research in that race concordance influences trust and patient's decision-making (Saha, Arbelaez, \& Cooper, 2003; Sohler, Fitzpatrick, Lindsay, Anastos, \& Cunningham, 2007; Street, Jr., O’Malley, Cooper, \& Haidet, 2008).

This pathway, however, did not apply when the dependent variable was the likelihood of getting a second opinion. It is important to note, however, that a decision to get a second opinion may not necessarily indicate that the individual is mistrustful of the clinician. The decision to get a second opinion may merely indicate that the individual is trying to obtain as many different perspectives on the matter in order to make a wellinformed decision. Although this study employed two dependent variables (i.e., estimated likelihood of getting the second opinion and having the bypass surgery) to assess patient decision-making, future studies should explore the relationship between race concordance and other dimensions of patient decision-making. For example, future studies might focus 
on the relationship between race concordance and the likelihood of seeing the same clinician again or the likelihood of adhering to a medication. This would allow researchers to assess whether trust in race-concordant relationships is contingent upon the type and gravity of a situation.

Racial centrality did not moderate the relationship between race of cardiologist and patient decision-making (i.e., the likelihood of seeking another opinion and likelihood of having the recommended heart surgery). Put another way, the impact of the cardiologist's ethnicity on the two patient decision-making outcomes did not depend on the racial centrality of African American participants. Controlling for racial centrality and the interaction term, patients who viewed the video with an African American cardiologist had a higher likelihood of seeking another opinion and likelihood of having the recommended heart surgery than patients who viewed the video with a European American cardiologist.

The relationship between race of cardiologist and the estimated likelihood of seeking another opinion became significant when racial centrality and the interaction term were controlled. This was merely due to a reduction of error that strengthens the predictability of race concordance on likelihood of seeking another opinion. Further, African American patients who viewed the video of the European American cardiologist, physician mistrust did not mediate the relationship between racial centrality and patientdecision making. Using the Baron and Kenny approach, racial centrality was not associated with patients' decision-making. 
These results indicate that racial centrality may not play a significant role in the context of patient-provider relationships. However, there are a few key points to keep in mind and these considerations might turn into opportunities for future studies. Although racial centrality was not associated with physician mistrust and patient decision-making, racial centrality may be associated with other contexts of healthcare. When considering their encounters in healthcare patients might mentally separate experiences with their physicians from their experiences with the overall healthcare system (e.g., interactions with medical staff, dealing with health insurance, making appointments). For example, patients may still have mistrust toward the general healthcare system, but may have positive experiences with their clinician. Racial centrality may not necessarily play a role in the relationship as long as there are positive interactions between the clinician and patient. Future studies should explore whether racial centrality plays a role in difference healthcare context, such as mistrust towards overall healthcare and preference towards race-concordant clinicians.

\section{Limitations}

Moving forward, the reader has to proceed with caution with the generalization of the study findings. I evaluated hypothetical decision-making. In real-world settings, many variables that were not taken into account in the study may contribute to both physicians' and patients' behaviors and evaluations, respectively. For example, Gordon and colleagues (2006) found that African American patients and their companions received significantly less information from clinicians and produced significantly fewer active participation utterances (i.e., asking questions, expressing concerns, and making 
assertions) than European American patients and their respective companions. However, when controlling companions' participation, ethnicity no longer predicted informationgiving. Clinicians' biases may also affect patient-provider interactions. Van Ryn and Burke (2000) found that clinicians view African American patients as less intelligent. This view may lead providers to be more dominant in the interactions. Clinicians may also not be conscious of their preferential treatment toward one particular group over another (Dovidio et al., 2008; Green et al., 2007; Penner et al., 2010), which may also lead clinicians to discourage ethnic minority patients from participating in the discussion.

We also cannot disregard the possibility that racial centrality may moderate the relationship between race of clinician and patients' decision-making. Cronbach's alpha for the racial centrality scale was less than .7. According to Murphy and Davidshofer (1988), when the scales have low reliability, it can severely underestimate the strength of the relationship among the variables. The standard error of a correlation coefficient is used to determine the confidence intervals around a true correlation of zero. When a scale has low reliability, a higher standard error will exist. Improve the reliability of a scale can reduce standard error, in turn strengthening the relationship between the variables. MacCallum, Zhang, Preacher, and Rucker (2002) also argue that dichotomizing variables into a high group and a low group, which was done with racial centrality in this study, can lead to inaccurate results pertaining to the analyses. They found that dichotomizing a variable led to loss of effect size and power. They suggest that these consequences can be easily avoided simply by using undichotomized measures. This approach also avoids 
criticisms that basing analyses and interpretations on arbitrary groups is an oversimplification of the phenomenon, which can be potentially misleading.

\section{Conclusion}

Trust has proven to be a significant area of study in patient-provider relationships. A patient's level of trust in a physician plays a significant role in patient and physician interactions and in patients' treatment adherence. However, African Americans are less trusting of physicians than are European Americans. Although it may be grounded in past unfavorable experiences this mistrust may also contribute to existing healthcare disparities (LaVeist, Nickerson, \& Bowie, 2000). While racial centrality does not seem to play a significant role in the context of patient-provider relationships, its role in other healthcare contexts is largely unexplored. Further research might investigate whether racial centrality affects overall healthcare trust and health-related behavior; increasing the number of African American physicians, however, would afford more opportunities for race concordance among African American patients. 


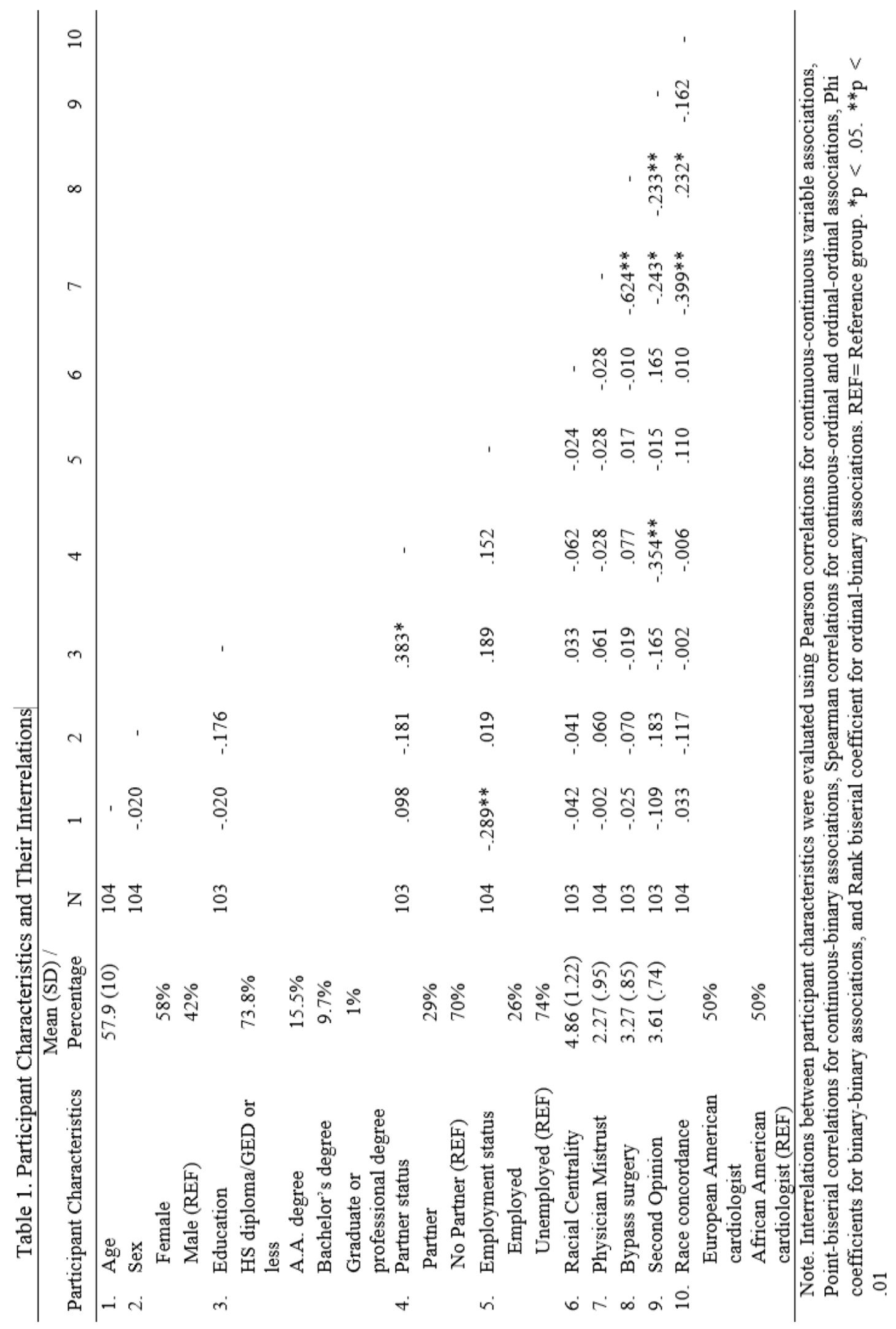


Table 2. Relationship of Demographic Predictors to Racial Centrality

\begin{tabular}{|c|c|c|c|c|}
\hline \multirow[t]{2}{*}{ Variables } & \multirow[b]{2}{*}{$\mathrm{B}(\mathrm{SE})$} & \multirow[b]{2}{*}{$\beta$} & \multicolumn{2}{|c|}{$\mathrm{CI}$} \\
\hline & & & Lower & Upper \\
\hline Age & $-.005(.013)$ & -.044 & -.031 & .020 \\
\hline $\begin{array}{l}\text { Sex } \\
\quad \text { Female } \\
\quad \text { Male (REF) }\end{array}$ & $-.117(.259)$ & -.047 & -.630 & .397 \\
\hline Education & $.083(.151)$ & .062 & -.216 & .382 \\
\hline $\begin{array}{l}\text { Partner status } \\
\text { Partner } \\
\text { No Partner (REF) }\end{array}$ & $-.228(.301)$ & -.085 & -.826 & .371 \\
\hline $\begin{array}{l}\text { Employment status } \\
\text { Employed } \\
\text { Unemployed (REF) }\end{array}$ & $-.091(.302)$ & -.033 & -.690 & .508 \\
\hline$R^{2}$ & .012 & & & \\
\hline$F$ & .232 & & & \\
\hline
\end{tabular}

Note. Results represent relations between each sociodemographic variable and racial centrality controlling for the other sociodemographic variables, as assessed using linear regression. $* p<.05 . * * p<.01$. 
Table 3. Relationship of Demographic Predictors to Physician Mistrust

\begin{tabular}{lcccc}
\hline \multicolumn{1}{c}{ Variables } & & \multicolumn{3}{c}{ CI } \\
\cline { 4 - 5 } & $\mathrm{B}(\mathrm{SE})$ & $\beta$ & Lower & Upper \\
\hline Age & $-.001(.010)$ & -.011 & -.021 & .019 \\
Sex & $.104(.197)$ & .055 & -.287 & .495 \\
$\quad$ Female & & & & \\
$\quad$ Male (REF) & & & & \\
Education & $.098(.115)$ & .095 & -.130 & .327 \\
Partner status & $-.099(.232)$ & -.048 & -.559 & .360 \\
$\quad$ Partner & & & & \\
$\quad$ No Partner (REF) & & & & \\
Employment status & & & & \\
$\quad$ Employed \\
Unemployed (REF)
\end{tabular}

Note. Results represent relations between each sociodemographic variable and physician mistrust controlling for the other sociodemographic variables, as assessed using linear regression. $* p<.05 . * * p<.01$. 
Table 4. Relationship of Demographic Predictors to Likelihood of Bypass Surgery

\begin{tabular}{|c|c|c|c|c|}
\hline \multirow[t]{2}{*}{ Variables } & \multirow[b]{2}{*}{$\mathrm{B}(\mathrm{SE})$} & \multirow[b]{2}{*}{$\beta$} & \multicolumn{2}{|c|}{ CI } \\
\hline & & & Lower & Upper \\
\hline Age & $-.003(.009)$ & -.038 & -.021 & .015 \\
\hline $\begin{array}{l}\text { Sex } \\
\quad \text { Female } \\
\text { Male (REF) }\end{array}$ & $-.129(.178)$ & -.075 & -.483 & .225 \\
\hline Education & $-.065(.104)$ & -.069 & -.271 & .142 \\
\hline $\begin{array}{l}\text { Partner status } \\
\text { Partner } \\
\text { No Partner (REF) }\end{array}$ & $.173(.209)$ & .093 & -.242 & .588 \\
\hline $\begin{array}{l}\text { Employment status } \\
\text { Employed } \\
\text { Unemployed (REF) }\end{array}$ & $.024(.210)$ & .012 & -.392 & .440 \\
\hline$R^{2}$ & .016 & & & \\
\hline$F$ & .306 & & & \\
\hline
\end{tabular}


Table 5. Relationship of Demographic Predictors to Likelihood of Getting Second Opinion

\begin{tabular}{|c|c|c|c|c|}
\hline \multirow[t]{2}{*}{ Variables } & \multirow[b]{2}{*}{$\mathrm{B}(\mathrm{SE})$} & \multirow[b]{2}{*}{$\beta$} & \multicolumn{2}{|c|}{$\mathrm{CI}$} \\
\hline & & & Lower & Upper \\
\hline Age & $-.005(.007)$ & -.068 & -.020 & .010 \\
\hline $\begin{array}{l}\text { Sex } \\
\quad \text { Female } \\
\quad \text { Male (REF) }\end{array}$ & $.174(.145)$ & .116 & -.114 & .462 \\
\hline Education & $-.023(.085)$ & -.028 & -.191 & .146 \\
\hline $\begin{array}{l}\text { Partner status } \\
\text { Partner } \\
\text { No Partner (REF) }\end{array}$ & $-.520(.170)$ & $-.319 * *$ & -.857 & -.182 \\
\hline $\begin{array}{l}\text { Employment status } \\
\text { Employed } \\
\text { Unemployed (REF) }\end{array}$ & $.030(.171)$ & .018 & -.308 & .369 \\
\hline$R^{2}$ & .146 & & & \\
\hline$F$ & 3.272 & & & \\
\hline
\end{tabular}

Note. Results represent relations between each sociodemographic variable and perceived physician care controlling for the other sociodemographic variables, as assessed using linear regression. $* p<.05 . * * p<.01$. 
Table 6. Results of Regression of Surgery Decision and Getting Second Opinion

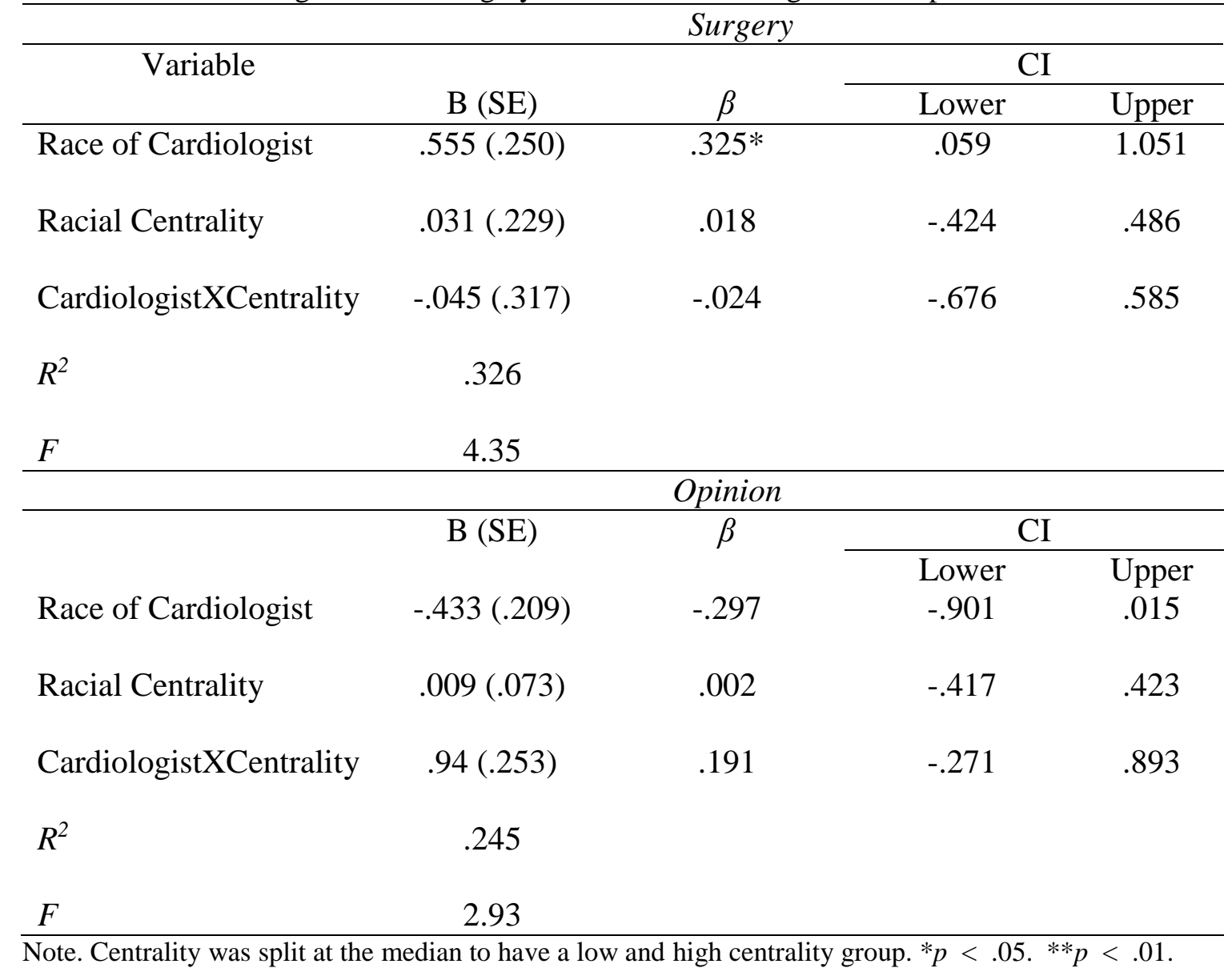




\section{Chapter 4}

Perceived discrimination and mistrust: The moderating role of racial identity 


\begin{abstract}
Mistrust in healthcare is associated with lower use of healthcare services and lower adherence to treatment among patients who are African Americans. Past experiences of discrimination may help explain why African Americans may mistrust healthcare and healthcare providers. However, some African Americans may be more vulnerable to perceptions of discrimination than others. Research is needed to understand the predictors of healthcare related mistrust among African Americans. Perceived discrimination may be more strongly related to mistrust toward healthcare and providers for African Americans who identify strongly with their own racial group (racial centrality) and feel that others viewed their group negatively (unfavorable public regard). The proposed study sought to address this issue. Upon conducting a primary crosssectional, survey data collection with local African American community members $(\mathrm{N}=210)$, I tested the moderated effect of racial identity (i.e., racial centrality and public regard) on perceived discrimination and mistrust (i.e., medical mistrust and physician mistrust). Perceived discrimination was also positively associated with medical mistrust and physician mistrust. While racial centrality and unfavorable public regard were not significant moderators, they were positively associated with medical mistrust. Results suggest that effects of racial identity may be context-specific in healthcare. Racial identity may be salient during general healthcare experiences, but may not play a significant role in the doctor's office. Further, perceived racial discrimination in healthcare may influence an individual's self-concept of race, which may lead them to
\end{abstract}


mistrust the overall healthcare system. Psychosocial interventions aimed at reducing discrimination-related stress might help to reduce the negative health consequences of discrimination especially for African Americans who are more vulnerable to experiences of discrimination.

Keywords: African Americans, racial identity, perceived discrimination, physician mistrust 
Perceived discrimination and mistrust: The moderating role of racial identity African Americans use health services at lower rates than do European Americans (Smedley, Stith, \& Nelson, 2009). Disparities in health services use and outcomes have been attributed to differences in access to care. However, compared to European Americans, African Americans use services that require a doctor's order (such as invasive procedures, hospitalization, or operations) at lower rates than do European Americans, even when their access to care, diagnosis, and illness severity are the same. This suggests that some disparities are emerging from the context of the doctor-patient interaction (Ashton et al., 2003). For example, physicians are less patient-centered (i.e., they are responsive to the patient's preferences, needs, and values) with African American patients than with European American patients (Johnson et al., 2004). In addition, ethnic minority patients express less affective and instrumental verbal behavior than European American patients and are less assertive (Schouten \& Meeuwesen, 2006). Gordon and colleagues (2006), for example, found that African American patients were less active participants in patient-provider interactions, making fewer active participation utterances (i.e., asking questions, expressing concerns, and making assertions) than European American patients. Trust, or lack thereof, is a key aspect of the relationship that contributes to these patient-provider differences. Trust has instrumental value in that it affects a host of important behaviors and attitudes, including patients' willingness to seek care, reveal sensitive information, remain with the physician, and recommend physicians to other members of their communities (Baker, Mainous III, Gray, \& Love, 2003; Berrios-Rivera et al., 2006; Thompson, Worthington, \& Atkinson, 1994; Trachtenberg, Dugan, \& Hall, 
2005). African Americans, however, report significantly lower trust in healthcare providers and the healthcare system compared to European Americans (Boulware et al., 2003; Doescher et al., 2000; Goodin et al., 2013; Gordon et al., 2006; King, 2003; LaVeist, Nickerson, \& Bowie, 2000; O'Malley et al., 2004). This deep mistrust has been linked to dissatisfaction and noncompliance with, and underuse of healthcare services, healthcare organizations, and health professionals (Hall et al., 2001; Hammond, 2010; LaVeist, Nickerson, \& Bowie, 2000; LaVeist, Isaac, \& Williams, 2009).

What contributes to medical mistrust? African Americans may have developed a mistrust of many social institutions, particularly from healthcare institutions, in response to past and contemporary forms of discriminatory treatment (Bates \& Harris, 2004; Brandon, Issac, \& LaVeist, 2005; Cuevas, O’Brien, \& Saha, 2015; Dula, 1994). For example, African Americans who have knowledge of the Tuskegee study have higher levels of mistrust toward medical care than those who are not aware of the Tuskegee study (Brandon, Issac, \& LaVeist, 2005; Goodin et al., 2013; Peek et al., 2011). Greater experience of racial discrimination is significantly associated with greater medical mistrust for African Americans (Peek, Nunez-Smith, Drum, \& Lewis, 2011). These findings corroborate other studies showing or discussing an association between perceived discrimination and mistrust among African Americans (Benkert et al., 2006; Dovidio et al., 2008; LaVeist, Nickerson, \& Bowie, 2000). Although discrimination is associated with delays in seeking medical care and poor adherence to medical care recommendations (Casagrande et al., 2007) independent of medical mistrust, recent studies are showing that medical mistrust serves as a mediator in the relationship between 
discrimination and adherence to doctor recommendations (Cuffee et al., 2013; Thrasher et al., 2008).

Why would some African Americans perceive less discrimination than other African Americans? Gurin, Miller, and Gurin (1980) argue that an individual's identification and consciousness play a role in how they may experience the outside world. As they define it, identification refers to the awareness of having ideas, feelings, and interests similar to others who share the same demographic characteristics, while consciousness refers to a set of political beliefs and action-orientations arising out of this awareness. They found that African Americans who closely identified with their race were more conscious of inequity and more likely to reject the legitimacy of their lower status than African Americans who did not identify with their ethnic group as much. Gurin, Miller, and Gurin (1980) argue that this awareness helps members identify the causes and consequences of their oppressed conditions. This argument helps explain why some African Americans are more perceptive of experiences of discrimination than other African Americans. The awareness of their conditions allows those who identify more with their race to perceive more racial discrimination than those who identify less with their race. Therefore, racial identity may be an antecedent to perceiving more racial discrimination.

Recent empirical work has found a consistent link between racial identity attitudes and experiences of racial discrimination (Neblett, Shelton, \& Sellers, 2004; Operario \& Fiske 2001; Sellers \& Shelton 2003; Shelton \& Sellers 2000). Operario and Fiske (2001) found that group members (Asian, Black, and Latino) who were highly ethnically 
identified reported more personal experiences of ethnic discrimination than did minority group members who identified less with their ethnic group. Similarly, Shelton and Sellers (2000) found that African Americans for whom race was a central component of their identity were more likely to attribute an ambiguous discriminatory event to race than African Americans for whom race was a less central component of identity. Racial identity has also been associated with mistrust toward healthcare providers and healthcare (Benkert et al., 2009; Shelton et al., 2010). Although racial identity may play an important role in the relationship between discrimination and mistrust, it remains an unexplored dimension especially within the context of patient-provider relationships.

In considering these ideas, it is important to define racial identity. Although different definitions of racial identity are available (for example, Parham \& Helms, 1981; Phinney, 1990), Sellers and colleagues (1998) provide a clear and comprehensive definition of racial identity, specifically of Black identity. Their Multidimensional Model of Racial Identity defines racial identity "as the significance and qualitative meaning that individuals attribute to their membership within the Black racial group within their selfconcepts" (Sellers et al., 1998, p. 23). Their definition derives from the integration of two main perspectives which they classify as mainstream and underground. The mainstream approach seeks to understand the cognitive processes and structures of different social identities within the self-concept (Turner \& Oakes, 1989). Black identity is viewed as one of many other identities an individual possesses. This mainstream approach emphasizes the importance of immediate context. When the context is manipulated, one of the many identities becomes salient correspondingly (Turner \& Oakes, 1989). Members of a 
stigmatized group are more likely to attribute negative feedback to prejudice than others in situations in which such an attribution is reasonable. Such external attributions seem to serve a protective function for self-esteem (Major \& O'Brien, 2005). Although the mainstream approach has produced important information about social identity and selfconcept, Sellers and colleagues (1998) argue that its focus has been on assessing the common psychological structures associated with group identities of different racial/ethnic groups, while neglecting the unique experiences of each group.

The underground approach, on the other hand, provides a framework for studying the ongoing cultural and experiential influences on African Americans. It also provides a metric with which to describe individual differences in the level of group identification with the group (Sellers et al., 1998). For example, Parham and Helms (1981) developed the Racial Identity Attitudes Scale (RIAS) to operationalize the Nigrescence model (Cross, 1980). The RIAS measures attitudes representative of attitudes African American individuals are likely to hold toward the self, toward Blacks, and toward European Americans as African Americans develop a psychologically healthy Black Identity. Although the mainstream and underground approaches differ in the types of research questions, methods, and results they have produced, Sellers and colleagues viewed them to be more complementary rather than contradictory. They were able to integrate these two approaches to develop the Multidimensional Model of Racial Identity (MMRI). The MMRI represents a comprehensive combination of a number of existing theories on group identity that is sensitive to the historical and cultural experiences that make racial identity a unique form of group identity for African Americans. 
Sellers and colleagues (1998) provide four dimensions that address the meaning of race in the self-concepts of African Americans: salience, centrality, regard, and ideology. I focus on two of these dimensions - centrality and public regard - because of their previous link to discrimination (Branscombe, Schmitt, \& Harvey, 1999; Sellers \& Shelton, 2003). Racial centrality refers to the extent to which a person normatively defines him or herself with regard to race, and is relatively stable across situations (Sellers et al., 1998). Sellers and colleagues (2003) found that those with high racial centrality have better mental health than those with low racial centrality. Interestingly, those with high racial centrality perceived more discrimination (Operario \& Fiske 2001; Sellers et al., 2003; Sellers \& Shelton, 2003). However, racial centrality also serves as a buffer between the harmful effects of discrimination and mental health.

The other dimension of Black identity, public regard, to be focused upon here may also play a role. Public regard is defined as the extent to which individuals feel that others view African Americans positively or negatively (Sellers et al., 1998). It is the individual's assessments of how one's group is viewed (or valued) by the broader society. Studies have shown that low public regard belief moderates the positive relationship between perceived discrimination and subsequent distress, such that perceived discrimination is more strongly related to distress for African Americans who believe African Americans are held in low regard compared to African Americans who believe African Americans are held in high regard.

High racial identity may not always be associated with favorable outcomes. For example, empirically, American Americans who have a greater feeling of closeness to 
other African Americans also have a lower level of socioeconomic attainment and a lower level of racial self-esteem (i.e., how the individual feels about the self as Black) than African Americans who have a lesser feeling of closeness to other African Americans (Demo \& Hughes, 1990). In the context of patient-provider relationships in healthcare, African American patients with high racial centrality may perceive more discriminatory behaviors from healthcare staff and providers, which in turn may undermine trust toward the healthcare system. Further, if the African American patient believes that non-Blacks hold negative views about his or her racial group (low public regard), they may interpret behaviors as discriminatory (Sellers \& Shelton, 2003) or detect subtle racist verbal and non-verbal cues from healthcare providers (Penner, Albrecht, \& Eggly, 2014). For example, Sellers and Shelton (2003) found that African American college students who felt that other groups hold more negative attitudes towards Blacks (low public regard) reported experiencing more racial discrimination, even after accounting for previous experiences of racial discrimination. Hence, African American patients who believe that non-African Americans hold negative views about their racial group (low public regard) may interpret non-African American physicians' behaviors as discriminatory, negatively affecting their trust toward the physicians.

Although racial centrality influences individuals' everyday lives, little is known as to whether these dimensions of racial identity (i.e., racial centrality and public regard) influence African Americans' healthcare experiences. I hypothesize that perceived discrimination will be more strongly related to mistrust toward healthcare and providers for African Americans who identify strongly with their own racial group (racial 
centrality) and feel that others viewed their group negatively (unfavorable public regard). In other words, racial identity will moderate the relationship between perceived discrimination and mistrust.

\section{Hypothesis}

1) Perceived discrimination is associated with medical mistrust and physician mistrust. Racial centrality moderates the relationship between perceived discrimination and medial mistrust (Model 1a) and physician mistrust (Model 1b). In other words, the relationship between perceived discrimination and both forms of mistrust will be stronger for African Americans who identified strongly with their own racial group (racial centrality).

2) Perceived discrimination is associated with medical mistrust and physician mistrust. Unfavorable public regard moderates the relationship between perceived discrimination and medical mistrust (Model 2a) and physician mistrust (Model 2b). In other words, the relationship between perceived discrimination and both forms of mistrust will be stronger for African Americans who feel that others viewed their group negatively (unfavorable public regard).

\section{Methods}

I established a partnership with the North/Northeast African American Community Health Center (NAACHC), an agency serving 40,000 African Americans living in the Portland and Gresham metro areas. Prior to this study, I met with the staff of this organization in 2014 to learn about the work they are doing in the community and also share some knowledge on health and healthcare disparities. Because of its 
established connection with the African American community, I contacted the organization to inquire about possibly assisting me in the participant recruitment process. I presented the overview of the study and welcomed any assistance they may have offered. I also established a relationship with Portland's African American Leadership Forum in the same year. The Portland African American Leadership Forum (PAALF) is another agency serving the African American communities of Portland and Gresham. PAALF's primary goal is to enforce an action agenda that improves the health and wellbeing of local African Americans. They seek to address the unique and interrelated issues of poverty and disparities that challenge us as a community. I was a 2014-2015 Fellow of PAALF's leadership initiative called African American Leadership Academy, which was a year-long training cohort program that addressed the personal, cultural, civic and professional needs of emerging Black leaders in Portland. During the training program, I built strong relationships with the program's staff and coordinators. Because they wanted to support a Fellow and because they wanted to support research for local African Americans, PAALF member were open to helping with project recruitment. Both PAALF and NAACHC assisted with recruitment by distributing flyers though their respective listservs, and by informing their respective organization members of the study.

\section{Participants}

Potential participants were identified based on eligibility and location.

Recruitment involved coordination with NAACHC and PAALF staff, who facilitated contact with potential participants. Because community members who attend NAACHC and PAALF were specific members of the African American community, research 
assistants and I posted study flyers in a variety of venues (community organizations, stores, barber and beauty shops, etc.) to obtain a representative sample of the African American population of Portland and Gresham. I also asked other healthcare organizations (e.g., Oregon Equity and Inclusion and Multnomah County Health Department) to distribute flyers through their listservs. Potential participants had to be age 18 or older; must have seen a clinician in the past year; must have been able to demonstrate understanding of the consent information through direct questioning; and must have been able to converse in English. Interested persons called a toll-free number or emailed me to learn more about the study and potentially participate. If the potential participant preferred to take questionnaire with paper and pencil, I and the potential participant agreed on a time to meet at Elevated Coffee (located at NE Martin Luther King Blvd.). If the potential participant preferred to participate online, I emailed the participant the link to the questionnaire. The online questionnaire contained the informed consent, where the participant had the option to agree or disagree to participate in the study. After each online participant completed the questionnaire, she or he had the opportunity to provide her or his mailing address to receive the incentive; participants who completed the questionnaire in person received the gift in person. Each participant received a $\$ 15$ Fred Meyer pre-paid card. Members of the research team noticed early on in the recruitment process that younger African Americans, particularly women, were most commonly participating. We, therefore, placed our efforts later on recruiting middle-aged or older African American men. We attended church services and 
community events to recruit this particular subsample. This concluded with us having more men taking the questionnaire with paper and pencil at the designated coffee shop.

\section{Measures}

Prior to data collection, I conducted eight cognitive interviews with Portland State University African American staff (four men and four women). The cognitive interviews helped me detect problem questions and other issues that surface; it also helped me detect items that may have suffered from high rates of missing data, out-of-range values, or inconsistencies with other questions (Groves et al., 2009). I used verbal probing to identify any problem items. For example, I asked questions such as, "How did you arrive at that answer? Was that easy or hard to answer? I noticed that you hesitated-tell me what you were thinking." I then assessed my notes to identify items that may have elicited miscomprehension, requests for clarification, and responses of "don't know" or declination to answer (Fowler, 1995). This allowed me to see what items needed to be modified or omitted prior to data collection. Based on this analysis no items were dropped from the questionnaire.

Perceived discrimination. Seven items were used to assess the occurrence of perceived discrimination in healthcare. The scale is a modified version from the Everyday Experiences of Discrimination scale (Williams et al., 1997), adapted for medical settings. The adapted version of the scale has been used to assess perceived discrimination in a medical setting among African Americans (Peek, Nunez-Smith, Drum, \& Lewis, 2011). The scale employs five frequency response codes ranging from "never" to "always." The scale includes items such as "You feel like a doctor or nurse is not listening to what you 
were saying" and "A doctor or nurse acts as if he or she is afraid of you." Using a sample of African American patients, Peek, Nunez-Smith, Drum, \& Lewis (2011) found the scale to have good internal consistency, test-retest reliability, convergent validity and discriminant validity. In the present study, the scale had good internal consistency $(\alpha=.92)$.

Racial Identity. Fourteen items measured racial identity. The items were from the Racial Centrality dimension and the Public Regard dimension of The Multidimensional Inventory of Black Identity (Sellers et al., 1997). The measures employ seven Likert-type response codes ranging from "strongly disagree" to "strongly agree." The Racial Centrality scale includes items such as "In general, being Black is an important part of my self-image" and "My destiny is tied to the destiny of other Black people." Responses were averaged, where higher scores indicated higher racial centrality. The Public Regard scale includes items such as "Overall, Blacks are considered good by others" and "In general, others respect Black people." Responses were averaged, where higher scores indicated more belief in public disregard. Reliability and construct validity for Racial Centrality and Unfavorable Public Regard were investigated in a study of 474 African American college students from predominantly African American universities and Cronbach's for centrality was found to be .77. (Sellers et al., 1997). In that study, public regard was dropped because of poor internal consistency. However, other studies found public regard to have a relatively high internal consistency, ranging from .74 to .81 to (Cokely \& Helms, 2001; Helms, 2002; Rivas-Drake, Hughes, Way, 2009). Cronbach's 
alpha for racial centrality in the present study was .69. For unfavorable public regard, Cronbach's alpha was .78.

Medical Mistrust. Seventeen items was used to assess the level of trust toward the healthcare system in general (Medical Mistrust Index V2.2; LaVeist, Nickerson, \& Bowie, 2000). The scale includes items such as "Patients should always follow the advice given to them at healthcare organizations" and "You'd better be cautious when dealing with healthcare organizations." The scale employs five Likert-type response codes ranging from "strongly disagree" to "strongly agree." Responses were averaged, where higher scores indicate more mistrust. This scale has demonstrated construct validity and reliability using a sample of European American and African American community members (LaVeist, Nickerson, \& Bowie, 2000). Using this scale, medical mistrust has been found to be associated with underutilization of health services. In the present study, the Cronbach's alpha was .83 for medical mistrust.

Physician mistrust. Eleven items were used to assess the interpersonal mistrust in patient-provider relationships (Trust in Physician Scale; Anderson \& Dedrick, 1990). It includes items such as "I sometimes distrust my doctor's opinion and would like a second one" and "I trust my doctor so much I always try to follow his/her advice." Before obtaining the mean of the scale, I flipped the positive worded items. For example, for item "I would trust my doctor's judgments about my medical care." a value of 1 represented Strongly Disagree. After flipping the values, a value of 5 represented Strongly Disagree. A summary measure of trust is obtained by taking the unweighted mean of the responses to the 11 questions and transforming that value to a $0-100$ scale. 
Higher scores reflected greater trust. The Trust in Physician Scale has demonstrated construct validity and has been used to assess patient trust toward physicians among diverse populations (Doescher, Saver, Franks, \& Fiscella, 2000; Nguyen et al., 2009; Thom, Ribisl, Stewart, \& Luke, 1999). Cronbach's alpha was .88 for physician mistrust in the present study.

Sociodemographics. Sociodemographics included age, gender, partner status, total annual household income, educational level, and employment status (employed or unemployed). Sociodemographics were treated as covariates in the analyses due to known associations with health.

\section{Data analysis}

Descriptive data analysis was used to describe demographics of the study sample and identify the levels of racial identity, perceived discrimination, and mistrust among this sample of African Americans. Descriptives included measures of central tendency, variation, frequency distributions, and sample proportions. I used the Mahalanobis Distance to detect outliers (Rousseeuw, \& Van Zomeren, 1990). Mahalanobis Distance is a measure of distance of each data point from the mean that takes into account the variances of the variables. Anything close to 3 is considered problematic. Using this method, no outliers were found in the data. I compared the modes of data collection to see whether there were any differences in the type of mode used and the variables of interest (i.e., demographics, predictors and outcomes). A total of 136 community members used the online questionnaire and a total of 74 community members used paper and pencil. 
I then computed bivariate correlations between the variables to determine which to include in the later analyses as covariates. I computed Ordinary Least Squares regression coefficients for racial identity (i.e., centrality and public regard) and mistrust (i.e., medical and physician mistrust), for racial identity and perceived discrimination, and for perceived discrimination and mistrust. After obtaining the information from the regressions, I conducted the moderated multiple regression analyses.

Models 1a: Regression of medical mistrust on perceived discrimination and centrality with a discriminationXcentrality interaction

To test Hypothesis 1 (with racial centrality as the moderator and medical mistrust as my dependent variable), I conducted a multiple linear regression. My predictors were perceived discrimination, racial centrality, and the interaction between perceived discrimination and racial centrality. This part of the analyses is referred to as Model 1a.

Prior to conducting the analyses, I noticed the distribution for racial centrality was negatively skewed $(n=198$, mean and standard deviation $=7.13(1.46)$, skewness $=-.646$, kurtosis $=.432$ ). Dichotomizing the variable into high and low groups would not make much sense since the low group would not be distinctly different from the high group. Therefore, I did not dichotomize it. Rather, I centered it with the other continuous variables to help reduce multicollinearity (Robinson \& Schumacker, 2009). I standardized the continuous variables (e.g., frequency of perceived discrimination, age) by having a mean of zero and a variance of one (these are features of any standardized variable). The mean of zero is important for avoiding multicollinearity and having a variance of one makes it easier to interpret the possible interaction. To help with 
interpretation of the interaction terms, one simply obtains the product of perceived discrimination and racial centrality (one standard deviation above and below the mean). The first model (1a) contained the predictors frequency of perceived discrimination (independent variable 1, which I shall refer to as IV1) and racial centrality (IV2), and discriminationXcentrality (IV3), with medical mistrust as the dependent variable. Model 1b: Regression of physician mistrust on perceived discrimination and centrality with a discriminationXcentrality interaction

To test Model $1 \mathrm{~b}$ (with racial centrality as the moderator and physician mistrust as my dependent variable), I conducted a multiple linear regression. My predictors were perceived discrimination, racial centrality, and the interaction between perceived discrimination and racial centrality. This part of the analyses is referred to as Model $1 \mathrm{~b}$. This model included the predictors frequency of perceived discrimination (IV1) and racial centrality (IV2), and discriminationXcentrality (IV3), with physician mistrust as the dependent variable.

Model 2a: Regression of medical mistrust on perceived discrimination and unfavorable public regard with a discriminationXregard interaction

To test Hypothesis 2 (with unfavorable public regard as the moderator and medical mistrust as my dependent variable), I conducted a multiple linear regression. My predictors were perceived discrimination, unfavorable public regard, and the interaction between perceived discrimination and unfavorable public regard. This part of the analyses is referred to as Model 2a. Similar to racial centrality, unfavorable public regard was negatively skewed $(n=200$, mean and standard deviation $=7.97(1.85)$, skewness $=-$ 
.554 , kurtosis $=-.006)$, with the great majority of participants feeling that others view African Americans negatively. Therefore, I did not dichotomize it. Rather, I centered it with the other continuous variables to help reduce multicollinearity (Robinson \& Schumacker, 2009). This model included the predictors frequency of perceived discrimination (IV1), unfavorable public regard (IV2), and discriminationXregard (IV3), with medical mistrust as the dependent variable.

Model 2b: Regression of physician mistrust on perceived discrimination and unfavorable public regard with a discriminationXregard interaction

Lastly, to test the second half of Hypothesis 2 (with unfavorable public regard as the moderator and physician mistrust as my dependent variable), I conducted a multiple linear regression. This part of the analyses is referred to as Model 2b. This model included the predictors frequency of perceived discrimination (IV1) and racial centrality (IV2), and discriminationXcentrality (IV3), with physician mistrust as the dependent variable.

\section{Results}

\section{Participant Characteristics}

The sample consisted of 210 African American participants. Participants were 42 years old on average $(\mathrm{SD}=14)$ with a median age of 40 . A total of 95 participants were women, 103 were men, and 6 were transgender. More than half of the participants were employed (66\%), $22 \%$ had an annual income less than $\$ 15,000$, and $86 \%$ reported having at least a Bachelor's degree. See Table 7 for participant characteristics and their interrelations with other study variables. 


\section{Demographic Analysis}

Before I conducted the main analyses, I tested whether sociodemographics predicted differences in the predictors and outcomes, respectively. These analyses were conducted to gain a better understanding of the sample I had at hand (see Tables 8-12 for results of these tests). Controlling for the other sociodemographic variables, results indicated racial centrality was positively associated with education $(\mathrm{B}=.583, \mathrm{SE}=.106, \mathrm{p}$ $<.01,95 \% \mathrm{CI}=.374, .793)$ and negatively associated with annual household income $(\mathrm{B}=-216, \mathrm{SE}=.095, \mathrm{p}=.027,95 \% \mathrm{CI}=-.402,-.029)$. Controlling for the other sociodemographic variables, unfavorable public regard was negatively associated with gender $(\mathrm{B}=-.623, \mathrm{SE}=.234, \mathrm{p}<.01,95 \% \mathrm{CI}=-1.09,-.162)$, in that females had more negative public regard than males. Controlling for the other sociodemographic variables, unfavorable public regard was positively associated with education $(B=.338, S E=.130, p$ $<.01,95 \% \mathrm{CI}=.081, .595)$ in that people with higher education were more likely to have negative public regard. Perceived discrimination was negatively associated with annual household income $(\mathrm{B}=-1.24, \mathrm{SE}=.43, \mathrm{p}=.005,95 \% \mathrm{CI}=-2.09,-.401)$, controlling for the other sociodemographic variables, and positively associated with education $(B=1.25$, $\mathrm{SE}=.48, \mathrm{p}=.019,95 \% \mathrm{CI}=.300,2.20)$. Medical mistrust was positively associated with education $(\mathrm{B}=.179, \mathrm{SE}=.049, \mathrm{p}=.001,95 \% \mathrm{CI}=.083, .276)$, controlling for the other sociodemographic variables. Physician mistrust was positively associated with education $(\mathrm{B}=.239, \mathrm{SE}=.10, \mathrm{p}=.028,95 \% \mathrm{CI}=.041, .436)$, controlling for the other sociodemographic variables, and negatively associated with income $(\mathrm{B}=-.193, \mathrm{SE}=.089$, $\mathrm{p}=.037,95 \% \mathrm{CI}=-.368,-.017)$. 


\section{Exploratory analysis}

I also tested whether there were significant associations among the predictors and outcomes, controlling for sociodemographics. This would allow me to gain a better understanding of the relationship the constructs have with each other prior to including the interactions terms to be tested in the hypothesized model. Controlling for sociodemographics, perceived discrimination was positively associated with medical mistrust $(B=.052, \mathrm{SE}=.007, \mathrm{p}<.001,95 \% \mathrm{CI}=.039, .065)$, physician mistrust $(\mathrm{B}=.084$, $\mathrm{SE}=.014, \mathrm{p}<.001,95 \% \mathrm{CI}=.056, .113)$, and racial centrality $(\mathrm{B}=.036, \mathrm{SE}=.017, \mathrm{p}=$ $.032,95 \% \mathrm{CI}=.003, .070)$. However, perceived discrimination was not associated with unfavorable public regard $(\mathrm{B}=.030, \mathrm{SE}=.021, \mathrm{p}=.157,95 \% \mathrm{CI}=-.012, .071)$. Controlling for sociodemographics, medical mistrust was positively associated with physician mistrust $(\mathrm{B}=.884, \mathrm{SE}=.134, \mathrm{p}<.001,95 \% \mathrm{CI}=.619,1.15)$, racial centrality $(\mathrm{B}=.454, \mathrm{SE}=.167, \mathrm{p}=.007,95 \% \mathrm{CI}=.124, .784)$, and unfavorable public regard $(\mathrm{B}=.758, \mathrm{SE}=.203, \mathrm{p}<.001,95 \% \mathrm{CI}=.356,1.16)$. Controlling for sociodemographics, physician mistrust was not associated with racial centrality $(\mathrm{B}=.048, \mathrm{SE}=.087, \mathrm{p}=.578$, $95 \% \mathrm{CI}=-.123, .220)$ and unfavorable public regard $(\mathrm{B}=.11, \mathrm{SE}=.115, \mathrm{p}=.339,95 \% \mathrm{CI}$ $=-.117, .338)$. Lastly, controlling for sociodemographics, racial centrality was not associated with unfavorable public regard $(B=.053, \mathrm{SE}=.064, \mathrm{p}=.404,95 \% \mathrm{CI}=-.072$, .179).

\section{Main Analyses}

I hypothesized that perceived discrimination would be associated with medical mistrust and physician mistrust. Further, racial centrality would moderate the relationship 
between perceived discrimination and mistrust (i.e., medical mistrust and physician mistrust). I conducted a multiple linear regression with perceived discrimination, racial centrality, and the interaction between perceived discrimination and racial centrality as predictors. Two separate multiple regression analyses were conducted. The first multiple regression analyses (Model 1a) had medical mistrust as its dependent variable, while the second (Model 1b) had physician as its dependent variable (see Table 13 for the models' results).

For Model 1a, the main effect of perceived discrimination on medical mistrust was significant $(\mathrm{B}=.317, \mathrm{SE}=.043, \mathrm{p}<.001,95 \% \mathrm{CI}=.231, .402)$. However, the main effect of racial centrality on medical mistrust was not significant $(B=.089, \mathrm{SE}=.048, \mathrm{p}=$ $.064,95 \% \mathrm{CI}=-.005,-.184)$. Racial centrality did not moderate the relationship between perceived discrimination and medical mistrust $(\mathrm{B}=.005, \mathrm{SE}=.04, \mathrm{p}=.904,95 \% \mathrm{CI}=-$ $.072, .082)$.

Similarly, for Model 1b, the main effect of perceived discrimination on physician mistrust was significant $(\mathrm{B}=.541, \mathrm{SE}=.094, \mathrm{p}<.001,95 \% \mathrm{CI}=.355, .728)$. However, the main effect of racial centrality on physician mistrust was not significant $(B=-.009, \mathrm{SE}=$ $.113, \mathrm{p}=.936,95 \% \mathrm{CI}=-.233, .134)$. Racial centrality did not moderate the relationship between perceived discrimination and physician mistrust $(\mathrm{B}=-.040, \mathrm{SE}=.088, \mathrm{p}=.650$, $95 \% \mathrm{CI}=-.214, .134)$.

I also hypothesized that unfavorable public regard would moderate the relationship between perceived discrimination and mistrust (i.e., medical mistrust and physician mistrust). I conducted a multiple linear regression with perceived 
discrimination, unfavorable public regard, and the interaction between perceived discrimination and unfavorable public regard as predictors. Two separate multiple regression analyses were conducted. The first multiple regression analyses (Model 2a) had medical mistrust as its dependent variable, while the second (Model 2b) had physician as its dependent variable (see Table 14 for the models' results).

For Model 2a, the main effect of perceived discrimination on medical mistrust was significant $(\mathrm{B}=.315, \mathrm{SE}=.041, \mathrm{p}<.001,95 \% \mathrm{CI}=.234, .397)$. The main effect of unfavorable public regard on medical mistrust was significant $(B=.157, \mathrm{SE}=.045, \mathrm{p}=$ $.001,95 \% \mathrm{CI}=.068, .247)$. However, unfavorable public regard did not moderate the relationship between perceived discrimination and medical mistrust $(\mathrm{B}=-.004, \mathrm{SE}=.044$, $\mathrm{p}=.930,95 \% \mathrm{CI}=-.082, .090)$.

For Model 2b, the main effect of perceived discrimination on physician mistrust was significant $(\mathrm{B}=.537, \mathrm{SE}=.093, \mathrm{p}<.001,95 \% \mathrm{CI}=.354, .720)$. However, the main effect of unfavorable public regard on physician mistrust was not significant $(B=.053$, $\mathrm{SE}=.102, \mathrm{p}=.604,95 \% \mathrm{CI}=-.149, .255)$. Racial centrality did not moderate the relationship between perceived discrimination and physician mistrust $(B=-.114, \mathrm{SE}=$ $.102, \mathrm{p}=.264,95 \% \mathrm{CI}=-.315, .087)$ 


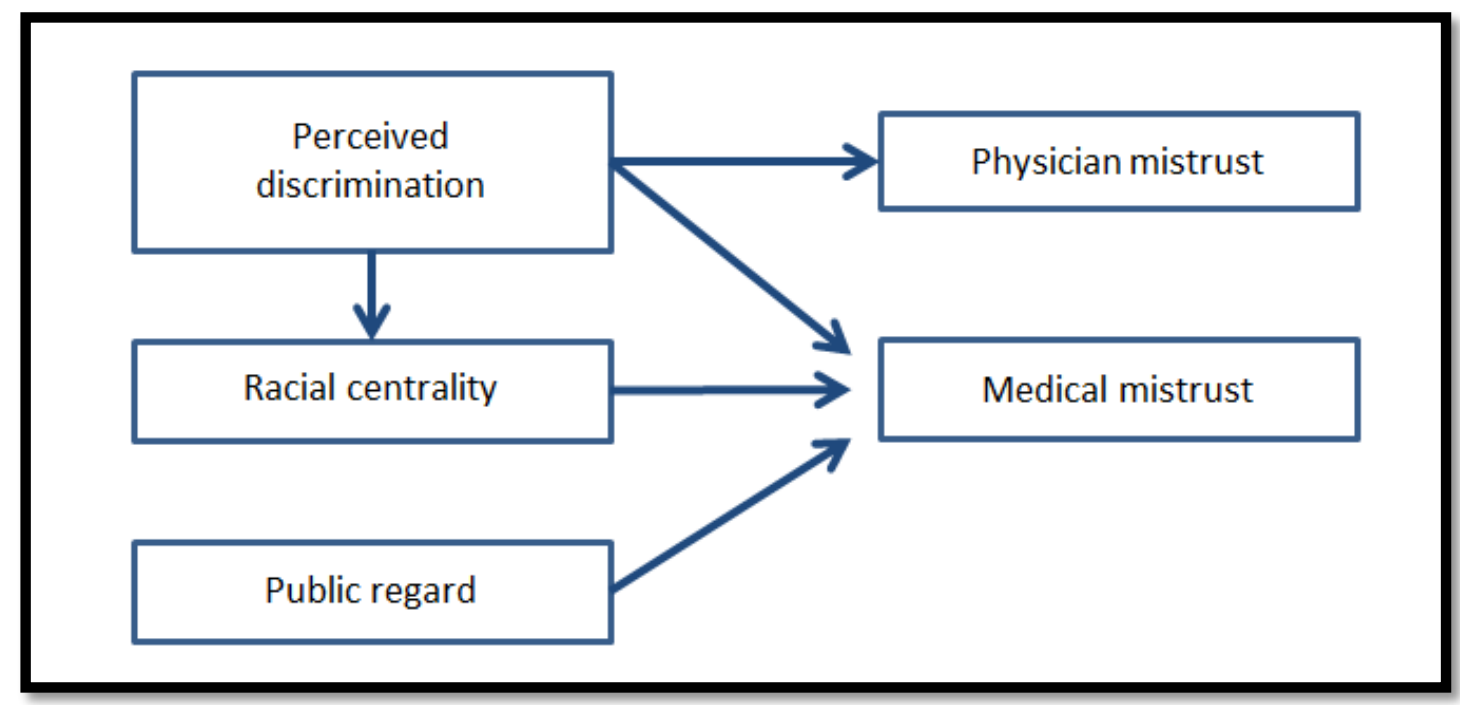

Figure 6. This figure represents the overall findings of the analyses. Each arrow indicates a significant relationship.

Overall, racial identity (i.e., racial centrality and unfavorable public regard) did not moderate the relationship between perceived discrimination and mistrust. Figure 6 displays the findings of the analyses. Perceived discrimination was positively associated with medical mistrust and physician mistrust. Racial centrality was positively associated with medical mistrust. Unfavorable public regard was also positively associated with medical mistrust.

\section{Discussion}

What contributes to medical mistrust and physician mistrust? This study suggests that perceived discrimination in healthcare may be related to both medical mistrust and physician mistrust. These findings corroborate other studies showing or discussing an association between perceived discrimination and mistrust among African Americans (Benkert et al., 2006; Dovidio et al., 2008; Goodin et al., 2013; LaVeist, Nickerson, \& Bowie, 2000). Further, Peek, Nunez-Smith, Drum, and Lewis (2011) found that 
perceived discrimination, specifically in healthcare, was associated with medical mistrust. However, all of their study participants had an established physician relationship, something that many Americans including African Americans do not have, which may have biased the participants' responses. This study teased apart mistrust into medical mistrust (i.e., lack of trust toward overall healthcare) and physician mistrust (i.e., lack of trust toward physicians). Our study provides further evidence that perceived discrimination, specifically in healthcare, is positively associated with both of these constructs.

This study also investigated whether racial identity moderated the relationship between perceived discrimination and medical and physician mistrust. Interestingly, this study showed that while racial centrality and low public regard were not significant moderators between perceived discrimination and the two dimensions of mistrust, they were positively associated with medical mistrust. Conversely, they were not significantly associated with physician mistrust.

One way to interpret these results is that racial identity may influence a person's attitude towards healthcare, prior to entering the doctor's office. However, once the person enters the doctor's office, racial identity plays a less significant role in patientprovider interactions. The person assumes the role of a patient, making race a less salient part of their healthcare experience. In other words, race may be a relevant part of selfconcept at particular moments in the healthcare experience. In this case, race may be a relevant part of self-concept when evaluating experience with medical staff and the overall healthcare institution. However, race may not be as relevant when they rate their 
attitudes toward their clinicians because they assumed the role of a patient at that particular moment in time. Patients may perceive discrimination in their interaction with non-medical staff and nurses (Cuevas, O'Brien, \& Saha, 2015). Sellers and colleagues (1998) state when racial identity is made salient, individuals' ideology and regard influences their behavioral response. Someone with high racial centrality may reduce the potential stressor (e.g., a non-medical staff displaying rude behaviors) by confronting the problem immediately, while someone with low racial centrality may respond to the potential stressor differently, or not at all. Depending on the extent to which a person normatively defines her/himself with regard to race (racial centrality) and how they feel that others view African Americans (unfavorable public regard), a patient may respond to negative stressors from non-medical staff and nurses interactions differently. These negative interactions may lead to more mistrust toward healthcare from those with high racial centrality and unfavorable public regard.

Investigating the relationship between racial centrality and healthcare behavioral responses may bring fruitful information. In this study, I only focused on attitudes and perspectives from African Americans. Understanding how these constructs are related to actual behavior can bring a new level of understanding as to how mistrust may manifest for people with high racial centrality compared to those with low racial centrality. For example, past studies have shown that medical mistrust is associated with cancer screening practices and cancer screening attitudes (Bynum et al., 2012; Cronan et al., 2008; Thompson et al., 2004). Now knowing that racial identity is related to medical 
mistrust, perhaps it may moderate the relationship between medical mistrust and cancer screening behaviors.

One important finding that needs to be discussed is that perceived discrimination was positively associated with racial centrality but not significantly associated with the belief that African Americans are held in low regard by society in general. Although it was expected that both dimensions of racial identity would be associated with perceived discrimination, we expected that the relationship between unfavorable public regard and perceived discrimination would be stronger. This may suggest that past experience of discrimination in healthcare may influence a person to seek others who experience similar stressors, giving way to identifying more with her or his racial group rather than the stressor influencing how she or he feels others view African Americans. Future studies should explore how racial identity is influenced by different healthcare contexts. For example, researchers can explore how racial discrimination is experienced in emergency rooms compared to primary care clinics and how racial discrimination in each context influences racial identity.

\section{Limitations}

There were some limitations to this study. First, the current study was crosssectional. Definitive results about whether perceived racial discrimination affects mistrust awaits through the use longitudinal study designs. Additional research is needed to elucidate exactly how racial discrimination might affect racial identity as well. Second, the modes of data collection that I used may have prevented some African Americans from participating in the study. The use of online and paper and pencil as modes of data 
collection required potential participants to be proficient in reading. This may have prevented some individuals from participating in the study. The use of face-to-face interviews could have been a good way offset this issue. However, because many factors needed to be deliberated before and during face-to-face interviews, such as interviewertraining, interview gender-effect, and cognitive interviews, I decided to focus on the two modes that were easier to implement. While paper and pencil mode captured more of the older individuals, the use of face-to-face interviews could have offered more opportunity to recruit members of the community of are of low-socioeconomic status. Third, the number of respondents who chose to respond to the survey may be different from those who chose not to respond, thus creating bias. Because mistrust is pervasive in the African American community, those who participated in the study may not be as mistrustful toward institutions (e.g., healthcare) as those who chose not to participate. Fourth, the distribution for racial centrality was negatively skewed. This may indicate that racial centrality may serve as a protective factor to cope with living in a predominantly European American city. Because African Americans are more likely to interact with non-African Americans more in Portland, Oregon, they may perceive more discrimination in their environment, which would make race more salient in the person's everyday life. These experiences, in turn, may influence a person to make race a more central component to the self-concept. Future studies should look at whether distribution of race centrality is contingent upon certain factors, such as geographic locations, racial density, and sense of community to make the claim whether the distribution of this construct was unique to this sample or generalizable to the wider population. 


\section{Conclusion}

Trust is vital to the creation of relationships between individuals and their health providers. Trust can affect a host of important behaviors and attitudes, including patients' willingness to seek care, reveal sensitive information to physicians, or even to recommend physicians to others in their communities. African Americans' lack of trust toward physicians and overall healthcare may contribute to lower usage of health services and poorer patient-provider relationships for them than for European Americans. This mistrust may be due to past and contemporary experiences of discrimination. Experiences in everyday life are dependent on one's identity. For African Americans, in particular, racial identity may play a role in their perceptions of discrimination, possibly leading to varying levels of mistrust. This study explored these relationships involving a primary data collection with a local sample of African American community members. Based on the findings, psychosocial interventions aimed at reducing discrimination-related stress might help to reduce the negative health consequences of discrimination especially for African Americans who are more vulnerable to experiences of discrimination. Further, the findings suggest that the context of where to intervene is critical. Medical mistrust was associated with racial centrality. Therefore, it is important to develop interventions to improve the trust of community members toward the healthcare system. For example, having more African American non-medical staff and nurses may reduce medical mistrust. Further, having welcoming environments that cater to African American patients (e.g., hanging African American art and paintings) may increase comfort and reduce anxiety of being an African American in healthcare. The issue remains, however, 
that those who mistrust healthcare may not even use healthcare service to begin with. Interventions are needed to reduce mistrust and increase service use for this particular population of the community. One way is to have medical staff and clinicians attend and participate in community events and meetings. This may help improve the trust by having healthcare providers be more visible in the community. While this may not reduce healthcare disparities, it is a potential step forward in improving trust toward physicians and overall healthcare. 


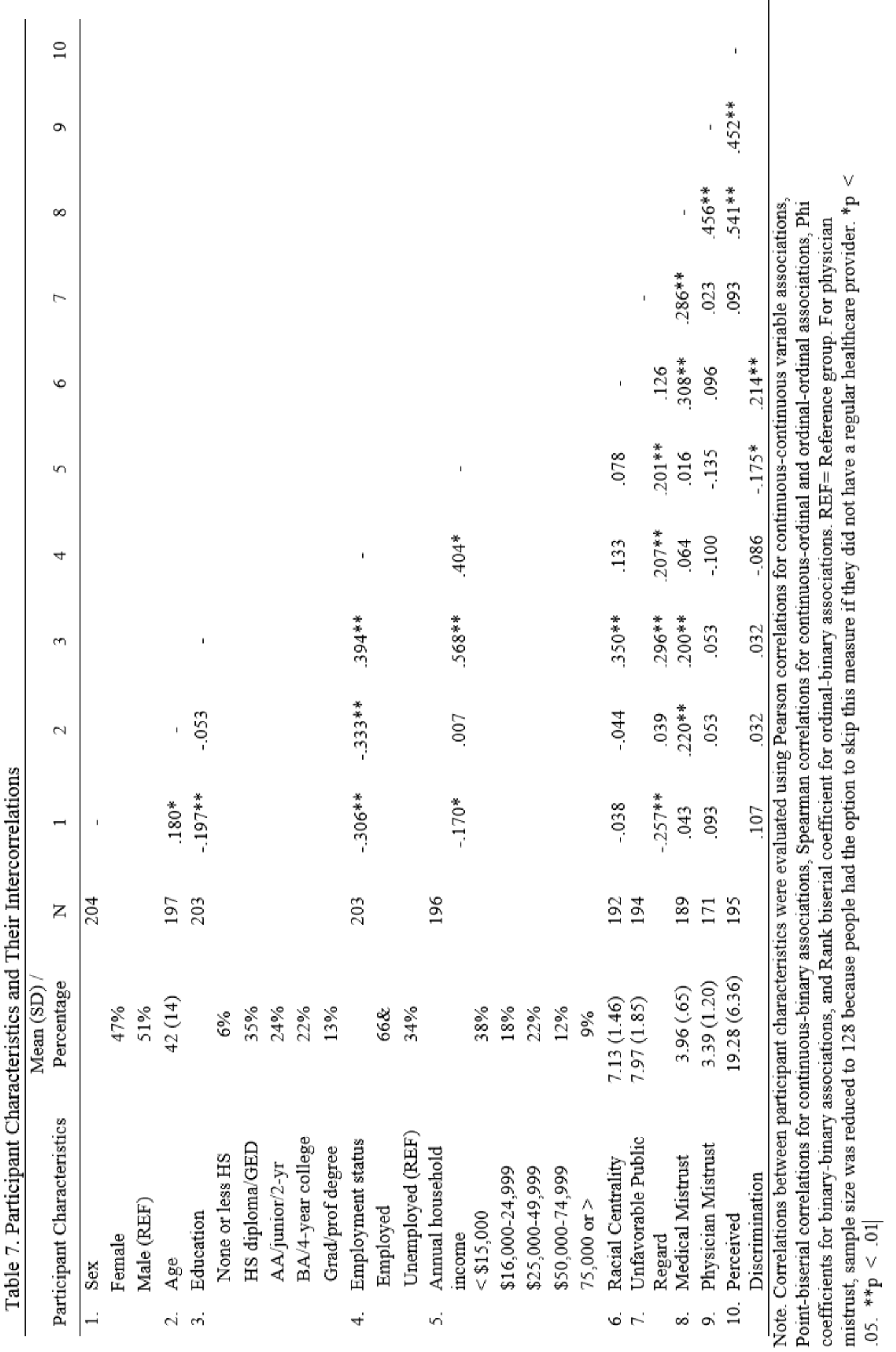


Table 8. Relationship of Demographic Predictors to Racial Centrality

\begin{tabular}{|c|c|c|c|c|}
\hline \multirow[t]{2}{*}{ Variables } & \multirow[b]{2}{*}{$\mathrm{B}(\mathrm{SE})$} & \multirow[b]{2}{*}{$\beta$} & \multicolumn{2}{|c|}{$\mathrm{CI}$} \\
\hline & & & Lower & Upper \\
\hline Age & $-.001(.008)$ & -.010 & -.017 & .014 \\
\hline $\begin{array}{l}\text { Sex } \\
\quad \text { Female } \\
\quad \text { Male (REF) }\end{array}$ & $-.006(.189)$ & -.002 & -.380 & .367 \\
\hline Education & $.583(.106)$ & $.464 * *$ & .374 & .793 \\
\hline Income & $-.216(.095)$ & $-.197 *$ & -.402 & -.029 \\
\hline $\begin{array}{l}\text { Employment status } \\
\text { Employed } \\
\text { Unemployed (REF) }\end{array}$ & $.127(.266)$ & .040 & -.398 & .652 \\
\hline$R^{2}$ & .164 & & & \\
\hline$F$ & 6.84 & & & \\
\hline
\end{tabular}

Note. Results represent relations between each sociodemographic variable and racial centrality controlling for the other sociodemographic variables, as assessed using linear regression. ${ }^{*} \mathrm{p}<.05 .{ }^{* *} \mathrm{p}<$ .01 
Table 9. Relationship of Demographic Predictors to Unfavorable Public Regard

\begin{tabular}{lcccc} 
& & & \multicolumn{2}{c}{ CI } \\
\cline { 5 - 5 } & $\mathrm{B}(\mathrm{SE})$ & $\beta$ & Lower & Upper \\
\hline Age & $.018(.010)$ & .144 & -.001 & .037 \\
Sex & $-.623(.234)^{* *}$ & -.196 & -1.09 & -.162 \\
$\quad$ Female & & & \\
$\quad$ Male (REF) & & & & \\
Education & $.338(.130)^{* *}$ & .218 & .081 & .595 \\
Income & $-.050(.117)$ & -.037 & -.280 & .181 \\
Employment status & $.674(.324)$ & .175 & .036 & 1.31 \\
$\quad$ Employed & & & & \\
Unemployed (REF) & & & & \\
$R^{2}$ & .157 & & & \\
$F$ & 6.43 & & & \\
\hline
\end{tabular}

Note. Results represent relations between each sociodemographic variable and unfavorable public regard controlling for the other sociodemographic variables, as assessed using linear regression. ${ }^{*} \mathrm{p}<.05 .{ }^{* *} \mathrm{p}<$ .01 
Table 10. Relationship of Demographic Predictors to Perceived Discrimination

\begin{tabular}{|c|c|c|c|c|}
\hline \multirow[t]{2}{*}{ Variables } & \multirow[b]{2}{*}{$\mathrm{B}(\mathrm{SE})$} & \multirow[b]{2}{*}{$\beta$} & \multicolumn{2}{|c|}{$\mathrm{CI}$} \\
\hline & & & Lower & Upper \\
\hline Age & $.045(.04)$ & .099 & -.024 & .115 \\
\hline $\begin{array}{l}\text { Sex } \\
\quad \text { Female } \\
\quad \text { Male (REF) }\end{array}$ & $1.02(.86)$ & .09 & -.675 & 2.71 \\
\hline Education & $1.25(.48)$ & $.228 * *$ & .300 & 2.20 \\
\hline Income & $-1.24(.43)$ & $-.262 * *$ & -2.09 & -.401 \\
\hline $\begin{array}{l}\text { Employment status } \\
\text { Employed } \\
\text { Unemployed (REF) }\end{array}$ & $-.423(1.19)$ & -.031 & -2.78 & 1.93 \\
\hline$R^{2}$ & .080 & & & \\
\hline$F$ & 3.05 & & & \\
\hline
\end{tabular}

Note. Results represent relations between each sociodemographic variable and perceived discrimination controlling for the other sociodemographic variables, as assessed using linear regression. ${ }^{*} \mathrm{p}<.05 .{ }^{*} \mathrm{p}<$ .01 
Table 11. Relationship of Demographic Predictors to Medical Mistrust

\begin{tabular}{lcccc}
\hline \multirow{2}{*}{ Variables } & & \multicolumn{3}{c}{ CI } \\
\cline { 4 - 6 } & $\mathrm{B}(\mathrm{SE})$ & $\beta$ & Lower & Upper \\
\hline Age & $.003(.004)$ & .056 & -.005 & .010 \\
Sex & $.071(.087)$ & .062 & -.101 & .243 \\
$\quad$ Female & & & & \\
$\quad$ Male (REF) & & & & \\
Education & $.179(.049)$ & $.324 * *$ & .083 & .276 \\
Income & $-.084(.044)$ & -.174 & -.171 & .003 \\
Employment status & $.059(.121)$ & .042 & -.180 & .298 \\
$\quad$ Employed & & & & \\
Unemployed (REF) & & & & \\
$R^{2}$ & .081 & & & \\
$F$
\end{tabular}

Note. Results represent relations between each sociodemographic variable and racial centrality controlling for the other sociodemographic variables, as assessed using linear regression. ${ }^{*} \mathrm{p}<.05 .{ }^{* *} \mathrm{p}<$ .01 
Table 12. Relationship of Demographic Predictors to Physician Mistrust

\begin{tabular}{|c|c|c|c|c|}
\hline \multirow[t]{2}{*}{ Variables } & \multirow[b]{2}{*}{$\mathrm{B}(\mathrm{SE})$} & \multirow[b]{2}{*}{$\beta$} & \multicolumn{2}{|c|}{$\mathrm{CI}$} \\
\hline & & & Lower & Upper \\
\hline Age & $-.006(.008)$ & -.067 & -.021 & .009 \\
\hline $\begin{array}{l}\text { Sex } \\
\quad \text { Female } \\
\quad \text { Male (REF) }\end{array}$ & $.273(.187)$ & .121 & -.097 & .643 \\
\hline Education & $.239(.100)$ & $.229 *$ & .041 & .436 \\
\hline Income & -.193 (.089) & $-.212 *$ & -.368 & -.017 \\
\hline $\begin{array}{l}\text { Employment status } \\
\text { Employed } \\
\text { Unemployed (REF) }\end{array}$ & $-.270(.257)$ & -.101 & -.778 & .237 \\
\hline$R^{2}$ & .069 & & & \\
\hline$F$ & 2.28 & & & \\
\hline
\end{tabular}

Note. Results represent relations between each sociodemographic variable and racial centrality controlling for the other sociodemographic variables, as assessed using linear regression. ${ }^{*} \mathrm{p}<.05 .{ }^{*} \mathrm{p}<$ .01 
Table 13. Regression of Mistrust with a DiscriminationXCentrality Interaction

\begin{tabular}{|c|c|c|c|c|}
\hline \multirow{3}{*}{ Variable } & \multicolumn{3}{|c|}{ Medical mistrust } & \\
\hline & \multirow[b]{2}{*}{$\mathrm{B}(\mathrm{SE})$} & \multirow[b]{2}{*}{$\beta$} & \multicolumn{2}{|c|}{ CI } \\
\hline & & & Lower & Upper \\
\hline Perceived discrimination & $.317(.043)$ & $.493 * *$ & .231 & .402 \\
\hline Racial Centrality & $.089(.048)$ & .137 & -.005 & .184 \\
\hline DiscriminationXCentrality & $.005(.039)$ & .008 & -.072 & .082 \\
\hline$R^{2}$ & .34 & & & \\
\hline \multirow[t]{4}{*}{$F$} & 10.59 & & & \\
\hline & \multicolumn{3}{|c|}{ Physician Mistrust } & \\
\hline & $\mathrm{B}(\mathrm{SE})$ & $\bar{\beta}$ & & \\
\hline & $.54(.09)$ & $.439 * *$ & $\begin{array}{c}\text { Lower } \\
.355\end{array}$ & $\begin{array}{c}\text { Upper } \\
.728\end{array}$ \\
\hline Racial Centrality & $-.009(.11)$ & -.007 & -.233 & .215 \\
\hline DiscriminationXCentrality & $-.04(.09)$ & -.037 & -.214 & .134 \\
\hline$R^{2}$ & .25 & & & \\
\hline$F$ & 5.79 & & & \\
\hline
\end{tabular}

Note. Centrality and discrimination were centered at its mean. ${ }^{*} p<.05 .{ }^{* *} p<.01$. 
Table 14. Regression of Mistrust with a DiscriminationXRegard Interaction

\begin{tabular}{|c|c|c|c|c|}
\hline \multirow{3}{*}{ Variable } & \multicolumn{4}{|c|}{ Medical mistrust } \\
\hline & \multirow[b]{2}{*}{ B (SE) } & \multirow[b]{2}{*}{$\beta$} & \multicolumn{2}{|c|}{ CI } \\
\hline & & & Lower & Upper \\
\hline Perceived discrimination & $.32(.041)$ & $.500 * *$ & .234 & .397 \\
\hline $\begin{array}{l}\text { Unfavorable Public } \\
\text { Regard }\end{array}$ & $.157(.045)$ & $.236^{* *}$ & .068 & 247 \\
\hline DiscriminationXRegard & $.004(.044)$ & .006 & -.082 & .090 \\
\hline$R^{2}$ & .38 & & & \\
\hline \multirow[t]{3}{*}{$F$} & 12.39 & & & \\
\hline & \multicolumn{3}{|c|}{ Physician Mistrust } & \\
\hline & B (SE) & $\beta$ & & \\
\hline Perceived discrimination & $.537(.093)$ & $.446 * *$ & $\begin{array}{c}\text { Lower } \\
.354\end{array}$ & $\begin{array}{l}\text { Upper } \\
.720\end{array}$ \\
\hline $\begin{array}{l}\text { Unfavorable Public } \\
\text { Regard }\end{array}$ & $.053(.102)$ & .041 & -.149 & .255 \\
\hline DiscriminationXRegard & $-.114(.102)$ & -.084 & -.315 & .087 \\
\hline$R^{2}$ & .26 & & & \\
\hline$F$ & 6.12 & & & \\
\hline
\end{tabular}

Note. Regard and discrimination were centered at its mean. ${ }^{*} p<.05 .{ }^{* *} p<.01$. 


\section{Chapter 5}

Mistrust: What have we learned? 
Mistrust: What have we learned?

Using multiple methods, these studies sought to provide a better understanding of how the race-related attitudes and perspectives of African American patients affect their race-discordant healthcare relationships with physicians. These studies did not, directly, examine upstream factors in the ecological model: such factors might include patients' access to healthcare, the policy contexts in which providers provide services, or the availability of race concordant physicians for patients who seek care. Rather, these studies worked from within an ecological understanding to look more closely at the reported experiences of perceived discrimination, social identity, attitudes and decisions.

In Study 1, I found that perceived discrimination arose when African American patients, particularly women, felt their symptoms or problems were discredited. Mistrust occurred when clinicians did not convey respect to patients, leaving patients to wonder whether their clinicians' treatment was discriminatory or not. Poor communication arose when clinicians did not acknowledge patients' perspectives during interactions. Patients often viewed these actions or inactions as discriminatory. In study 2, I found that African American patients who viewed video-recorded, standardized vignettes depicting a cardiologist recommending heart bypass surgery to a patient diagnosed with angina and 3-vessel coronary artery disease were less likely to trust European American cardiologistactors and less likely to get the hypothetical bypass surgery than African Americans who viewed a video with an African American cardiologist. Racial centrality did not moderate the relationship between ethnicity of the cardiologist-actor and patients' decision making. 
Furthermore, racial centrality was not associated with trust toward the cardiologist-actors for those who viewed the video with the European American cardiologist-actor.

In study 3, I found that racial centrality and perceptions of low public regard were positively associated with medical mistrust; however, they were not significantly related to mistrust of physicians, and they did not significantly affect the relationship between perceived discrimination and medical mistrust. Perceived discrimination was positively associated with racial centrality. Perceived discrimination was also positively associated with medical mistrust and physician mistrust.

Taken together, what do the findings mean? In Figure 7 below, I have modified the figure that I originally posed in Chapter 1 to now reflect the findings of all three completed studies. This new figure provides a conceptual representation of what may be potentially happening once we consider the findings of all three studies. This is not a representation of empirically tested causal paths; rather, it is a model of my thoughts about these concepts. The model begins at the far left with objective discrimination, which can take the form of verbal or nonverbal behaviors, or may even take the form of omitting verbal or nonverbal behaviors. For example, a physician may not express concern during the interaction or may not listen to the patient when the patient is describing his or her symptoms. Based on study 1, the patient may perceive these behaviors from the physician as discriminatory. This then leads to the patient having less trust in physicians and the general healthcare system. 


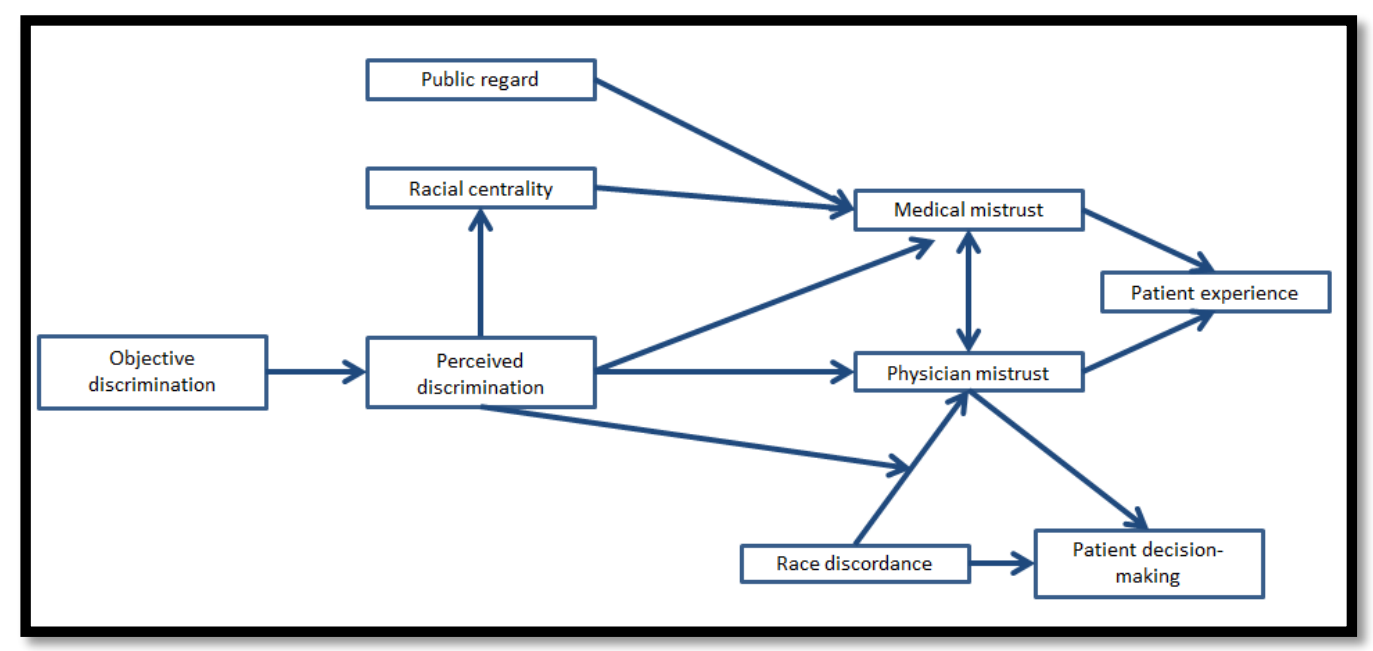

Figure 7. A conceptual model reflecting the findings of all three studies.

Although Study 1 showed that most patients did not express a preference for a race-concordant physician, Study 2 showed that the race/ethnicity of physicians does play an important role in patients' trust and decision-making. As found in Study 2 and shown in the figure above, for African American patients, the race of the physician is directly associated with mistrust of the physician and both directly and indirectly with decisions the patient makes. In other words, African American patients may be less trusting of European American physicians, which in turn can lead to patients not adhering to the physicians' recommendations.

Study 3 asked whether the relationship between perceived discrimination and mistrust depends, in part, on the centrality of African American identity. I found that perceived discrimination was positively associated with racial centrality, but not significantly associated with the belief that African Americans are held in low regard by society in general. This finding for racial centrality is consistent with the idea that past experience of discrimination in healthcare may influence a person to value a feeling of 
connectedness with others who share similar experiences. Seeing oneself as treated similarly to other African Americans may lead to a stronger sense of shared identity with other African Americans. This in turn can undermine the trust patients feel in services that are provided by and controlled by outgroup members.

The three studies composing this dissertation were not designed together as a single, mixed methods project; in fact two of these studies involved secondary analyses. Even so, the three projects together provide something of a mosaic to bring forth new information about African Americans in healthcare. The studies provide important complementary strengths and to some extent they also complement each other's weaknesses.

In study 1 , I conducted a secondary analysis of focus group discussions. Focus groups allow one to identify the perspectives of participants, as well as to understand their shared experiences, while accessing the language participants used to think and talk about the study topics. For this study, this method helped give me a better understanding about African Americans' experience in healthcare. It also allowed me to identify the situations that give rise to certain barriers in healthcare for African Americans. This would not have been accomplished if I had used quantitative methods, for example to ask patients about their experiences using my own terminology or in a numeric way. However, one major limitation to this study was that the original investigators designed the interview guide and collected data prior to my own arrival on the research team. Particular information that I might like to have had available was not collected; for example, in some instances the moderator could have probed the respondents for more 
information about mistrust and other aspects that negatively affect patient-provider communication. This could have given me a better understanding of other behaviors patients may have perceived as discriminatory. Further, focus groups depend upon group interaction. Depending upon the population, the topic, and potentially also upon situational factors, normative influences on participants' commentary can be high in focus groups. In other words, real or imagined social pressures can influence individuals' decisions to report perspectives that differed from the perceived norm of the group. This is a commonly recognized limitation of focus groups (Ritchie \& Lewis, 2003). In part to minimize this problem, the research team trained the focus group moderators to welcome all points of view on topics of discussion and to solicit a wide range of experiences from study participants. Future investigators may want to conduct in-depth interviews to encourage participants to share more about what they consider to be a good or bad relationship with their physicians.

In study 2, I used secondary data from a laboratory study. Laboratory research allows social scientists to carefully remove or control variables extraneous to the variables under study, and to detect important relationships between and among psychological variables (Mortensen \& Cialdini, 2010). For example, the random assignment of patients to view a video with either an African American cardiologist-actor or a European American cardiologist-actor helped me to determine whether the ethnicity of the cardiologist-actor influenced the patient to endorse the hypothetically recommended bypass surgery. Because of the stylized and highly controlled nature of laboratory research, studies such as these can also be replicated. One such replication 
might involve replication in another area of the country, in order to investigate whether the Study 2 findings are indeed generalizable to African American patients from other regions of the country. Further, variables in the study can be altered to detect different effects. For example, future laboratory studies might use cardiologist-actors who are racially ambiguous in order to detect whether patients have different levels of mistrust toward them compared to racially unambiguous cardiologist-actors. This may provide us with insight into the complexities that exist in the real-world setting. In real-world settings, many variables that were not taken into account or controlled in the study may contribute to both physicians' and patients' behaviors and evaluations, respectively. In fact, the variables researchers work so hard to control in the lab may actually be the variables that carry the most weight outside the lab, overpowering the variables upon which a line of research has focused intently (Mortensen \& Cialdini, 2010). With all of these issues considered, this controlled laboratory study was a great strength because it allows Study 2 to provide a foundation for future research. More studies focusing on the effectiveness of patient-centered care in real-world settings are needed (Cooper et al., 2003). In particular, studies should try to investigate the interplay between patients' past experiences of discrimination and clinicians' biases and how they moderate interactions, medical decision making, and patients' health-related outcomes.

Lastly, in study 3, I explored the relationships among perceived discrimination, racial identity, and medical mistrust involving a primary data collection with a local sample of African American community members. Because I conducted Study 3 as a primary data collection, I was able to explore variables that were not explored in Study 1 
and Study 2. For example, medical mistrust and perceptions of low public regard were not central components to the other studies' aims, but by including these constructs, I was able to look at how racial identity and mistrust are related with each other and with racial discrimination. In addition, I was able to recruit a wider range of community members to participate in Study 3 than were recruited either for Study 1 (African Americans in Portland, Oregon who were living with diabetes or hypertension or both) or for Study 2 (African Americans in Portland, Oregon who were living with heart disease or at-risk of having heart disease and who were patients in a particular health care system). Criteria for Study 3 participation were primarily that someone identify as African American and that someone saw a doctor within the five years prior to the study. By partnering with healthcare clinics, I was able to recruit people who visited the healthcare system recently. Also, by distributing flyers during church services and events I was able to recruit community members I would not otherwise have found at a healthcare clinic. Furthermore, by giving community members the opportunity to participate via online or with paper and pencil I was able to engage the involvement of both younger and older African Americans.

Limitations to Study 3 include, first, that it was cross-sectional in nature. Definitive results about whether perceived racial discrimination affects mistrust awaits through the use longitudinal study designs. Additional research is needed to elucidate exactly how racial discrimination might affect racial identity as well. While the mode of data collection allowed me to recruit a wider range of community members, these modes required potential participants to be proficient in reading. This may have prevented some 
individuals from participating in the study. The use of face-to-face interviews could have been a good way to offset this issue. However, because many factors needed to be deliberated before and during face-to-face interviews, such as the training of interviewers, and potential gender effects for interviewers, I decided to focus on the two modes that were easier to implement. This decision was consistent with the description of total survey quality, offered by Biemer and Lyberg (2003): investigators allocate study resources in order to maximize data accuracy within the constraints of a given study. Paper and pencil mode captured more of the older individuals and this was a strength; however, the use of face-to-face interviews could have offered additional opportunity to recruit members of the community who were of low socioeconomic status. Future studies may benefit from using different recruitment strategies and data collection methods to recruit African Americans of different socioeconomic status and age.

Having a community-based sample in study 3 allowed me to obtain a better understanding of the broader African American community. Interestingly, when comparing the distributions of the variable racial centrality between study 2 participants and study 3 participants they were starkly different. In study 2 , the data for racial centrality was normally distributed, while the data for racial centrality in study 3 was negatively skewed. As noted, the sampling frame for these two studies differed, which may have played a key role in their respective findings. In study 2, study participants were recruited at a hospital-based, adult primary care clinic. The study investigators also recruited patients 40 years or older whose medical records indicated a diagnosis of coronary artery disease or coronary artery disease risk factors (e.g., smoking, 
hypertension, diabetes, or hyperlipidemia). They were chosen because they were more likely to relate to the vignettes about coronary artery disease treatment options. Although this recruitment strategy was needed in order for the laboratory design to be effective, the participants in this study represented a very specific group of the African American community. In study 3 , my sampling approach was much wider. Not only did I have clinics and hospitals as recruitment sites, but my research assistants and I posted study flyers in a variety of locations (e.g., college campuses, barber and beauty shops, churches) and enrolled people during community events and church services. We did this because we wanted the sample to be truly community-based, not clinic-based. We wanted to obtain a wide range of perspectives and attitudes about healthcare and racial identity, racial centrality being a good example. The negatively skewed distribution of racial centrality in study 3 may be the experience of being an African American in Portland, Oregon. Being an African American in a predominantly European American city, race would be salient in the person's everyday life. For example, African Americans may perceive more discrimination in Portland, Oregon compared to African Americans living in a more diverse city like Atlanta, Georgia. Because race becomes salient in this kind of environment, race becomes a core part of the person's self-concept. Sellers and colleagues (1997) suggest that racial identity salience is a relevant part of a person's selfconcept at a particular moment in time and is highly sensitive to both the context of a situation as well as the person's proclivity to define her/himself in terms of race (i.e., centrality). When racial identity is made salient through interactions, the person's ideology and regard influences their perspective of the situation and their behavioral 
response. Living in a predominantly European American city, African Americans may perceive more discrimination, making racial identity more salient to a person's selfconcept. Racial identity, in turn, may serve as a protective factor to deal with the struggle of being a visible minority. This coping mechanism helps then to maintain collective selfesteem and positive self-image about being Black.

\section{Conclusion}

Together these studies offered a better understanding of the race-related attitudes that African American patients bring to their healthcare providers' offices, with particular attention to the construct of mistrust - the reluctance of African Americans to endorse that their doctors think of them as persons, for example, or that their doctors hold their interests at heart. Using multiple methods, I addressed new questions about African Americans' experiences in patient-provider relationships. Although these studies did not directly investigate upstream influences in the ecological model (e.g., segregation), they provide an opportunity to investigate how these broadly contextual influences are manifested in the doctor's office and how they shape patient experiences. For example, Shelton and colleagues (2010) found that African Americans who live in highly segregated areas had higher levels of mistrust compared to African Americans who lived in lower segregated areas. The high level of mistrust in segregated areas may be in response to past experience of poor medical treatment. Therefore, the lack of confidence that the health care system would provide appropriate care for African Americans would negatively affect the patients' interactions with their doctor. 
What are the next steps for research in this area? Considering that other important dimensions of the Black experience were not investigated (e.g., gender identity, religious identity), future studies can use the model presented in this chapter to explore how these identities also shape attitudes and behaviors in the context of healthcare. Future interventions might draw from this line of research to strengthen the ability of African Americans to receive the healthcare they need. For example, this study offers insight in where cultural competency training should place its efforts on to improve the quality of care for African American patients. We know that stereotypic teaching strategies (such as treating one ethnic group one way and African Americans another) may have an adverse effect on patients' experiences. Cultural competency training could emphasize that African Americans differ in dimensions of the Black experience such as racial identity. Physicians should be mindful that they are members of a particular cultural group, but are also individuals who come in with their own unique perspective and experience influenced by the community that they come from. Being conscious of such phenomena can help physicians, particularly those of a different ethnic background, improve the quality of care they provide to African American patients. 
References

Aiken, L. S., \& West, S. G. (1991). Multiple regression: Testing and interpreting interactions. Newbury Park, CA: Sage.

Altice, F., Mostashari, F., \& Friedland, G. (2001). Trust and the Acceptance of and Adherence to Antiretroviral Therapy. Journal of Acquired Immune Deficiency Syndrome, 28(1), 47-58.

Anderson, L. A., \& Dedrick, R. F. (1990). Development of the trust in physician scale: A measure to assess interpersonal trust in patient-physician relationships. Psychological Reports, 67(3f), 1091-1100.

Ashton, C. M., Haidet, P., Paterniti, D. A., Collins, T. C., Gordon, H. S., O’Malley, K., Peterson, L. A., Sharf, B. F., Suarez-Almazor, M. E., Wray, N. P., \& Street, R. L., Jr. (2003). Racial and ethnic disparities in the use of health services: Bias, preferences, or poor communication? Journal of General Internal Medicine, 18, 146-152. doi: 10.1046/j.1525-1497.2003.20532.x

Bach, P. B., Pham, H. H., Schrag, D., Tate, R. C., \& Hargraves, J .L. (2004). Primary care physicians who treat Blacks and Whites. The New England Journal of Medicine, 351, 575-584. doi: 10.1056/NEJMsa040609

Baker, R., Mainous III, A. G., Gray, D. P., \& Love, M. M. (2003). Exploration of the relationship between continuity, trust in regular doctors and patient satisfaction with consultations with family doctors. Scandinavian Journal of Primary Health Care, 21(1), 27-32. 
Baron, R. M., \& Kenny, D. A. (1986). The moderator-mediator variable distinction in social psychological research: Conceptual, strategic, and statistical considerations. Journal of Personality and Social Psychology, 51(6), 1173-1182.

Bates, B. R., \& Harris, T. M. (2004). The Tuskegee Study of Untreated Syphilis and public perceptions of biomedical research: a focus group study. Journal of the National Medical Association, 96(8), 1051-1064.

Benkert, R., Hollie, B., Nordstrom, C. K., Wickson, B., \& Bins-Emerick, L. (2009). Trust, mistrust, racial identity and patient satisfaction in urban African American primary care patients of nurse practitioners. Journal of Nursing Scholarship, 4l(2), 211-219.

Benkert, R., Peters, R. M., Clark, R., \& Keves-Foster, K. (2006). Effects of perceived racism, cultural mistrust and trust in providers on satisfaction with care. Journal of the National Medical Association, 98(9), 1532-1540.

Berrios-Rivera, J. P., Street, R. L., Garcia Popa-lisseanu, M. G., Kallen, M. A., Richardson, M. N., Janssen, N. M., Marcus, D.M., Reveille, J.D., Warner, N.B. \& Suarez-Almazor, M. E. (2006). Trust in physicians and elements of the medical interaction in patients with rheumatoid arthritis and systemic lupus erythematosus. Arthritis Care \& Research, 55(3), 385-393.

Biemer, P. P. \& Lyberg, L.E. (2003). Introduction to Survey Quality. Hoboken, NJ: John Wiley \& Sons. 
Blendon, R. J., Buhr, T., Cassidy, E. F., Perez, D. J., Hunt, K. A., Fleischfresser, C., Benson, J. M., \& Herrmann, M. J. (2007). Disparities in health: Perspectives of a multi-ethnic, multi-racial America. Health Affairs, 26(5), 1437-1447.

Bollen, K. A., \& Stine, R. A. (1992). Bootstrapping goodness-of-fit measures in structural equation models. Sociological Methods \& Research, 21(2), 205-229.

Bonds, D. E., Foley, K. L., Dugan, E., Hall, M. A., \& Extrom, P. (2004). An exploration of patients' trust in physicians in training. Journal of Health Care for the Poor and Underserved, 15(2), 294-306.

Boulware, L. E., Cooper, L. A., Ratner, L. E., LaVeist, T. A., \& Powe, N. R. (2003). Race and trust in the health care system. Public Health Reports, 118(4), 358-365. Boyatzis, R.E. (1998). Transforming qualitative information: Thematic analysis and code development. Thousand Oaks, CA: Sage.

Brandon, D. T., Isaac, L. A., \& LaVeist, T. A. (2005). The legacy of Tuskegee and trust in medical care: is Tuskegee responsible for race differences in mistrust of medical care? Journal of the National Medical Association, 97(7), 951-956.

Branscombe, N. R., Schmitt, M. T., \& Harvey, R. D. (1999). Perceiving pervasive discrimination among African Americans: Implications for group identification and well-being. Journal of personality and social psychology,77(1), 135-149.

Bynum, S. A., Davis, J. L., Green, B. L., \& Katz, R. V. (2012). Unwillingness to participate in colorectal cancer screening: examining fears, attitudes, and medical mistrust in an ethnically diverse sample of adults 50 years and older. American Journal of Health Promotion, 26(5), 295-300. 
Campbell, M. K., Hudson, M. A., Resnicow, K., Blakeney, N., Paxton, A., \& Baskin, M. (2007). Church-based health promotion interventions: Evidence and lessons learned. Annual Review of Public Health, 28, 213-234.

Casagrande, S. S., Gary, T. L., LaVeist, T. A., Gaskin, D. J., \& Cooper, L. A. (2007). Perceived discrimination and adherence to medical care in a racially integrated community. Journal of General Internal Medicine, 22(3), 389-395.

Centers for Disease Control and Prevention. (2013). Social Ecological Model. Retrieved from http://www.cdc.gov/cancer/crccp/sem.htm on October 28, 2014.

Chin, M. H., Walters, A. E., Cook, S. C., \& Huang, E. S. (2007). Interventions to reduce racial and ethnic disparities in health care. Medical Care Research and Review, 64(5), 7S-28S.

Chow, J., Jaffee, K., \& Snowden, L. (2002). Racial/ethnic disparities in the use of mental health services in poverty areas. American Journal of Public Health, 93(5), 792797. Retrieved October 13, 2014, from http://ajph.aphapublications.org/doi/abs/10.2105/AJPH.93.5.792

Cohen, J. (1992). A power primer. Psychological Bulletin, 112(1), 155.

Cokley, K. O., \& Helm, K. (2001). Testing the construct validity of scores on the Multidimensional Inventory of Black Identity. Measurement and Evaluation in Counseling and Development, 34(2), 80-95.

Collins, K. S., Tenney, K., \& Hughes, D. L. (2002). The quality of health care for African Americans: Findings from the Commonwealth Fund 2001 Health Care Quality Survey (Commonwealth Fund Publication 524). Retrieved February 9, 2015, from 
SUMMARY OF ALL THREE STUDIES

http://www.commonwealthfund.org/ /media/Files/Publications/Other/2002/Mar/ Quality $\% 20$ of $\% 20$ Health\%20Care $\% 20$ for $\% 20$ African $\% 20$ Americans $\% 20 \% 20 \mathrm{~A}$ $\% 20$ Fact $\% 20$ Sheet/Collins_factsheetafam\%20pdf.pdf

Cooper, L. A., Beach, M. C., Johnson, R. L., \& Inui, T. S. (2006). Delving below the surface. Journal of General Internal Medicine, 21(S1), S21-S27.

Cooper, L. A., Roter, D. L., Johnson, R. L., Ford, D. E., Steinwachs, D. M., \& Powe, N. R. (2003). Patient-centered communication, ratings of care, and concordance of patient and physician race. Annals of Internal Medicine,139(11), 907-915.

Cooper-Patrick, L., Gallo, J. J., Gonzales, J. J., Vu, H. T., Powe, N. R., Nelson, C., \& Ford, D. E. (1999). Race, gender, and partnership in the patient-physician relationship. Journal of the American Medical Association, 282(6), 583-589.

Corbie-Smith, G., Thomas, S. B., \& George, D. M. M. S. (2002). Distrust, race, and research. Archives of Internal Medicine, 162(21), 2458-2463.

Cronan, T. A., Villalta, I., Gottfried, E., Vaden, Y., Ribas, M., \& Conway, T. L. (2008). Predictors of mammography screening among ethnically diverse low-income women. Journal of Women's Health, 17(4), 527-537.

Cross, W. E. (1971). The Negro-to-Black conversion experience. Black World, 20(9), 1327.

Cross, W. E. (1980). Models of psychological nigrescence: A literature review. Black Psychology, 2, 81-98.

Cuevas, A.G., O'Brien, K., \& Saha, S. (2015). “I always feel like I'm getting skipped over:" African American experiences in healthcare. Manuscript in preparation. 
Cuffee, Y. L., Hargraves, J. L., \& Allison, J. (2011). Exploring the association between reported discrimination and hypertension among African Americans: a systematic review. Ethnicity \& Disease, 22(4), 422-431.

Cuffee, Y. L., Hargraves, J. L., Rosal, M., Briesacher, B. A., Schoenthaler, A., Person, S., Hullett, S. \& Allison, J. (2013). Reported racial discrimination, trust in physicians, and medication adherence among inner-city African Americans with hypertension. American Journal of Public Health, 103(11), e55-e62.

Demo, D. H., \& Hughes, M. (1990). Socialization and racial identity among Black Americans. Social Psychology Quarterly, 364-374.

Diala, C., Muntaner, C., Walrath, C., Nickerson, K. J., LaVeist, T. A., \& Leaf, P. J. (2000). Racial differences in attitudes toward professional mental health care and in the use of services. American Journal of Orthopsychiatry, 70(4), 455.

Doescher, M. P., Saver, B. G., Franks, P., \& Fiscella, K. (2000). Racial and ethnic disparities in perceptions of physician style and trust. Archives of Family Medicine, 9(10), 1156-1163.

Dovidio, J. F., Penner, L. A., Albrecht, T. L., Norton, W. E., Gaertner, S. L., \& Shelton, J. N. (2008). Disparities and distrust: the implications of psychological processes for understanding racial disparities in health and health care. Social Science \& Medicine, 67(3), 478-486.

Dula, A. (1994). African American suspicion of the healthcare system is justified: what do we do about it? Cambridge Quarterly of Healthcare Ethics, 3(03), 347-357. 
Egede, L. E., \& Bosworth, H. (2008). The future of health disparities research: 2008 and beyond. Journal of General Internal Medicine, 23(5), 706-708.

Facione, N. C., \& Facione, P. A. (2007). Perceived prejudice in healthcare and women's health protective behavior. Nursing Research, 56(3), 175-184.

Fowler, F. J. (1995). Improving survey questions: Design and evaluation (Vol. 38). Thousand Oaks, CA: Sage Publications.

Fowler-Brown, A., Ashkin, E., Corbie-Smith, G., Thaker, S., \& Pathman, D. E. (2006). Perception of racial barriers to health care in the rural South. Journal of Health Care for the Poor and Underserved, 17(1), 86-100.

Goodin, B. R., Pham, Q. T., Glover, T. L., Sotolongo, A., King, C. D., Sibille, K. T., Herbert, M.S., Cruz-Almeida, Y., Sanden, S.H., Staud, R., Redden, D.T., Bradley, L.A., \& Fillingim, R. B. (2013). Perceived racial discrimination, but not mistrust of medical researchers, predicts the heat pain tolerance of African Americans with symptomatic knee osteoarthritis. Health Psychology, 32(11), 1117-1126.

Gordon, H. S., Street, R. L., Jr., Sharf, B. F., \& Souchek, J. (2006). Racial differences in doctors' information-giving and patients' participation. Cancer, 107(6), 13131320.

Gordon, H. S., Street, R. L., Sharf, B. F., Kelly, P. A., \& Souchek, J. (2006). Racial differences in trust and lung cancer patients' perceptions of physician communication. Journal of Clinical Oncology, 24(6), 904-909.

Green, A. R., Carney, D. R., Pallin, D. J., Ngo, L. H., Raymond, K. L., Iezzoni, L. I., \& Banaji, M. R. (2007). Implicit bias among physicians and its prediction of 
SUMMARY OF ALL THREE STUDIES

thrombolysis decisions for black and white patients. Journal of General Internal Medicine, 22(9), 1231-1238.

Greer, T. M., Brondolo, E., \& Brown, P. (2014). Systemic racism moderates effects of provider racial biases on adherence to hypertension treatment for African Americans. Health Psychology, 33(1), 35-42.

Groves, R. M., Fowler, F. J., Couper, M. P., Lepkowski, J. M., Singer, E., \& Tourangeau, R. (2009). Survey Methodology. NJ: Wiley and Sons, Inc.

Gurin, P., Miller, A. H., \& Gurin, G. (1980). Stratum identification and consciousness. Social Psychology Quarterly, 30-47.

Haas, J. S., Phillips, K. A., Sonneborn, D., McCulloch, C. E., Baker, L. C., Kaplan, C. P., ... \& Liang, S. Y. (2004). Variation in access to health care for different racial/ethnic groups by the racial/ethnic composition of an individual's county of residence. Medical care, 42(7), 707-714.

Hall, M. A., Dugan, E., Zheng, B., \& Mishra, A. K. (2001). Trust in physicians and medical institutions: What is it, can it be measured, and does it matter? Milbank Quarterly, 79(4), 613-639.

Hall, M. A., Zheng, B., Dugan, E., Camacho, F., Kidd, K. E., Mishra, A., \& Balkrishnan, R. (2002). Measuring patients' trust in their primary care providers. Medical Care Research and Review, 59(3), 293-318.

Hammond, W. P. (2010). Psychosocial correlates of medical mistrust among African American men. American Journal of Community Psychology, 45, 87-106. 
Hammond, W. P. (2010). Psychosocial correlates of medical mistrust among African American men. American Journal of Community Psychology, 45(1-2), 87-106.

Hayes, N. (1997). Theory-led thematic analysis: social identification in small companies. In N. Hayes (Ed.), Doing qualitative analysis in psychology (pp. 93-114). New York, NY: Psychology Press.

Hoyo, C., Yarnall, S. H., Skinner, C. S., Moorman, P. G., Sellers, D., \& Reid, L. (2005). Pain predicts non adherence to pap smear screening among middle-aged African American Women. Preventive Medicine, 41, 439-445.

Hughes, D. L., \& DuMont, K. (2002). Using focus groups to facilitate culturally anchored research. American Journal of Community Psychology, 21, 775-806.

Johnson, R. L., Roter, D., Powe, N. R., \& Cooper, L. A. (2004). Patient race/ethnicity and quality of patient-physician communication during medical visits. American Journal of Public Health, 94(12), 2084-2090.

Kaiser, C. R., \& Miller, C. T. (2003). Derogating the victim: The interpersonal consequences of blaming events on discrimination. Group Processes \& Intergroup Relations, 6(3), 227-237.

Katz, R. V., Green, B. L., Kressin, N. R., James, S. A., Wang, M. Q., Claudio, C., \& Russell, S. L. (2009). Exploring the "legacy" of the Tuskegee Syphilis Study: A follow-up study from the Tuskegee Legacy Project. Journal of the National Medical Association, 101(2), 179-183. 
SUMMARY OF ALL THREE STUDIES

King, W. D. (2003). Examining African Americans' mistrust of the health care system: expanding the research question. Commentary on "Race and trust in the health care system". Public Health Reports, 118(4), 366-367.

Krieger, N. (1990). Racial and gender discrimination: risk factors for high blood pressure? Social Science \& Medicine, 30(12), 1273-1281.

LaVeist, T. A., \& Nuru-Jeter, A. (2002). Is doctor-patient race concordance associated with greater satisfaction with care? Journal of Health and Social Behavior, 43, 296-306.

LaVeist, T. A., \& Nuru-Jeter, A. (2002). Is doctor-patient race concordance associated with greater satisfaction with care? Journal of Health and Social Behavior, 296306.

LaVeist, T. A., Isaac, L. A., \& Williams, K. P. (2009). Mistrust of health care organizations is associated with underuse of health services. Health Services Research, 44, 2093-2105.

LaVeist, T. A., Nickerson, K. J., \& Bowie, J. V. (2000). Attitudes about racism, medical mistrust, and satisfaction with care among African American and white cardiac patients. Medical Care Research and Review, 57(4), 146-161.

Lecci, L., \& Johnson, J. D. (2008). Black anti-White attitudes: The influence of racial identity and the Big Five. Personality and Individual Differences, 44(1), 182-192.

MacCallum, R. C., Zhang, S., Preacher, K. J., \& Rucker, D. D. (2002). On the practice of dichotomization of quantitative variables. Psychological Methods, 7, 19-40. 
Major, B., \& O'Brien, L. T. (2005). The social psychology of stigma. Annual Review of Psychology, 56, 393-421.

Markus, H. R. (2008). Pride, prejudice, and ambivalence: Toward a unified theory of race and ethnicity. American Psychologist, 63, 651-670.

Mayr, F. B., Yende, S., D’Angelo, G., Barnato, A. E., Kellum, J. A., Weissfeld, L., Yealy, D. M., Reade, M. C., Milbrandt, E. B., \& Angus, D. C. (2010). Do hospitals provide lower quality of care to Black patients for pneumonia? Critical Care Medicine, 38(3), 759-765.

Mechanic, D. (1998). The functions and limitations of trust in the provision of medical care. Journal of Health Politics, Policy and Law, 23(4), 661-686.

Moore, A., Hamilton, J., Knafl, G., Godley, P., Carpenter, W., Bensen, J.T., Mohler, J.L., Mishel, M. (2012). Patient Satisfaction Influenced by Interpersonal Treatment and Communication for African American Men: The North Carolina-Louisiana Prostate Cancer Project (PCaP). American Journal of Men's Health, 6(5), 409419.

Mortensen, C. R., \& Cialdini, R. B. (2010). Full-cycle social psychology for theory and application. Social and Personality Psychology Compass, 4(1), 53-63.

Mpofu, E., \& Harley, D. A. (2006). Racial and Disability Identity Implications for the Career Counseling of African Americans With Disabilities. Rehabilitation Counseling Bulletin, 50(1), 14-23.

Murphy, K. R., \& Davidshofer, C. O. (Eds.). (1988). Psychological testing. Principles, and Applications. Upper Saddle River, New Jersey: Prentice Hall. 
Napoles-Springer, A. M., Santoyo, J., Houston, K., Perez-Stable, E. J., \& Stewart, A. L. (2005). Patients' perceptions of cultural factors affecting the quality of their medical encounters. Health Expectations, 8(1), 4-17.

Neblett, E.W., Jr., Shelton, J.N., \& Sellers, R.M. (2004). The role of racial identity in managing daily hassles. In G. Philogène (Ed.). Race and identity: The legacy of Kenneth Clark (pp. 77 - 90). Washington, DC: American Psychological Association Press.

Nguyen, G. C., LaVeist, T. A., Harris, M. L., Datta, L. W., Bayless, T. M., \& Brant, S. R. (2009). Patient trust-in-physician and race are predictors of adherence to medical management in inflammatory bowel disease. Inflammatory Bowel Diseases, 15(8), 1233-1239.

Nguyen, G. C., LaVeist, T. A., Harris, M. L., Datta, L. W., Bayless, T. M., \& Brant, S. R. (2009). Patient trust-in-physician and race are predictors of adherence to medical management in inflammatory bowel disease. Inflammatory Bowel Diseases, 15(8), 1233-1239.

O'Malley, A. S., Sheppard, V. B., Schwartz, M., \& Mandelblatt, J. (2004). The role of trust in use of preventive services among low-income African-American women. Preventive Medicine, 38(6), 777-785.

Operario, D., \& Fiske, S. T. (2001). Ethnic identity moderates perceptions of prejudice: Judgments of personal versus group discrimination and subtle versus blatant bias. Personality and Social Psychology Bulletin, 27(5), 550-561. 
Parham, T. A., \& Helms, J. E. (1981). The influence of Black students' racial identity attitudes on preferences for counselor's race. Journal of Counseling Psychology, 28(3), 250-257.

Peek, M. E., Cargill, A., \& Huang, E. S. (2007). Diabetes health disparities a systematic review of health care interventions. Medical Care Research and Review, 64(5 suppl), 101S-156S.

Peek, M. E., Nunez-Smith, M., Drum, M., \& Lewis, T. T. (2011). Adapting the Everyday Discrimination Scale to medical settings: Reliability and validity testing in a sample of African American patients. Ethnicity \& Disease, 21(4), 502-509.

Peek, M. E., Wagner, J., Tang, H., Baker, D. C., \& Chin, M. H. (2011). Self-reported racial/ethnic discrimination in healthcare and diabetes outcomes. Medical Care, 49(7), 618-625.

Penner, L. A., Dovidio, J. F., Edmondson, D., Dailey, R. K., Markova, T., Albrecht, T. L., \& Gaertner, S. L. (2009). The experience of discrimination and Black-White health disparities in medical care. Journal of Black Psychology, 35(2), 180-203.

Penner, L. A., Dovidio, J. F., West, T. V., Gaertner, S. L., Albrecht, T. L., Dailey, R. K., \& Markova, T. (2010). Aversive racism and medical interactions with Black patients: A field study. Journal of Experimental Social Psychology,46(2), 436440.

Penner, L., Albrecht, T.L., \& Eggly, S. Behind the curtain: Implicit racial attitudes in medical interactions. Manuscript in preparation. 
Penner, L.A. (2014, June). Behind the curtain: Implicit racial attitudes in medical interactions. In A.G. Cuevas (Chair), Discrimination and Health Inequities: Raising and Exploring New Questions. Symposium was conducted at the SPSSI's $10^{\text {th }}$ Biennial Conference: Social Action and Change: Opportunities, Resistance, Inertia, and Mobilization, Portland, OR.

Phinney, J. S. (1990). Ethnic identity in adolescents and adults: review of research. Psychological Bulletin, 108(3), 499-514.

Rim, S. H., Hall I. J., Fairweather, M. E., Fedorenko, C. R., Ekwueme, D. U., Smith, J. L., Thompson, I. M., Keane, T. E., Penson, D. F., Moinpour, C. M., Zeliadt, S. B., \& Ramsey, S. D. (2011). Considering racial and ethnic preferences in communication and interactions among the patient, family member, and physician following diagnosis of localized prostate cancer: Study of a US population. International Journal of General Medicine, 4, 481-486.

Ritchie, J. \& Lewis. J. (Eds.) (2003). Qualitative research practice: A guide for social science students and researchers. London, England: Sage Publications.

Rivas-Drake, D., Hughes, D., \& Way, N. (2009). A preliminary analysis of associations among ethnic-racial socialization, ethnic discrimination, and ethnic identity among urban sixth graders. Journal of Research on Adolescence, 19(3), 558-584.

Roberts, K. J. (2002). Physician-patient relationships, patient satisfaction, and antiretroviral medication adherence among HIV-infected adults attending a public health clinic. AIDS Patient Care and STDs, 16(1), 43-50. 
Robinson, C., \& Schumacker, R. E. (2009). Interaction effects: centering, variance inflation factor, and interpretation issues. Multiple Linear Regression Viewpoints, 35(1), 6-11.

Rousseeuw, P. J., \& Van Zomeren, B. C. (1990). Unmasking multivariate outliers and leverage points. Journal of the American Statistical Association, 85(411), 633639.

Rowley, S. J., Sellers, R. M., Chavous, T. M., \& Smith, M. A. (1998). The relationship between racial identity and self-esteem in African American college and high school students. Journal of Personality and Social psychology, 74(3), 715.

Saha, S. (2007). What is “cultural competence?" African Americans' perspectives on patient-physician interactions. Paper presented at the Society of General Internal Medicine National Meeting, New Orleans, LA.

Saha, S., \& Beach, M. C. (2011). The impact of patient-centered communication on patients' decision making and evaluations of physicians: A randomized study using video vignettes. Patient Education and Counseling, 84(3), 386-392.

Saha, S., Arbelaez, J. J., \& Cooper, L. A. (2003). Patient-physician relationships and racial disparities in the quality of health care. American Journal of Public Health, 93(10), 1713-1719.

Saha, S., Arbelaez, J., \& Cooper, L. (2003). Patient-physician relationships and racial disparities in the quality of health care. American Journal of Public Health, 93(10), 1713-1719. 
Saha, S., Komaromy, M., Koepsell, T. D., \& Bindman, A. B. (1999). Patient-physician racial concordance and the perceived quality and use of health care. Archives of Internal Medicine, 159, 997-1004.

Scheppers, E., van Dongen, E., Dekker, J., Geertzen, J., \& Dekker, J. (2006). Potential barriers to the use of health services among ethnic minorities: A review. Family Practice, 23, 325-348.

Schoenthaler, A., Montague, E., Baier Manwell, L., Brown, R., Schwartz, M. D., \& Linzer, M. (2014). Patient-physician racial/ethnic concordance and blood pressure control: the role of trust and medication adherence. Ethnicity \& Health,19(5), 565-578.

Schouten, B. C. \& Meeuwesen, L. (2006). Culture and medical communication: A review of the literature. Patient Education and Counseling, 64, 21-34.

Sellers, R. M., \& Shelton, J. N. (2003). The role of racial identity in perceived racial discrimination. Journal of Personality and Social Psychology, 84(5), 1079-1092.

Sellers, R. M., Caldwell, C. H., Schmeelk-Cone, K. H., \& Zimmerman, M. A. (2003). Racial identity, racial discrimination, perceived stress, and psychological distress among African American young adults. Journal of Health and Social Behavior, 302-317.

Sellers, R. M., Rowley, S. A., Chavous, T. M., Shelton, J. N., \& Smith, M. A. (1997). Multidimensional Inventory of Black Identity: A preliminary investigation of reliability and constuct validity. Journal of Personality and Social Psychology, 73(4), 805-815. 
Sellers, R. M., Smith, M. A., Shelton, J. N., Rowley, S. A., \& Chavous, T. M. (1998). Multidimensional model of racial identity: A reconceptualization of African American racial identity. Personality and Social Psychology Review, 2(1), 18-39.

Shelton, J. N., \& Sellers, R. M. (2000). Situational stability and variability in African American racial identity. Journal of Black Psychology, 26(1), 27-50.

Shelton, R. C., Winkel, G., Davis, S. N., Roberts, N., Valdimarsdottir, H., Hall, S. J., \& Thompson, H. S. (2010). Validation of the group-based medical mistrust scale among urban Black men. Journal of General Internal Medicine, 25(6), 549-555.

Sims, M., Wyatt, S. B., Gutierrez, M. L., Taylor, H. A., \& Williams, D. R. (2009). Development and psychometric testing of a multidimensional instrument of perceived discrimination among African Americans in the Jackson Heart Study. Ethnicity \& Disease, 19(1), 56-64.

Smedley, B. D., Stith, A. Y., \& Nelson, A. R. (Eds.). (2009). Unequal Treatment: Confronting Racial and Ethnic Disparities in Healthcare (with CD). National Academies Press.

Sohler, N. L., Fitzpatrick, L. K., Lindsay, R. G., Anastos, K., \& Cunningham, C. O. (2007). Does patient-provider racial/ethnic concordance influence ratings of trust in people with HIV infection? AIDS and Behavior, 11(6), 884-896.

Sorkin, D. H., Ngo-Metzger, Q., \& De Alba, I. (2010). Racial/ethnic discrimination in health care: impact on perceived quality of care. Journal of General Internal Medicine, 25(5), 390-396. 
Speight, S. L., Vera, E. M., \& Derrickson, K. B. (1996). Racial self-designation, racial identity, and self-esteem revisited. Journal of Black Psychology, 22(1), 37-52.

Street, R. L., O’Malley, K. J., Cooper, L. A., \& Haidet, P. (2008). Understanding concordance in patient-physician relationships: personal and ethnic dimensions of shared identity. The Annals of Family Medicine, 6(3), 198-205.

Terrell, F., \& Terrell, S. L. (1981). An inventory to measure cultural mistrust among Blacks. The Western Journal of Black Studies, 5(3), 180-184.

Thom, D. (2002). Patient trust in the physician: Relationship to patient requests. Family Practice, 9(5), 476-483. doi: 10.1093/fampra/19.5.476

Thom, D. H., Ribisl, K. M., Stewart, A. L., \& Luke, D. A. (1999). Further validation and reliability testing of the Trust in Physician Scale. Medical care, 37(5), 510-517.

Thompson, C. E., Worthington, R., \& Atkinson, D. R. (1994). Counselor content orientation, counselor race, and Black women's cultural mistrust and selfdisclosures. Journal of Counseling Psychology, 41(2), 155-161.

Thompson, H. S., Valdimarsdottir, H. B., Winkel, G., Jandorf, L., \& Redd, W. (2004). The Group-Based Medical Mistrust Scale: psychometric properties and association with breast cancer screening. Preventive Medicine, 38(2), 209-218.

Thompson, V. L. S., Bazile, A., \& Akbar, M. (2004). African Americans' perceptions of psychotherapy and psychotherapists. Professional Psychology: Research and Practice, 35(1), 19-26.

Thrasher, A. D., Earp, J. A. L., Golin, C. E., \& Zimmer, C. R. (2008). Discrimination, distrust, and racial/ethnic disparities in antiretroviral therapy adherence among a 
national sample of HIV-infected patients. JAIDS Journal of Acquired Immune Deficiency Syndromes, 49(1), 84-93.

Trachtenberg, F., Dugan, E., \& Hall, M. A. (2005). How patients' trust relates to their involvement in medical care. Journal of Family Practice, 54(4), 344-352.

Traylor, A. H., Schmittdiel, J. A., Uratsu, C. S., Mangione, C. M., \& Subramanian, U. (2010). The predictors of patient-physician race and ethnic concordance: A medical facility fixed-effects approach. Health services research, 45(3), 792-805.

Turner, J.C. \& Oakes, P.J. (1989). Self-categorization theory and social influence. In P.B. Paulus (Ed.), Psychology of group influence (2nd ed., pp. 233-275).

U. S. Census Bureau. "Portland city, Oregon - 2007-2011 American Community Survey.” Retrieved February 9, 2015 from http://factfinder2.census.gov/faces/tableservices/jsf/pages/productview.xhtml?pid =ACS_11_5YR_DP05.

Unger, R. K. (1979). Toward a redefinition of sex and gender. American Psychologist, 34(11), 1085-1094.

Van Houtven, C. H., Voils, C. I., Oddone, E. Z., Weinfurt, K. P., Friedman, J. Y., Schulman, K. A., \& Bosworth, H. B. (2005). Perceived discrimination and reported delay of pharmacy prescriptions and medical tests. Journal of General Internal Medicine, 20(7), 578-583.

Van Ryn, M., \& Burke, J. (2000). The effect of patient race and socio-economic status on physicians' perceptions of patients. Social Science \& Medicine, 50(6), 813-828. 
Voils, C. I., Oddone, E. Z., Weinfurt, K. P., Friedman, J. Y., Schulman, K. A., \& Bosworth, H. B. (2004). Who trusts healthcare institutions? Results from a community-based sample. Ethnicity \& Disease, 15(1), 97-103.

Weinick, R. M., \& Krauss, N. A. (2000). Racial/ethnic differences in children's access to care. American Journal of Public Health, 90(11), 1771-1774.

Williams, D. R., Yu, Y., Jackson, J. S., \& Anderson, N. B. (1997). Racial differences in physical and mental health socio-economic status, stress and discrimination. Journal of Health Psychology, 2(3), 335-351.

Willis, G., DeMaio, T., \& Harris-Kojetin, B. (1999). Is the bandwagon headed to the methodological promised land? Evaluation of the validity of cognitive interviewing techniques. In M. Sirken, D. Herrmann, S. Schechter, N. Schwarz, J. Tanur, \& R. Tourangeau (Eds.), Cognition and Survey Research. New York: Wiley. 